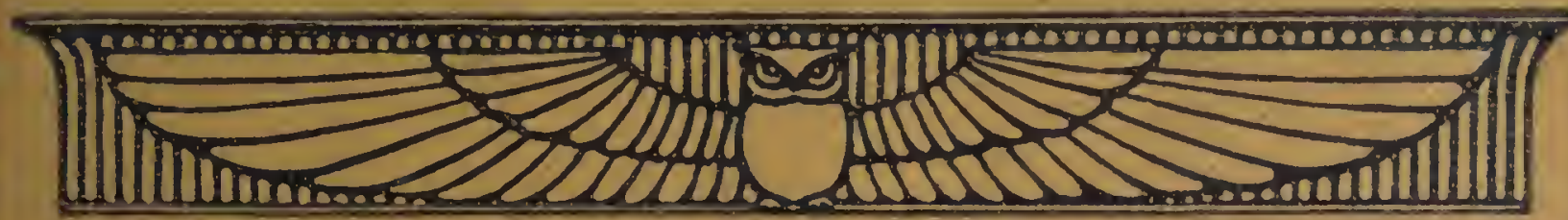

HOME UNIVERSITY LIBRARY

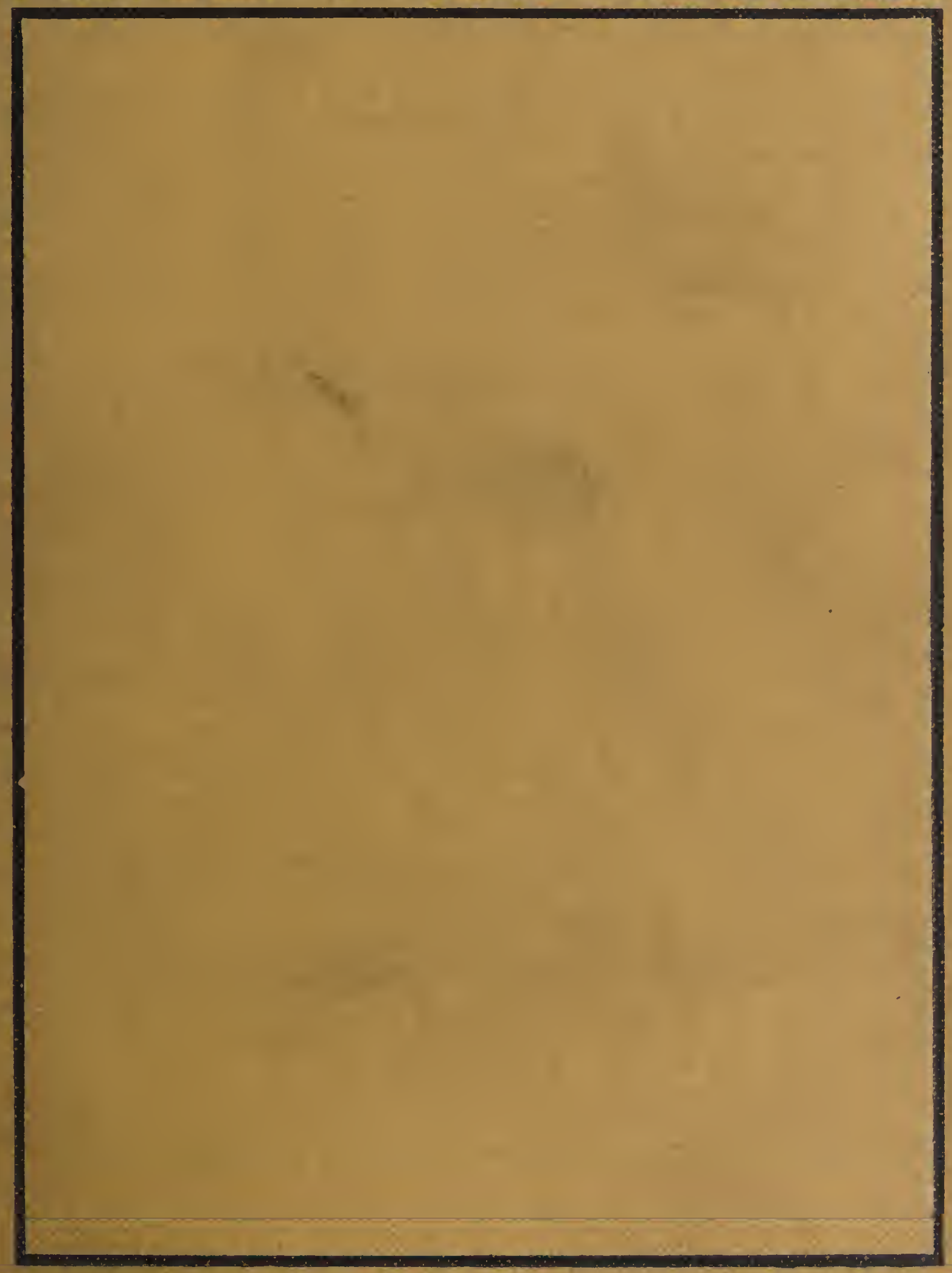




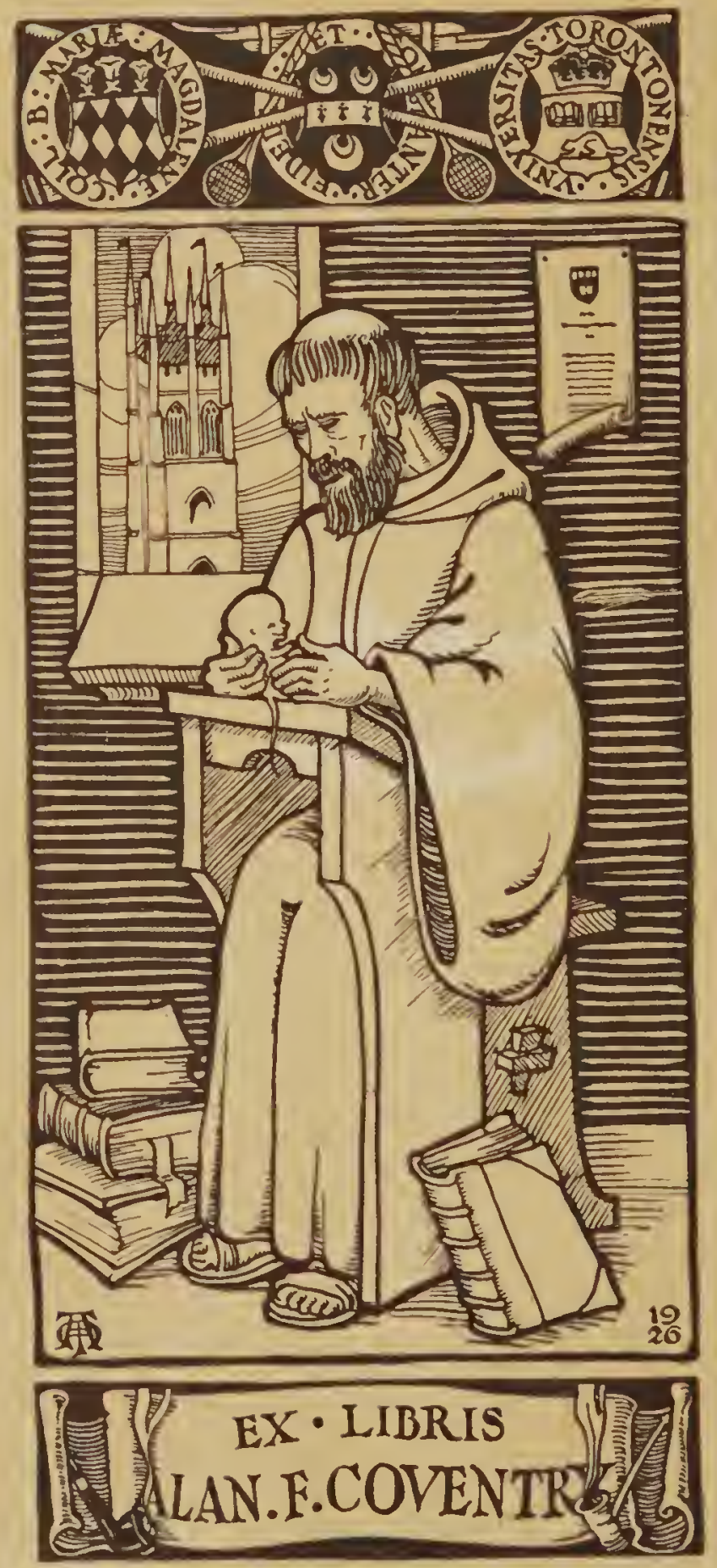


a. Thing of tor to

luiv ${ }^{2} .^{2}$

b.th Kont.

tods.216. 



\title{
HOME UNIVERSITY LIBRARY OF MODERN KNOWLEDGE
}

\author{
No. 14
}

\section{Editors:}

HERBERT FISHER, M.A., F.B.A.

PROF. GILBERT MURRAY, LIIT.D.,

LL.D., F.B.A.

PROF. J. ARTHUR THOMSON, M.A.

PIOF. WILLIAM T. BREWSTER, M.A. 
A complete classified list of the volumes of THE Home University LibRARy already published will be found at the back of this book. 


\section{EVOLUTION}

BY

\section{PATRICK GEDDES}

PROFESSOR OF BOTANY, ST. ANDREWS UNIVERSITY

AND

\section{J. ARTHUR THOMSON}

REGIUS PROFESSOR OF NATURAL HISTORY, ABERDEEN UNIVERSITY

Foint Authors of "The Evolution of Sex," etc.

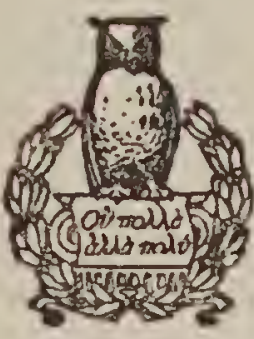

NEW YORK

HENRY HOLT AND COMPANY

LON DON

WILLIAMS AND NORGATE 


\section{COPYRIGHT, 19II, \\ BY \\ HENRY HOLT AND COMPANY}

THE UNIVERSITY PRESS, CAMBRIDGE, U.S.A. 


\section{CONTENTS}

CHAP. PAGH

Introduction • • • • • • . • . . . . vii

I Evidences of Evolution from Exploren and PALfentrologist . • . . . . . . . . 15

II Evidences of Evolution from Axatomist, Embryologist and Physiologist . . . 40

111 Great Steps in Evolution . . . . . . 67

IV Variation AND HeREDITY . . . . . . 112

V Selection . . . . . . . . . . 143

VI Organisu, Function and Environuent. . 183

VII Evolution Theories in thein Social Origins AND Inter-Actrons • • • • . • . . 212

VIII The Evolution Process Once More ReinterPRETED . • . . . . • . . . 233

Bimliograph . . . . . . . . . . 249 
Digitized by the Internet Archive in 2020 with funding from University of Toronto 


\section{INTRODUCTION}

Despite the many and wide differences so obvious in every community - of age and sex, of regional origins and historic groupings, of occupations and interests, of experience and intelligence, efficiency and originality, of education, manners and morals, of wealth and rank, and so on-each generation has more in common than its individuals may realize. Layman and cleric, pressman and prime minister, message-boy and millionaire respond not merely to their respective callbells, nor in common to the peal of general rejoicing, to the tolling of sorrow; but through their minds there vibrates also a certain unison, a response, though it may be more or less unconscious, to the key-notes of their age. How this unison underlies the apparent differences is easily seen on differing intellectual levels. The boy in the train buys Tit-Bits, but the man in the villa takes in the new Britannica; the specialist concentrates upon the "Proceedings" of his learned society, while the university principal reviews his "Calendar" of all the studies: so far they seem widely apart. But, after all, their differences are only of degree and not of kind; 
all four are children of the recent and passing phase of knowledge, characterized by the encyclopædia-whether in "articles" or in "papers," in lecture-courses or in snippets from them-all is but a question of magnitude, a matter of detail. All four readers alike are interested in knowledge of one sort or another; but these are seen mainly as knowledges, and as advancing analyses, rather than as a growing synthesis. So, though they all read very different newspapers, these newspapers are yet much the same, all vividly retrospective of yesterday, and keenly criticizing such and such of its doings, but as yet with little sight of how the day's items are resultants of far distant yesterdays, sowings for far distant morrows. Yet ideas of unity amid diversity, of order amid change, have also long been growing, even finding expression, and this not merely, as sporadically in all ages, in impressions and speculations on decline or on better things; but in clearer and more comprehensive surveys of the processes of change, even inquiries into its method. These, in fact, have gone towards making up that general idea we now more or less share, of the universe as not only orderly, but in process of change. Changing order, orderly change, and this everywhere -in nature inorganic and organic, in indi- 
vidual and in social life-for this vast conception, now everywhere diffusing, often expressed, rarely as yet applied, we need some general term-and this is Evolution.

Now, if this be gaining ground as a conception of the world-process, it is time to be inquiring farther into it: how is this to be done? On one hand historically, thus quickly appropriating the best thought as yet reached by others; on the other hand directly, at first hand and for oneself, in our own environment of life and work and contact with nature. In the former way we shall save time, and in the latter gain definiteness; hence impartially deciding on both, we may most spcedily turn for our outlines to our encyclopsedia, say Chambers' articles "Evolution" and "Darwinian Theory" ; and for direct experience take a holiday in the woods or by the shore. At first the general ideas of our reading, the details of our field-observing, may seem to have little in common, like the old philosopher and the boy collector among our acquaintances: but gradually they come together: orderly change in general, changing order amid particulars, are more and more seen to be at one: thus we become evolutionists. We hear of boy collectors becoming old philosophers, yet remaining boy collectors still: Darwin above all. Among his foremost 
fellows, Wallace, Haeckel, Hooker are still with us; and later ones in increasing number. Observing and thinking, thinking and observing; outdoor and indoor, and outdoor again; that is a game at which we all can play; with education and evolution alike mingled in its process and in its winning.

Evolution in astronomy, from Kant to Lockyer; evolution in chemistry and physics, from Lucretius to the alchemists, and thence to Ramsay and his fellow-alchemists of today; evolution in geology, from Leonardo and Palissy to Lyell and Darwin and onwards all these large retrospects of the history of science are needed for a grasp of cosmic evolution. Their impetus, their methods too, have once and again impelled the student of organic nature towards evolutionary interpretations, and still do so; while the thought of the physicist and of the naturalist are increasingly of interest and suggestion towards the distinctively human and social studies.

Yet it was essentially in the very opposite way that modern evolution doctrines really originated; as a social theory, that of progress: and this generally diffused spirit of the later eighteenth century, and the earlier nineteenth, has both consciously and unconsciously stimulated naturalist and physicist towards their evolutionary inquiries and 
doctrines. Of this social ferment of evolutionary thought there have been as yet two main phases; and first the French eighteenth century "Progress of Humanity," that characteristic doctrine of the Encyclopedists and Physiocrats, of Rousseau, and of the Revolution at its best, and this expressed for history by Condorcet, for living nature by Lamarck. The second phase is that of the Industrial Revolution in Britain, from Watt and Arkwright to Stephenson and Wheatstone; and thence to a nineteenth-century manufacturing and commercial world-predominance, proportionately culminating from 1851 to 1860 or thereby; with its characteristic "self-made men," its colonial expansion and growing empire.

It was the former period, with its theories of society and of morals, which gave birth to the "Doctrine of Evolution"; while the latter period, with its competitive industry, its resultant "population question," etc., has found its expression in the "Doctrine of Natural Selection." Each of these two great advances of thought is thus the philosophic epic of a great nation at its epoch; and Lamarck and Darwin are their representative prophets respectively.

In the generation after Darwin research was necessarily actively specialized in biology; 
and the social perspective, with its conscious application to evolutionary research, has been little employed by naturalists since Darwin and Wallace, despite its extraordinary fruitfulness in their hands. Now, however, it begins to return, witness the Eugenic movement: and in these pages we shall not hesitate to avail ourselves of it.

We may even utilize it for teaching purposes, beginning with the doctrine of natural selection. As Paley's famous "watch argument" appeared at the outset of the mechanical age, so again at its culmination we may avail ourselves of the conspicuous progress of invention to explain and illustrate Darwin's great doctrine. In fact, we may socratically elicit it from the freshman who supposes himself quite unacquainted with biology or its theories. For he knows the points of a bicycle, and something of the story of its development from his father's "bone-shaker," at one time by the introduction of ball-bearings, at another by the invention of pneumatic tyres, each new make, thanks to this or that better "adaptation," being eminently successful in surviving against its kindred bu: less developed competitors in the struggle for existence. From bicycle, or similarly motor or aeroplane, we pass readily enough to bicyclist, to racehorse 
and bird: and we see how we may explain the evolution of their swiftness in like manner. The man in the street is thus a Darwinian without knowing it, and the worldsuccess of Darwin's theory is thus more readily understood; the age had found its man, the hour its voice.

But what of outdoor nature? "The field in summer, the study in winter" is a good rule, yet not a sufficient one; the evolutionist's studies should as far as possible include both elements of observation and interpretation day by day. Hence Darwin's is perhaps the most exemplary of scientific lives, incessantly rising from sight to insight, yet this as constantly freshening sight anew. From boyish truancies, through youthful travels and maturing researches his observations and his speculations went on enricining one another; and thus their interpretation and theory have been an "open sesame" to new fields, new volumes of personal discovery, new impulses to fresh workers. Naturalist and thinker, teacher and pupil, will thus long be inspired by the example of Darwin as rambler, traveller and observer, yet also as dreamer and interpreter. The study of biology is thus by no means merely abstract, nor mainly in the library; it ever arises from and returns to living nature, and goes on 
throughout that annual season-drama of which we are but the awakening spectators. So psychology has its concrete natureobservation in child study, in animal behaviour; and just as ethics has its side of everyday life, so sociology its current events. Nature studies and social studies must again be generalized, and this not only separately but in unison. How so? By and from Regional Survey. Relief and climate, geological and botanical surveys, anthropological, archæological and historic surveys all underlie our social studies. Our concrete science thus generalizes into a comprehensive regional survey, natural and social, rural and urban; as our abstract sciences advance and unite into a philosophy of evolution. In measure as our abstract interpretations and our concrete surveys come together and unify, our geography becomes geogeny, that is, it develops from mere empirical worlddescription into a rational vision of worlddevelopment. And correspondingly, the abstract of this, which is our evolution doctrine, becomes applicable in education and in social life.

Enough, then, of introductory outline; in the following chapters we endeavour to elucidate some of these large propositions more clearly. 


\section{EVOLUTION}

\section{CHAPTER I}

EVIDENCES OF EVOLUTION FROM EXPLORER AND PALIEONTOLOGIST

The Voyage of the "Beagle" - The Galapagos Islands Other Geographical Evidence-Resemblances of Present Forms and Past Ones - The Ancestry of the HorseConnecting Links - Other Palæontological Evidences.

The Voyage of the "Beagle."-We think of the voyage of the "Challenger" as a $\mathrm{Co}$ lumbus-voyage in the history of Biology, for it revealed a new world - the strange, silent, cold, dark, plantless world of the abyssal sea. But a far greater Columbusvoyage was that of the "Beagle" (1831-6), which led Darwin, as the supreme fieldnaturalist, at once widest and intensest, to make the whole world new. For it was during this voyage that the evolutionist view of Nature was vitally borne in on Darwin's mind. He tells us so himself: "On my return home in the autumn of 1836 I immediately began to prepare my journal for publication, and then saw how many facts indicated the 
common descent of species. .. In July (1837) I opened my first notebook for facts in relation to the Origin of Species, about which I had long reflected, and never ceased working for the next twenty years. . . . Had been greatly struck from about the month of previous March on character of South American fossils, and species on Galapagos Archipelago. These facts (especially latter) origin of all my views."

This interesting biographic fact, that what Darwin saw on the Galapagos Islands and elsewhere on his journeyings was (or at least seemed to him) the origin of all his views, justifies us in giving precedence to the "evidences" of evolution that have come from his and other explorations.

Tile Galapagos Islands. - Let us take the case of these islands (some six hundred miles west of the coast of South America), which impressed Darwin so much when he visited them in 1835 . What exactly was it that impressed him? He found that each island had its own distinctive animal population, especially of reptiles and birds. And yet the species in one island were the counterparts of those in another, and almost all had their counterparts in the adjoining parts of the continent. What a riddle indeed - unless it meant that the corresponding species on 
the different islands and on the continent were blood-relations with a common descent? Thus it was that in the Galapagos Archipelago Darwin felt himself "brought near to the very act of creation."

"My attention," Darwin writes, "was first thoroughly aroused by comparing together the numerous specimens, shot by mysclf and several other parties on board, of mocking thrushes, when, to my astonishment, I discovered that all those from Charles Island belonged to one species (Mimus trifasciatus); all from Albemarle Isiand to $M$. parvulus; and all from James and Chatham Islands (between which two other islands are situated as connecting links) belonged to $\mathbf{M}$. melanotis."

All subsequent investigations have confirmed Darwin's observations, both in their general result and in details. Thus it has since been shown by Ridgway that the thrushes from James and Chatham Islands of the same group are also of distinct species. And of one hundred and twenty-eight specimens of a lizard called Tropidurus collected by the "Albatross" from eight of the islands, Dr. Baur writes just as Darwin did: "I was not a little astonished to find that nearly every island contained a peculiar race of species of this lizard, and that not a single 
island contained more than one race or species." 'The same is true of the tortoises and the birds, and no scientific interpretation has been suggested except that which Darwin gave- of divergent evolution from a common stock.

We cannot here enter into a discussion of the geologrical history of the Galapagos Islands, in regird to which there is some difference of opinion; it must suffice to stilte one of the theories - that advanced hy Baur in the Woods Holl Biologrical Lectures for 1894. "At a former period these islands were connected with each other, forming a single larre island, which itself at a still earlier lime was united with the continent, probably with Central America and the West indies. When this large island was not yet broken up into a series of smaller islands, the number of sinecies must have been very much smaller; probably there was only one species of Nesomimus, of Certhidia, of Tropidurus, of the laind 'Tortoise, and so on. Through isolation into single islands the peculiar differentiation of the species began; an originally single species was differentiated in many different forms; every, or nearly every, island developed its peculiar races. We still see to-day that islands which are close together and not separated by deep water show 
the same species, like James and Jervis, or Hood and Gardner. The faunas of the larger central islands are again more closely related to each other than are the faunas of the more isolated islands like Tower, Bindloc, Abingdon, Hood and Charles. The tortoise of Duncan is closest to the tortoise from $\mathrm{Ab}$ ingdon; at the same time the Tropidurus of Duncan comes nearest to that of Abingdon. The prevention of intercrossing after the separation of the islands, the time of separation, and the difference in the conditions on the different islands, are the factors which produce the different races."

We may also refer the student to Wallace's fascinating "Island Life" for further illustrations of the evolutionary suggestiveness of the exploration of islands.

Other Geographical Evidences.-As in other parts of this little book we have dwelt on one interesting illustration of a large subject, we cannot do more than reier briefly to some of the other geographical evidences.

With the help of the palmontologist it is sometimes possible to come to a conclusion as to the original headquarters of a particular race of plants or animals, and then it is found that the present-day distribution of the members of the race is readily intelligible on the evolutionary assumption of diffusion from 
the original centre, and of transformation into new species in relation to the new conditions encountered. Some of the particular case leap to the eye, but they are unmeaning conundrums without the evolutionist clue. Darwin has, in fact, brought us more nearly back to the Noah's ark of our childhood than we commonly realize; for do not all these stories of thrushes, lizards and what not quaintly recall the origin of human races from the dispersion of Shem, Ham and Japheth?

In Mesozoic times, when there were nc Mammals higher than Marsupials, Australia was separated off from the Asiatic continent. Therefore it is that there are no higher Mammals in Australia, except the somewhat mysterious dingo, the bat, which find the sea no barrier, and the rabbits, for which man is responsible.

A final argument is furnished by the contrast in the fauna and flora of oceanic and of continental islands. The former, being usually of volcanic origin, have always a very distinctive fauna and flora, which Wallace las explained as being due to the fortuitous contributions borne from diverse quarters by currents, winds and birds. Other islands, which are isolated pieces of continents, have a fauna and flora like that of the nearest part of the mainland. 
Resemblances of Present Forms and PAST ONES. - Another seed-impression that was borne in on Darwin's mind during his journeyings was the striking resemblance between the living and the extinct forms in the same area. On his travels into the interior of South America he made large collections, both of living animals and of fossils dug from the red mud of the Pampas, and what impressed him most was that the extinct bore a notable correspondence to the extant. No living creatures are more characteristic of the South American fauna than the sloths and ant-eaters; no fossils are more characteristic than the gigantic Megatheriums and Glyptodonts; and the important fact is the structural resemblance between these creatures of the past and those of the present-a structural resemblance which suggested to Darwin that the explanation might be, indeed must be, one of blocdrelationship. "This wonderful relationship," he wrote, "in the same continent between the dead and the living will, I do not doubt, hereafter throw more light on the appearance of organic beings on our earth, and their disappearance from it, than any other class of facts." This is, to be sure, a cautious statement; but it seems not unlikely that it was while thus digging his 
fossils on the Pampas that Darwin laid vital hold upon the principle long nascent in geology, and especially impressed upon him by Lyell, that the present is the child of the past-an idea which he spent so much of his life in substantiating. Let us consider some olher illustrations of the palrontological evidence.

Fossil Horses.- Huxley made a strong statement in 1855 as to the futility of seeking in the study of fossils for confirmation of the coctrine of evolution, but after a quarter of a century of investigation he was as strongly of the opposite opinion, declaring that "if zoologists and embryologists had not put forward the theory, it would have been necessary for palæontologists to invent it." One of the many reasons which led him to a warm appreciation of "the palæontological evidence," was a visit to America, wisere he saw the famous series of fossil horses which Marsh had unearthed from American Tertiary bedsone of the most impressive of pedigrees that has yet been disclosed. For although we are not even now able to state the lineage of the modern horse, the chief steps in the evolutionary process stand out with clearness, and he must be dull indeed who can see the admirably arranged and convincing series in the museums at Yale and New York without 
a thrill of admiration at the wonderful reconstruction of the ancient history of the noblest race of animals, and that most widely identified with man. Since Huxley's day the fossil horse has been "the cheval de bataille of the evolutionist."

In spite of many puzzles, the pedigree is one of the completest and most striking instances of a well-preserved genealogical series. It illustrates evolution, as it were, in process, for the gradations are very gradual; and natural selection also, for the advances in the adaptation of the limbs to swifter locomotion, of the neck to reach the low grass, of the teeth for more effective chewing, and so on, are all such as may be reasonably interpreted in terms of the selection of relatively better-fitted variations. Let us, since the case is a classic one, attempt an outline of the geological history of the horse family, following the careful work of the successors of Marsh and Cope, notably of Lull and Matthew.

The horse-like animals probably sprang from an extinct stock known as the Condylarthra, which was first represented in Europe and Asia, and afterwards in North America. The Condylarthra had five toes on each foot and a large part of the sole was on the ground. One of them, Phenacodus, was called by its 
discoverer, Professor E. D. Cope, a "five-toed horse," but this is not to be taken too literally. "The first undoubted horse-like animal appearing in the rocks of North America is a little creature not more than eleven inches high, known to science as Eohippus. This interesting animal had already made a long stride in the direction of the modern horse, as the number of toes is now reduced to four in front and three behind, and the bones of the wrist and ankle have shifted so as to interlock, which greatly strengthens the foot." It seems that Eohippus was also represented in Britain, and it is possible that migrants by way of Asia and what is now the Behring Strait started the American stock. Apparently more primitive than Eohippus is the "coney-like creature" Hyracotherium, but only the skull is known. "Commencing with the Hyracotherium," Dr. Matthew writes, "twelve stages have been recognized from as many successive formations, showing the gradual evolution of the race into its modern form; and each stage is characteristic of its particular geological horizon. Besides the main line of descent which led into the modern horses and zebras, there were several collateral branches which have left no descendants."

Also in the Nocene there was Protorohip- 
pus, with four toes in front and three behind, the side ones behind touching the ground. It seems to have been about fourteen inches high, and the evolution of speed had begun. During the Eocene times North America was in great part forest-clad, but "the moist climate gave rise to many streams and lakes, along the shores of which grew sedgy meadows that in turn gave rise to grassy plains. These were the conditions under which the horses made their first appearance, and the increasing development of grass lands gave the initial trend to their evolution."

Somewhat later, in the Oligocene, Mesohippus makes its appearance, the hind-foot with three toes as before, but the fore-foot with the little toe reduced to a splint, so that only three remain, the side ones just touching the ground. The middle or third toe is now much larger than the side toes, which no longer bear much of the weight of the animal, save on marshy ground. The grinding teeth have become more complex. One of the species of Mesohippus was about the size of a sheep, and one of the treasures in the Yale Museum that brings the past very vividly back to us is the nearly perfect skull of its new-born foal. Of the physical conditions of the Oligocene, Dr. Lull writes: "The drying up of streams and lakes, due to the 
increasing aridity of climate, gave great impetus to the development of broad meadow lands, and to the true prairie as well. Thus there were three conditions-woodland, meadows and dry prairie, which seem to have given rise to several parallel lines of evolution, some of which terminated, being overcome in the struggle for existence, while others flourished and gave rise to the horses of the Miocene."

Of the Miocene types we may select Protohippus, with three toes on each foot, but only one touching the ground. The shortcrowned teeth without cement are now replaced by long-crowned cement-covered teeth like those of the modern horse. Protohippus was about thirty-six inches high at the shoulder, and had a wide distribution from Texas to Montana and Oregon. In a closely related genus, Merychippus, we find the first instance of the completion of a bridge of bone at the hinder border of the orbit, one of the characteristic differences between the skull of a horse and that of a carnivore, for instance. Merychippus is of particular interest, because it is almost certainly in the direct line of ancestry to all subsequent Equidæ. The forest-horse, Hypohippus, with spreading three-toed feet, suited, like the reindeer's, for soft ground, is a good ex- 
ample of those horses that became extinct during the Miocene, leaving no descendants, and Anchitherium, found both in Europe and in America, was probably also on a side branch. Of the Miocene period, Dr. Lull says: "This was a time of continental eleration and great expansion of our western prairies and a consequent diminution of the forest-clad areas." Many forms very perfectly adapted to soft herbage became extinct, "but the great majority were more plastic and in consequence underwent a remarkable development, during this period reaching the culmination in numbers and kinds."

In the Pliocene there was a wide representation of the Old World genus Hipparion, must of the species still three-toed. It was probably derived from the American Neohipparion, a swift, deer-like animal, about forty inches in height at the shoulder. "In the Siwalik beds of India is found a one-toed Hipparion, and it has been suggested that the modern zebras may be the living descendants of this genus. It is certainly not in the line to the common horse, Equus caballus, which makes its appearance, however, in the Upper Pliocene beds both of Eurasia and North America-the climax of a long evolutionary progression." 
We have dwelt on the case of the horse's pedigree at once longer and stranger than any fairy ride-because it is one of the best instances of its kind, and from one such we may learn all. But we have only given the bare outlines of a remarkable story, well worth reading in detail. In the enthusiasm of early discoveries the matter seemed simpler than it really is, and the mistake was made of hurriedly constructing a linear series which showed, for instance, the gradual reduction of toes from five to one, and supposing that this was a genuine pedigree. More detailed and critical inquiry has shown, however, that there were several collateral series, and it is not quite justifiable to fill up gaps along one line by links which belong to other lines of descent. One critic points out that Equus actually appears in the rock record before some of its alleged ancestors, and Depéret writes in his interesting "Transformations of the Animal World": "The supposed pedigree of the Equidæ is a deceitful delusion, which simply gives us the general process by which the tridactyl hoof of an Ungulate can transform itself, in various groups, into a monodactyl hoof, in view of an adaptation for speed." It is interesting to notice, however, that among competent critics of too hastily constructed pedigrees even the 
severest do not in the least impugn the doctrine of evolution.

What seems clear is this, that in early Eocene times there lived small five-toed hoofed quadrupeds of generalized type, that the descendants of these were gradually specialized throughout long ages along similar but by and by divergent lines, that they lost toe after toe till only the third remained, that they became taller and swifter, that they gained longer necks, more complex teeth and larger brains. So from the short-legged splayfooted plodders of the Eocene marshes there were evolved light-footed horses running on tiptoe on the dry plains.

We can only refer to the importance for an evolutionist outlook of thus trying to correlate the changes in the animal with the changes in the external conditions. The evolution of the horse is wrapped up with the evolution of the plains, and of their grasses also, for these made their first appearance in Tertiary times. The early ancestors probably lived in the warm luxuriant forests, but as colder, drier climate set in, and the forests shrank, the progressive "hippoids" took more and more to the open. Even in regard to the teeth we can understand that the change from the short-crowned to the long-crowned type enabled the animals, as 
Dr. Matthew notices, "to subsist on the hard, comparatively innutritious grasses of the dry plains, which require much more thorough mastication before they can be of any use as food than do the softer green foods of the swamps and forests."

We must not leave this question of the horse's evolution without calling attention to a fact of great interest, that in the individual development there is a series of changes which to some extent correspond with the historical steps represented by forms like Eohippus, Mesohippus, Protohippus, Merychippus, and so on. Professor Cossar Ewart has shown, for instance, that the small nodule at the end of the splint bone is separate in the embryo, and is the representative of one or more of the joints of the second or the fourth digit which, apart from this, would seem to have entirely passed away. It is well known that in a monstrosity of our familiar one-toed horse the splint bone on each side of the main cannon-bone is enlarged, and bears a complete digit, so that a three-toed horse, such as the one Julius Cæsar rode, occasionally still walks upon the earth. Such cases of symmetrical three-toed development may be fairly interpreted as reversions to the ancestral type, and are to be distinguished from unsymmetrical extra 
toes, which are mere duplications without ancestral interest, and comparable to the occasional occurrence of a sixth finger in man.

In his very interesting study of "Wild Traits in Tame Animals" (1897) Dr. Louis Robinson refers to survivals of behaviour which date from the old wild life in the open plains. It was imperative long ago that the young foals should run with their mothers, and to this day they do not gorge themselves with milk as calves do. When alarmed, horses hold their heads high, as when wild upon the plains; they bite very closely when grazing; in both respects they differ markedly from cattle. "Shying" is a relic of the instinct of swerving suddenly from a suspicious rustling and the like which used to mean the presence of a lurking foe. Such survivals are interesting and strike our fancy; but the past lives in the present even more clearly in regard to structure than in regard to habit, and by the "button" at the lower end of the splint bones the modern horse is indubitably linked back to its polydactyl ancestors.

Connecting Links.--There is no more complete or striking contrast of aspect and habitat, habit and temperament in the animal kingdom than that between the average bird and the average reptile; and yet every zoologist is sure that birds sprang 
from some ancient reptilian or saurian stock. He has not ceased to wonder how this transition can have come about; "how the slow, cold-blooded, scaly beast ever became transformed into the quick, hot-blooded, feathered bird, the joy of creation"; but he does not doubt that the transition was effected. He is still unwilling to make any positive statement in regard to the precise pedigree of birds, and yet he is confident that they sprang from a reptilian stock. What are the reasons for this confidence?

They are threefold:-(1) There are, in spite of appearances, numerous structural resemblances between birds and reptiles, from the scales on the feet to the composition and the articulation of the lower jaw; (2) there are deep similarities in development, for the embryo bird and the embryo reptile travel at first along parallel paths, and only gradually part company; and (3) there are extinct types which to some extent bridge the conspicuous gap. A word, then, in regard to these connecting links.

One of the most treasured fossils in the world-of which the British Museum and the Berlin Museum have each one of the two known specimens - is the oldest known bird, Archæopteryx. These priceless skeletons were found well preserved in the lith- 
ographic stone of Bavaria, and the grain of the stone - a hardened mud-is so fine that the impressions of the feathers are well seen, and most of the bones are clear. Archæopteryx was a creature about the size of a crow, probably arboreal, and beyond all doubt a bird - the earliest bird we know of. But what gives it a peculiar interest is that while it is not far from a typical bird in its skull, its merry-thought, and its legs, it is in some other respects markedly reptile-like. It has, for instance, teeth in both jaws, a long tail like a lizard's, and a strange wing, welldeveloped yet unfinished, with its three digits ending in unmistakable claws.

Now Archæopteryx was very far from being a beginner on the bird line of evolution; its wings and its legs prove that. It is also possible that it was an offshoot from the direct line, and thus not ancestral to any bird now living. Still, we cannot but regard it as "a connecting link" in the sense that it shows in its structure a combination of reptilian and avian characters, the latter, of course, fully predominating.

Fossil Series.-One of the finest examples of a well-preserved series of kindred forms is afforded by an extinct freshwater snail, Paludina neumayri, which is very abundant in some Tertiary deposits in Slavonia. The 
oldest form has a more or less smooth shell, the youngest has a conspicuously ridged shell, and there are fifteen gradations between the two. Before the complete series was known it was usual to distinguish half a dozen or more species; but with the beautifully graduated, really continuous series before us, we feel-fossils as they are - that we see a species varying before our eyes. If conditions had arisen that assured survival and success only to the markedly ridged forms, the intermediate gradations would soon have fallen into the minority and disappeared as living creatures from the scene, and a ridged species, apparently discontinuous, would have been established.

Similarly in the neighbourhood of Steinheim in Wuirtemberg, in calcareous deposits that mark the flocr of an old Tertiary lake, there are enormous quantities of a small snail, Planorbis multiformis, which has been carefully studied by Hyatt and others. And again, since the whole history has been unearthed, we see evolution before our eyes. The particularly interesting feature is that there are four or so primitive forms which are very like one another, and that each of these is the starting-point of a series the termini of which are very different. The contrast between the beginning and the end 
of a series, e.g. between a high spiral and a flat spiral, is often so striking that no one would hesitate in calling them distinct species. Yet they are connected by a long series of fine gradations.

Some are surprised that such series are not commoner if Evolution has been the mode of the becoming of things; but they have not adequately understood how great are the odds against the preservation of such records. Only hard parts make good fossils; only certain kinds of deposits make suitable tombs; many rocks have been unmade and re-made several times;- these and many other facts enable us to understand "the imperfection of the geological record." As Darwin said, we must look at the geological record " as a history of the world imperfectly kept, and written in a changing dialect; of this history we possess the last volume alone, relating only to two or three countries. Of this volume, only here and there a short chapter has been preserved; and of each page, only here and there a few lines." And again he said: "We shall perhaps best perceive the improbability of our being enabled to connect species by numerous fine intermediate fossil links, by asking ourselves whether, for instance, geologists at some future period will be able to prove that our different breeds of 
cattle, sheep, horses and dogs are descended from a single stock or from several aboriginal stocks. . . This could be effected by the future geologist only by his discovering in a fossil state numerous intermediate gradations; and such success is improbable in the: highest degree."

Other Palmontological Evidences.There is a sublime suggestiveness in the broad fact that in successive periods of the earth's history higher and higher animals appear. Fishes make their appearance in the Silurian, Amphibians in the Carboniferous, Repiiles in the Permian, and Birds in the Jurassic. The record as regards plants is perhaps more striking in some of its details than in its broad outlines (see Dr. Scott's volume in this series on "The Evolution of Plants"), but every one will allow that there were Cryptogams before there were Phanerogams, and Cycads and Conifers before there were any ordinary Flowering Plants.

There are other sets of suggestive facts to which reference might be made if space permitted: there is the absence of sudden breaks or cataclysms; there is gradual waxing and waning of races; there is the remarkable phenomenon of what may be called the adolescence and senescence of genera, if not even species; there is the occurrence of old- 
fashioned generalized types which link together a number of now divergent stocks; but perhaps we have said enough to show that the facts brought to light by the explorations of palæontologists are suggestive of the evolutionist interpretation, and there is no other reading of the rock-record that does not leave the facts enigmatical. In emphasizing the importance of this line of argument, Huxley said: "The primary and direct evidence in favour of Evolution can be furnished only by palæontology. The geological record, so soon as it approaches completeness, must, when properly questioned, yield either an affirmative or a negative answer: if Evolution has taken place there will its mark be left; if it has not taken place there will lie its refutation." But it is more consistent with the science of to-day to put the case more confidently, and we would quote the opinion of a living palæontologist of high achievement, Professor W. B. Scott of Princeton: "The geological record is not so hopelessly incomplete as Darwin believed it to be. Since 'The Origin of Species' was written our knowledge of that record has been eno:mously extended, and we now possess no complete volumes, it is true, but some remarkably full and illuminating chapters. The main significance of the whole lies in the 
fact that, just in proportion to the completeness of the record is the unequivocal character of its testimony to the truth of the evolutionary theory.

The wealth and interest of the palæontological record is, in fact, only nowadays coming to be fully appreciated by the palæontologists themselves. From collectors and specialists they are becoming not only museum-makers, but so far also artists, not only arranging their specimens in clear evolutionary series, like the horses at Yale or the elephants' teeth at South Kensington, or setting up their skeletons in living attitudes, like the marvellous group of Iguanodons which are the glory of the Brussels Museum, but becoming also sculptors, and modelling their ancient monsters as they must actually have lived. Nearly a couple of generations ago this was tried, as notably for the Ichthyosaurs and Plesiosaurs (Liassic fish-dragons and swan-dragons) at the Crystal Palace, where to this day there are some weird survivals, but with inaccuracies which were only too severely criticized. Now, however, the magnificent Central Natural History Huseum of New York has not a few examples of this new branch of the animal sculptor's art, which hardly yield in vividness and convincingness to the life-like triumphs of 
the best of museum taxidermists. Yet even these are but a beginning; as the evolutionary mode of presentment increasingly dominates our collections, as already in the "Phyletic Museum" which has been so appropriately established as the Haeckel memorial at Jena, or in the central hall of the Natural History Museum in London, our galleries will increasingly develop their panoramic renewal of the forms of life throughout their evolution, and will thus express the record of the palæontologist as a wonderland for the child -whose continual interest in strange beasts, a delight thrilled with terror, is perhaps itself a survival and a recapitulation of the past mental experience of our race. 


\section{CHAPTER II}

EVIDENCES OF EVOLUTION FROM ANATOMIST, EMBRYOLOGIST AND PHYSIOLOGIST

Three Foundations of the Doctrine of Descent-Homologies-New Organs from Old-Classification-Vestigial Structures-The Recapitulation Dectrine. Experimental Evolution-Direct Evidence of Blood-relationship-Man as Transformist.

Three Foundations of the Doctrine of Descent.-The general theory of organic evolution-for so long conveniently called the "doctrine of descent"-has a tripod basis.

(a) It rests, as we have seen, on definitely "historical" evidence-on what can be actually proved in regard to ancestry. Thus recent discoveries have made the lineage of the elephant convincingly clear, equalling, if not surpassing, in evidential value that of the horse itself.

(b) It rests also upon anatomical evidence, on the disclosure of structural resemblances, often beneath a mask of functional differences, which are in many cases so intimate, so thoroughgoing, so detailed, that it is impossible to doubt that they spell affliation. 
(c) It rests thirdly upon embryological evidence, for the individual development seems almost to go out of its way to reveal the evolution of the race. The familiar development of frog-spawn into tadpoles and froglings is in some respects almost startling in its recapitulation of the evolution of the Amphioian race from fish ancestors - an evolution vouched for by the data of palæontology and comparative anatomy.

Following the historical order, we pass from the distributional evidences of errolution-whether horizontal and geographical, or vertical and palrontographical-to the anatomical data. These are of three kinds at least: (1) there is the recognition of homologies, i.e. of deeply-rooted structural and developmental similarities; (2) there are the facts of classification, that species fades into species, that genus is linked to genus, that tentative genealogical trees are possible; and (3) there is the occurrence of vestigial structures, of which there is no feasible interpretation except in terms of past history.

Homologies. - When two or more structures, organs or specialized parts, in one and the same organism, or in several organisms, show a deep resemblance in their architecture and also in their manner of development, they are said to be homologous. When they 
resemble one another in having a similar use, in discharging the same function, they are said to be analogous. This distinction of the two kinds of likeness, which are confused in popular thought and language, is of farreaching importance. The discipline of comparative anatomy, largely by help of the Platonic idea of the "archetype"-the essential or ideal form of each group or species - had made the idea of homology clear before it reached its evolutionist interpretation; and research increasingly showed that if classification is to be a grouping together of forms that are deeply alike, it must rest on a recognition of homologies, and that a grouping according to analogical resemblances is bound to be fallacious.

Aristotle (384-322 B. c.) recognized real kinship when he ranked whales with mammals, not with fishes; and bats with mammals, not with birds. And from that early date till now the successful classifiers of animals or of plants have been those who saw clearly through all deceptive suggestions of functional resemblance (analogy), and got down to the sure foundation of structural and developmental resemblance (homology).

To make the distinction between homologies of essential form and mere analogies of use more concrete, let us recall the three 
instances of Owen, to whom it owes its classic statement:-

(1) The wing of a bird and the arm of a man; they are both fore-limbs, with fundamentally the same structure as regards bones and muscles, nerves and blood-vessels; they are homologous, but not analogous.

(2) The wing of a bird and the wing of a butterfly; they are both organs of true flight, but they have no structural or developmental resemblance; they are analogous, but not homologous.

(3) The wing of a bird and the wing of a bat; they are both fore-limbs of similar structure and development; they are both organs of true flight; they are at once homologous and analogous.

Now, the evolutionary suggestiveness of homologies is indisputable. If we take, for instance, a series of fore-limbs among backboned animals - the arm of a frog, the paddle of a turtle, the wing of a bird, the fore-leg of a horse, the flipper of a whale, the wing of a bat, and the arm of man-we find detailed homology not only as regards the bones, but as regards muscles, nerves, and blood-vessels. Throughout there is close similarity in the fundamental material and in the mode of origin, but the final results how different! There is moulding and shaping and twisting 
of the same old materials, and-it is Nature's conjuring-there is something new every time. But the facts being so, it is very difficult to suggest any interpretation except one-that the resemblance is due to bloodrelationship. As Darwin said: "How inexplicable is the similar pattern of the hand of a man, the foot of a dog, the wing of a bat, the flipper of a seal, on the doctrine of independent acts of creation! How simply explained on the principle of the natural selection of successive slight variations in the diverging descendants from a single progenitor!"

New Organs From OLD.-Another set of suggestive facts is found in what the comparative anatomists have shown in regard to many of the structural novelties which appear at point after point in the animal series, that they are old organs in a new guise. The poison gland of a snake is usually a specialization of the parotid salivary gland; the milkglands of ordinary mammals are specializations of the sebaceous glands of the skin, while those of the egg-laying duckmole and spiny ant-eater are nearer the sweat-gland type; the chain of three minute bones in the mammalian ear, conveying vibrations from the drum to the inner ear, is in a sense quite new, and yet its links were forged long before there 
were any mammals; similarly, the Eustachian tube which runs past the ear to the back of the mouth in amphibians, reptiles, birds and mammals corresponds to the first gill-cleft or spiracle of a shark. Begging the question, we may state it as one of the laws of evolution that markedly new structures have often arisen from the transformation of old structures of quite different function.

Classification.- Some reckon that there are over a million different species of living creatures, and, in any case, there are many myriads. Now these species are, in many cases, linked together by varieties which make strict severance difficult. They are like constellations, well-defined at first glance, which on closer inspection are seen to be connected by outlying members with adjacent constellations. Moreover, they can be rationally arranged in genera, orders, families and classes; yet between these there appear not a few remarkable connecting links; there is structural progress from the unicellular organisms upwards along various lines of organization; and it is possible to make a provisional genealogical tree which is becoming less and less shadowy every year, though the mutual relations of the larger branches are still very obscure. 
A practical study of the species of plants and animals, and of the way one category of classification includes those beneath itclasses, orders; orders, families; families, genera; genera, species; species, varieties; and varieties, individuals-gives us "an impression of affiliation" which we do not get from a classification of rocks or other inanimate objects. It is impossible not to feel in biological classification the suggestion of pedigrees and heraldry.

Vestigial Structures.-Both in plants and animals it is common to find minute and more or less useless representatives of organs which are well developed and functional in related forms. It is impossible for us nowadays to keep from calling these structures vestigial (a better term than rudimentary, which should be kept for what is incipient), and from regarding them as the tell-tale evidences of remote ancestry. Darwin compared them to the unsounded letters in many words, such as the "o" in leopard, the "b" in doubt, the "g" in reign, which are quite functionless, but tell us something about the history of these words. Every one is familiar with the numerous functionless flaps and buttons in clothing which once had a meaning they have now lost. Similar "vestigial structures" or "survivals" persist in 
the recesses of all manner of venerable institutions.

From this point of view our own body is a veritable museum of relics. But these are not all equally venerable. In the first place, there are antique structures which are present only in the embryo, not normally coming to anything in the adult, as is the case with all the visceral clefts (or gill-clefts) except the first, which survives as the Eustachian tube. In the second place, there are old-fashioned structures which persist in adult life, but in much disguised form. Thus the gill-arches, whose primary significance (in the lower Vertebrates) was to support gills, persist in our body, almost unrecognizably transformed, in the skeletal support of the tongue and in the framework of the larynx. In the third place, there are vestigial structures in a stricter sense, because far more recentdwindling residues persistent in adult life, but either functionless or relatively unimportant, such as the minute "third eyelid" which lies in the median angle of our eye, or the muscles of the ear, which in occasional individuals are strong enough to move the trumpet, or the vermiform appendix on the large intestine. This last anachronism seems not merely to have outlived its usefulness; it often costs a man his life. It is "like an idle 
person in a community," peculiarly liable to go wrong and give rise to serious mischief. Indeed, this is true of not a few other vestigial organs.

There is no lack of eloquent examples from the animal kingdom. The baleen whale has no functional teeth, and yet it has the usual two sets-which never cut the gum. Whales have no visible hind-legs, yet many show vestiges, with bones, cartilages, and even unmoving muscles, which are buried deep below the surface and absolutely useless. Most snakes are absolutely limbless, but in the boa constrictor and some of its relatives there are quite distinct hind-legs, though these are so diminutive as to require looking for, even on a big specimen.

The Recapitulation Doctrine.-The greatest of embryologists, von Baer (17921876), was not an evolutionist, for reasons which his dates in part explain; yet he was one of the first to make clear what has always been eloquently suggestive of evolutionthe remarkable resemblance between the embryos of different types of the same great group. Thus, if we take the higher Vertebrates, viz. reptiles, birds and mammals, there is an undeniable resemblance between their embryonic stages. They seem, as it were, to travel for a considerable distance 
along the same road, or along closely parallel roads, before they diverge, each on its own path of development.

It is only in a very general way that we can accept the late Professor Milnes Marshall's epigram, that the individual climbs up its own genealogical tree; yet there is no doubt that the development of the individual is in some measure interpretable as a condensed recapitulation of the presumed racial evolution. There is no doubt that in many cases the developing embryo pursues a strangely circuitous path instead of progressing straight towards its goal, and the only light that we can throw on many instances of this circuitousness-when it is not adaptive to the peculiar conditions of development-is the light from the past. The living hand of the past is upon the embryo, constraining it to follow the old route of its race, and often reasserting its power in trivial details, even when a considerable short-cut has been made.

Thus in the development of every reptile, bird and mammal there are residues of gillclefts, sometimes imperfectly opening, which have no respiratory significance whatsoever, which can hardly be said to be of any use at all, except that, the first one becomes the Eustachian tube connecting the ear with the back of the moth. There is no known inter- 
pretation of these except as recapitulations of the respiratory apparatus of remote aquatic ancestors.

Every one is familiar with the bony flatfishes, such as plaice, flounder and sole, which have an asymmetrical body flattened from side to side. They rest and swim on their right or left side, which is unpigmented, and both eyes are on the upturned pigmented side. Now these markedly asymmetrical fishes begin their life with perfect symmetry just like other fishes. They retain this for some considerable time and live near the surface. At a certain stage a very remarkable lop-sidedness of growth and alteration of equilibrium sets in; they begin to sink towards the bottom, the eye on the downturned side travels round, or even in part through, the margin of the head; in short, a metamorphosis occurs. Different naturalists may read different meanings into the word "recapitulate," but in some sense it is surely true that these flat fishes recapitulate in their early development the form of symmetrical ancestors.

We have already referred to the case of the baleen whale, which has two sets of teeth in embryonic life. They never cut the gum, they are absorbed at a very early stage, they are not of the slightest use. It appears to us 
that in the inheritance of the baleen whale there must be definite "representative particles" corresponding to the typical mammalian dentition, that they are still strong enough to insist on some expression in development, and that so far as teeth are concerned the whalebone whale is, therefore, recapitulating, obviously in much condensed form, an ancestral condition.

A fish has a two-chambered heart, with an auricle that reccives impure blood from the body and a ventricle that drives it to the gills. In amphibians the auricle is divided lengthwise by a partition, so that the heart becomes three-chambered. In reptiles the ventricle is partially divided by a similar partition, and this becomes complece in the case of the crocodile. In birds and mammals the heart of the adult is four-chambered, with two auricles and two ventricles. But when we inquire into the development of the heart of the bird or of the mammal, we find a series of stages which are in a general way parallel to the historical evolution of the heart as we see it registered in the successive gradesfish, amphibian and reptile. The same impression is to be gained from a study of the development of the brain, the skull, the kidneys, and other organs. It seems to us impossible to deny that there is in the stages 
of organogenesis (the development of organs) some sort of repetition of the stages in the evolution of organs. The embryo of a higher Vertebrate has still in some measure to recapitulate the steps taken by the developing embryo of a lower Vertebrate; and though we may say that this is an architectural necessity, that the end could be reached in no other way, the facts seem to press us to go further and say that something in the inheritance, which is due to literal bloodrelationship, compels the repetition.

Professor T. H. Morgan states the case as follows:- "The most fundamental difference between the view of von Baer and modern views is due to our acceptation of the theory of evolution, which seens to make it possible to get a deeper insight into the meaning of the repetition, that carries us far ahead of von Baer's position. For with the acceptance of this doctrine we have an interpretation of how it is possible for the embryonic stages of most members of a group to have the same form, although they are not identical. There has been a continuous, although divergent, stream of living material, carrying along with it the substance out of which the similar embryonic forms are made. As the stream of embryonic material divided into different paths it 
has also changed many of the details, sometimes even all; but, nevertheless, it has often retained the same general method of development that is associated with its particular composition. We find the likeness, in the sense of similarity of plan, accounted for by the inheritance of the same sort of substance; the difierences in the development must be accounted for in some other way."

In thinking of the repetition or recapitulation there are two distinct ideas to be kept in mind. On the one hand, each stage in embryonic development is, as Professor His put it long ago, "the physiological consequence of the preceding stage and the necessary condition for the following." "If the embryo is to reach the complicated endforms, it must pass, step by step, through the simpler ones." On the other hand, the inheritance of a living creature is, in some manner that we cannot image, a condensation of ancestral initiatives which are materially represented in the living substance and compel the developing embryo to re-tread, to some extent at least, the path taken by the embryos of its ancestors.

Let us take the particular case of the notochord, a supporting axial rod, present for some time at least in all Vertebrate embryos, and always arising in the same way as a fold 
along the dorsal median line of the embryonic gut. In a few old-fashioned types, such as lancelet and lamprey, there is no backbone, but the notochord persists throughout life. From fishes upwards it is gradually replaced in development by the backbone. The notochord does not become the backbone, but is replaced by it. The two are quite different embryologically, the notochord arising from the inner germinal layer or endoderm, the backbone arising, like the rest of the internal skeleton, from the middle germinal layer or mesoderm. In point of fact, the backbone develops from a mesodermic sheath around the notochord, a permanent structure around a temporary structure, as a tall tower might be built around an internal scaffolding of wood. Now, what is the relation between the more primitive axis or notochord and its more effective substitute the backbone, seeing that the former does not become the latter? In his interesting theory of "the substitution of organs," Kleinenberg suggested that the notochord supplies the stimulus, the necessary developmental condition, for the formation of the backbone when suitable materials are forthcoming. Of course we require to know more precisely how the old-fashioned structure prepares the way for and stimulates the growth of its future substitute, but the 
general idea of one organ leading on to another is suggestive. It is consistent with our general conception of development-that each stage supplies the necessary condition for the next; it helps us to understand more clearly how new structures, too incipient to be functional, and old structures, too transitory to be of direct use, may persist; in short, it makes the process both of development and of evolution more intelligible. But to the idea of the architectural utility of the notochord as a piece of scaffolding, we must add, unless the recapitulation is simply metaphorical, the idea that the notochord is laid down to-day in the development of a higher Vertebrate because of a continuity of germinal material since the days of the ancestral forms which had no backbone at all.

It must be admitted that the recapitulation doctrine has been often stated in somewhat crude and exaggerated form, so that many saving-clauses are necessary. The human embryo is never like a little fish or a little reptile; the resemblance is between embryonic stages. The recapitulation is general, not exact; there is often abbreviation and a masking of the old by the new. On the one hand, old-fashioned features may drop out, having no significance either in embryonic, larval or adult life; on the other hand, many 
new features have been added on as adaptations to novel conditions. The recapitulation is seen more in the stages in the development of organs than in the development of the organism as a whole, and the reason for this is obviously to be found in the individuality or specificity of every creature. Increased precision of embryological work discloses individual characteristics even in early stages of development; indeed, a skilled embryologist (exaggerating a litile in his turn) has said that even a blind man could distinguish embryos of the duck from those of the fowl as early as the second or third day of incubation. The developing frog is in many ways like a developing fish, for instance, as regards its heart and circulation, but it is none the less, from almost the very outset, an amphibian and nothing else.

It must also be frankly stated that we are apt to get into a vicious circle in arguing about recapitulation. We infer the pedigree from the development, and then say that the development recapitulates the pedigree. But this is not quite so bad as it seems, since no racial history or phylogeny is worth considering for a moment that does not show the anatomical affiliation of actual forms, whether living or fossil, and embryological investigation cannot do more than suggest 


\section{EVIDENCES OF EVOLUTION}

clues. Again, we consider the circuitousness of the frog's life-history and find in it an evidence of the reality of recapitulation. We say that in the development of many of its organs the frog repeats steps which were taken by the fish stock from which the race of Amphibians sprang. We then use this as one of "the evidences of evolution" - which we have already assumed. But the fallacy here is simply that we cannot directly demonstrate the truth of the loctrine of descent; we can only bring forward facts which suggest it, and which it serves to interpret.

When all is said, then, there remains good reason for keeping firm hold of this idea, which was first clearly stated in its full evolutionary importance by Haeckel, first in his notable "Generelle Morphologie," and later in his more popular treatises. This he termed the "fundamental biogenetic law" that "Ontogeny, or the development of the individual, is a shortened recapitulation of phylogeny, or the evolution of the race."

Even apart from recapitulation, we must admit the suggestive general fact that the developing organism passes through a series of stages, which often differ from one another in the same sort of way as related species differ from one another.

Experimental Evolution.-In his "Nova 
Atlantis," that far-sighted Utopia of science which has already been so largely realized, Bacon suggested that experiments should be set agoing in order to discover how far surroundings can affect and transform living creatures; and many naturalists have dreamed of and pleaded for such an Institute of Experimental Evolution. One such has lately been founded in the United States, the precursor, it is to be hoped, of many in Europe. "Since Nature," said Isidore Geoffroy Saint-Hilaire, "left to herself never allows us to witness modifications of much magnitude in the conditions of life, it is clear that only one way is open to us if we wish to perceive such modifications and to examine their effects on the organism; we must oblige Nature to perform that which she would not spontaneously accomplish." Good expositions of the results of various sets of experiments will be found in H. De Varigny's "Experimental Evolution" (1892), and more recently in T. H. Morgan's "Experimental Zoology" (1907); and we camnot here do more than give a few typical illustrations.

In a few cases it has been found possible to induce experimentally what may be called an adaptive response. Thus Professor Poulton's beautiful experiments on the pupæ of certain butterflies show that the colour of 
the chrysalid is affected by the colour of the surroundings, which operates in some mysterious way through the skin. When the pupation occurs on a light background the chrysalids are lighter; when on a dark background the chrysalids are darker. This is undoubtedly an advantageous response, for it has been proved experimentally that in natural conditions survival depends in great part on the inconspicuousness of the pupæ in the place where they are fastened.

In connection with experimentally induced adaptive responses Professor T. H. Morgan makes an important note: "It is remarkable how rare are adaptive structural responses, when we recall the fact that adaptation of the organism to its surroundings is one of its most characteristic properties. The poverty of adaptive structural response does not encourage one to look to external agents as having brought about directly the structural adaptation of organisms to external conditions, even if it could be shown that such influences are inherited."

Many naturalists have experimented with the pupæ of butterflies and moths, subjecting them, for instance, to unusual conditions of temperature, and many very interesting results have been reached. In cases where there are distinct summer and winter adult 
forms, the pupa which should give rise to the former may be made to give rise to the latter, or the pupa may be affected by cold or by heat so that what emerges resembles not the local form of the species, but a northern or southern variety. Perhaps the most important general result from our present point of view is that "the differences effected by changes in the environment have been shown in some cases to resemble the kind of differences that separate species from each other." This is suggestive and important, though it does not by any means prove that species have arisen in this way.

Mr. J. T. Cunningham put very young flounders in an aquarium lighted from below, and observed that as they underwent their peculiar metamorphosis the pigment first disappeared as usual from the downturned side, and then (in 11 cases out of 13) reappeared under the unusual stimulus of light from below. This shows that the normal absence of pigment on the down-turned side of a flat-fish is due to the absence of the lightstimulus in each individual case.

Some forty years ago Schmankewitsch made a study of a natural experiment that occurred in a salt lagoon which was divided by a dam into an upper and a lower part, the latter the salter of the two. In a spring flood 
in 1871 the waters of the upper part swept over the dam and reduced the salinity in the lower part. Thereafter great numbers of a tiny brine-shrimp, Artemia salina, were observed in the lower part, having been presumably washed in. After a time the dam was repaired, the water gradually regained its great salinity, and the brine-shrimps in the course of their rapid generations lost the well-developed caudal fins characteristic of Artemia salina and became like another form without caudal fins, Artemia milhausenii. Passing from observation to experiment, Schmankewitsch found that gradual concentration of the water led to the replacement of typical forms of Artemia salina by forms like Artemia milhausenii, and he also showed that if the forms without caudal fins were kept in brine which was gradually diluted, a pair of conical prominences, each with a bristle, appeared after some weeks at the end of the tail. Schmankewitsch did not regard the change he observed as a transformation of one species into another, and it seems fairly clear that there is no species Artemia milhausenii. What he did show was that alterations in the salinity of the water are, in the course of generations, followed by slight changes in the form of the tail. Bateson and others have 
shown that there is great variability in the character of the tail and bristles of Artemia salina, and that the tailless form is connected by intermediate stages with the fully tailed typical form. A careful discussion of this fremuently misstated case will be found in Bateson's "Materials for the Study of Variation" (1894).

Direct Evidence of Blood RelationsHip.-Various workers-Friedenthal, Uhlenbuth and Nuttall-have brought forward experimental evidence of blood-relationship, and this in the most complete and literal sense. Friedenthal points out that when the blood of a horse is transfused into an ass, that of a hare into a rabbit, or that of an orang into a gibbon, or that of man into a chimpanzee, there is a harmonious mingling of the two. But when human blood is transfused into eel, pigeon, horse, dog, cat, lemur or "non-anthropoid" ape, there is no harmonious mingling. The human blood serum behaves in a hostile way to the other blood, causing great disturbance, marked, for instance, by the destruction of the red blood corpuscles. The difference in the two sets of cases is that in the first the organisms are closely related, in the second they are not. Another form of the same kind of experiment is given by Uhlenhuth and Nuttall. 
The blood-serum of a rabbit which has had human blood injected into it forms a precipitate with human blood. It forms almost as marked a precipitate when it is added to the blood of an anthropoid ape. As Schwalbe sums up in the recent Darwin centenary volume: "The reaction to the blood of the lower Eastern monkeys is weaker, that to the Western monkeys weaker still; indeed, in this last case there is only a slight clouding after a considerable time and no actual precipitate. The blood of the Lemuridæ (Nuttall) gives no reaction or an extremely weak one, that of the other mammals none whatever. We have in this not only a proof of the literal blood-relationship between man and apes, but the degree of relationship with the different main groups of apes can be determined beyond possibility of mistake."

Man as Transformist.-It is time, however, to pass from the laboratory to the breeding-pen and experimental plot, to recall the very striking transformations that man, by selective breeding, has effected in his domesticated animals and cultivated plants. Darwin pointed to what has taken place in the case of sheep and cattle, cabbages and apples, and a score of other cases, and pressed home the question: If Man has been instrumental in fixing all these varieties in a short time, 
what may not Nature have effected in a very long time?

There are over two hundred very wellmarked breeds of domestic pigeons, and there are at least ten that would be ranked as distinct genera if they occurred wild; yet there is very strong evidence that all are scions of the blue rock-dove, Columba livia. In the same way there is very strong evidence that all the breeds of poultry-Hamburghs and Dorkings, Bantams and Silkfowl, and all the rest of them, are descended from the jungle-fowl, Gallus bankiva, still found wild in some parts of India and the Malay Islands. Since the canary was introduced into Europe about the middle of the sixteenth century, over a dozen very distinctive races have been established; and of course varieties for "the fancy" without end.

It is a remarkable fact that, in spite of the accuracy, assiduity and collecting acquisitiveness which characterize botanical systematists, we know very little that is quite certain about the pedigrees of cultivated plants. As De Vries says: The origin and history of the greater part of our garden Howers, fruits and vegetables are obscure; we see them as they are, and do not know whence they came. The original habitat for a whole genus or for a species at large may 
be known, but questions as to the origin of the single forms of which it is built up ordinarily remain unanswered."

But in spite of obscurities as to origin, the evolution of cultivated plants is still going on before our eyes. Whether we visit the nearest country flower-show, or admire from enchanting distance Mr. Burbank's latest creations-the "primus berry," the "phenomenal berry," the "Bartlett plum," the spineless cactus, and the rest, or see the Mendelian experimenters positively manipulating the inheritances of our ccreals, we cannot doubt that we are in the presence of evolution in actual process.

It is necessary, however, to point out that the results of Mendelian experiments have somewhat modified our view of what man is able to achieve in the way of establishing new breeds. In many cases it seems as if he were only assisting in the "unpacking" of the extremely complex inheritance of the wild type. It may seem that new peculiarities are emerging, but in many cases what is being effected is a process of analysis and of selection. There seems to be no doubt, for instance, that the colour-varieties of the domestic rabbit are but analyzed in varying measure and mixture from that beautiful synthesis of hues which we see in the wild 
rabbit. As similar analytical varieties probably occur in Nature, the facts of domestication may retain their position among the "evidences of evolution," though our interpretation of many of them is being altered by the Mendelians.

In this case, and throughout all consideration of "evidences," it must be remembered that the evolution idea cannot be logically demonstrated. It is not a simple induction from particulars, thoroughly as particulars support it. It is a way of looking at the becoming of things; and it is the only scientific modal interpretation that has been suggested. It is a formula that fits the facts, and all the facts it fits are its "evidences." 


\section{CHAPTER III}

\section{GREAT STEPS IN EVOLUTION}

Evolution a great Succession of Achievements-The Beginnings - Protoplasm and Organisms-Characteristic lieatures of Living Creatures-Origins among the ProtozosThe Protists-Plants and Animals-The Cell-Cycle-The Beginning of a Body-Beginning of Death-The Origin of Sex-The Beginnings of Brains-The, Beginnings of Behaviour-Progress along muluy Lines - The Aseent of Vertebrates-The Aseent of Man-Evolution as Retrogressive-Deterioration and Parasitism.

\section{Evolution a Grest Succession of} Achrevements.- It is impossible to appreciate our own human position aright unless we see it in the light of history. We must think of the distant stone ages-when man made weapons of chipped flints and then of polished stone; of the prehistoric metal ages that followed-when man made weapons and utensils of copper, of bronze, and then of iron; and of the gradual growth of civilization along many lines. We are so familiar with the result that we are apt not to think enough of the long succession of achievements-each a great event in human history. It is one of the uses of a museum, provided it be on evolutionary lines, like the Pitt 
Pivers Museum at Oxford, to give us detailed pictures of the state of things in age after age. We must have a series of human skulls, a series of weapons-a series of everything that has evolved.

Similarly, no one can adequately appreciate a fully-formed creature, whether an oak tree or the bird on its branches, a frog or an eel, a butterfly or a starfish, who does not know the stages of its individual derelopment, from the apparent simplicity of the fertilized egg-cell onwards. Looking down from the summit of a pass which it has taken us all day to reach, we see the rillage in the valley from which we started at daybreak. and it seems like a great stone's-throw off. The dips and ascents, turns and twists, of our path are all lost to sight; only those who have walked over it know what the climb has really been. So it is with a retrospect on crolution.

It is an easy thing for us to say that the world of life we see around us to-day has evolved; with equal ease our grandparents said that it had been created. But it is incumbent on the able-minded to give to this doctrine of descent a solid body of fact, so that they may realize something of the grandeur and, let us add, of the difficulty of the proposition. In other volumes of this 


\section{GREAT STEPS IN EVOLUTION}

series the student will be helped to fill in some of the details of the evolution chart, thus Dr. Scott deals with the pedigree of Plants, Professor Gamble with Animal Life, Dr. Keith and Mr. Marett between them with man; what we propose in this chapter is to indicate in a general way a few of the great steps in Organic Evolution.

The Beginnings. - Until the earth cooled and consolidated it was quite unfit to be a home of life. It follows that at some uncertain, but inconceivably distant date, living creatures appeared on the scene. The question is : What was the manner of their becoming upon the previously tenantless carth? Our answer must be that we do not know. But to obviate worse answers we may submit two or three suggestions.

It may be that germs of life came to our earth embosomed in meteorites. This was the suggestion of Richter, Heimholtz and Lord Kelvin. But it is difficult to conceive of anything like the protoplasm we know surviving transport in a meteorite.

Some authorities who have found satisfaction in the meteorite-vehicle theory have also suggested that life is as old as matter. It must be noted, however, that the life we know is always associated with highly complex substances known as proteids, which 
are more like termini than beginnings in material evolution.

It may be that what we call "living" evolved in Nature's laboratory from what we call "not-living," for though prolonged experiments have led biologists to adhere dogmatically to the dictum "omne vivum e vivo," this is not inconsistent with supposing that spontaneous generation occurred in favourable conditions very long ago. Verworn has elaborated a suggestion due to the great physiologist Pfiuger (1875), that the cyanogen radical ( $\mathrm{CN}$ ) may have been the starting-point of the proteid molecule which is the essential part of the physical basis of life. As cyanogen and its compounds arise in an incandescent heat when the necessary nitiogenous compounds are present, they may have been formed while the earth was still aglow; with their property of ready decomposition they were forced into correlation with various other compounds likewise due to the great heat; when water was precipitated upon the earth these compounds entered into chemical relations with the water and its dissolved salts and gases, and thus originated extremely labile, very simple, undifferentiated living substance, which perhaps fed, as Sir Ray Lankester has suggested, upon "antecedent steps in its own evolution." 


\section{GREAT STEPS IN EVOLUTION $7{ }^{\circ}$}

It must be noted, however, (1) that al-. though the synthetic chemist can now manufacture artificially such natural organic products as urea, alcohol, grape sugar, indigo, oxalic acid, tartaric acid, salicylic acid and caffeine, he has not yet come near the artificial synthesis of proteids; (2) that we are at a loss to suggest what, in Nature's as yet very hypothetical laboratory of chemical synthesis, could take the place of the directive chemist; and (3) that there is a great gap between making organic matter and making an organism.

It is plain, therefore, that the doctrine of the origin of the living from the not-living cannot be held at present with a clear or easy mind, yet we must admit that as an hypothesis it is in harmony with the general trend of evolutionary theory. If facts accumulate which make the hypothesis a tenable interpretation, it will not in any way affect the dignity and value of living creatures, nor of our own life. If the dust of the earth did naturally give rise to living creatures, if they are in a real sense born of her and the sunshine, then the whole world becomes more continuous and vital, and all the inorganic groaning and travailing becomes more intelligible.

Protoplasm and Organisms.-If we whip 
up in a tumbler some white of egg, some yolk of egg, some casein from milk, and so on, we have got a mixture of proteids, one excellent to feed protoplasm with, but we have not got protoplasm itself. Our tumbler-mixture is only a fortuitous concourse of proteids; whereas protoplasm is an integrate of proteids, perhaps with fats and amyloids as well-a fortunate combination of molecules in instable, even mobile, yet enduring equilibrium.

It is probable that the potency of living matter is in part an expression of the complex inter-relations of the diverse proteids and other substances of which it is composed. No single substance may mean very much, but in combination they are irresistible. Indeed we may compare protoplasm to a successful firm which orres its success to an unusually fortunate combination of partners-of inventive, organizing, administrating, pushing, competitive and other geniuses!

But there is something more. The firm works as a unity, and this is its essential secret. It is unified from within, whether by a common purpose, or by the predominant will of its leading partners, or by something of both. And the organism has likewise its secret, its internal unity, which we are still far from understanding. 


\section{GREAT STEPS IN EVOLUTION}

Characteristic Features of Living Crentures. - The chemists tell us that the physical basis of life always includes proteids and similar highly complex substances, and that the process of living involves an intricate series of combustions and fermentations and reconstructions, many of whih can be imitated outside the body altogether and expressed in chemical formulie. On the other hand we cannot give a chemical description of any complete vital function, or of any activity of the living creature as a whole-and unless, as the Germans say, we throw away the baby with the bath, we cannot ignore the most salient fact, that all the manifold chemical processes are correlated and controlled in a unified behaviour, in a purposive agency. Even the amceba is no fool.

The physicists tell us that the liring creature resembles some wonderful kind of engine; it is a material system adapted to transform matter and energy; and it illustrates in its living a number of well-known physical phenomena, of surface-tension, of diffusion, of elasticity, of hydrostatics, of thermodynamics, of clectricity, and so on. At the same time it has to be admitted that not even the simplest vital activity, such as the passage of digested food from the ali- 
mentary canal into the blood-vessels, can be completely described in terms of physical formulæ. The fact is that when we add up the components revealed by chemical and physical analysis, they do not amount to the whole resultant which we see in a vital action, even of a simple sort.

It is indeed profitable to compare a living creature to a machine, and a fertile method of discovery to press this comparison to its hardest. Yet the living organism differs from any machine in its greater efficiency; and especially in this, that the transfer of energy into it is attended with effects conducive to further transfer and retardative of dissipation. Again in this, that it is a self-stoking, self-repairing, self-preservative, self-adjusting, self-increasing, self-reproducing engine! And this also must be remembered in comparing a living creature and a machine, that the latter is no ordinary sample of the inorganic world. It is an elaborated tool, an extended hand, and has inside of it a human thought. It is because of these qualities that highly complex machines come to be so like organisms. But no machine profits by experience, nor trades with time as organisms do. Therefore it is that the formulæ that serve to describe the activity of a machine will not suffice for 
living creatures which demand an historical explanation.

When we leave the chemical and physical standpoint, and look at the living creature as biologists, we recognize four chief characteristics-growth, cyclical development, effective response, and unified behaviour. The living creature grows after a fashion all its own, not as a rolling snowball, by mere accretion, but by a unifying incorporation; not even as a crystal grows, at the expense of dissolved material chemically the same as itself, but at the expense of material different from itself. Again, it has a cyclical development, from egg-cell to seedling, from seedling to beanstalk; from egg-cell to tadpole, from tadpole to frog; it shows an orderly, correlated, regulated succession of events, which leads from apparent simplicity to obvious complexity; but, as Huxley puts it, "no sooner has the edifice, reared with such exact elaboration, attained completeness, than it begins to crumble." Inanimate objects have a certain power of response to external stimuli, as a piece of potassium shows when thrown on a basin of water, but the responses of a living creature in normal surroundings are effective, self-preservative, usually making for betterment. Lastly, the living creature has a persistent unified be- 
haviour, a power of profiting by experience, a creative capacity as a genuine agent.

Origins among the Protozon.--It is well over two centuries since the Dutch microscopist, Leeuwenhoek, exhibited to the Royal Society of London some of those unicellular animals or animalcules which we now call Protozoa-the Fellows present signing an affdavit that they had really seen the minute creatures. This was the beginning of a study which has been extraordinarily fertile in itself and in its bearing on other lines of research. As has become so emphatic recently, the study is one of enormous practical importance to man, since some of the most terrible diseases, such as malaria and sleeping sickness, are due to Protozoa, but the study is also of fundamental theoretical importance. For the Protozoa give us so to speak, a natural analysis of the elements which compose the higher animals; the phases of their life-cycles are sometimes echoed in the cellular variations of man himself; a few of them seem to linger in a state of relative simplicity, approximating to that which must have characterized the true Protozoa, or first animals; they are, as it were, permanent germ-cells which never get beyond the ovum and sperm stage; and they show us the beginnings of division of 
labour and its structural aspect which we call differentiation, the beginnings of sex and of reproduction, the beginnings of a body and of death. "Protozoology," as it is quaintly called nowadays, is a fascinating study in origins.

The Protists.-It is useful to retain Haeckel's term "Protists" for those simplest of all living creatures, which lie at the base of the $V$-shaped tree of life, showing no definite bias towards distinctively plant or distinctively animal characteristies. How far removed even these simplest of the simple may be from the first living creatures we do not know, but they have remained, as it were, in chronic indecision, neither clearly plants nor animals. In studying them we are brought face to face with one of the meat steps in evolution, and one of the earlisi-a dichotomy, like many other great steps-the parting of the ways between plants and animals.

Plants and Animals. - We have all grown up with our minds coloured by the childish game of "Animal, Vegetable or Mineral?" and in too many schools they still teach that there are three kingdoms of Nature. But this is a surviving error of the alchemists, continued by the early encyclopxdists of nature, but broken down by Linnæus, who 
clearly discerned that there are only two: the living and the non-living, the truly organized and the merely aggregated. Hence in his immortal "System of Nature" he unites Animalia and Vegetabilia as Organisata, and separates Mineralia as Conserta. True, he falls somewhat from this again, witness his famous, but very fallacious, aphorism"Minerals grow; Plants grow and live; Animals grow, live and feel"; yet the great distinction of life is not lost sight of.

Since Claude Bernard, more than a generation ago, wrote his famous book, "Phénomènes de la vie communs aux animaux et aux végétaux," it has been recognized that the beech-tree feeds and grows, digests and breathes, as really as does the squirrel on its branches; that in regard to none of the main functions (except excretion, which plants have little of) is there any essential difference; and that plants, though for the most part, as it were, asleep, give many striking illustrations of their power of movement and their irritability.

We must remember also that plants and animals are alike in fundamental architecture, being built up of cells and various modifications of cells. And there is a third deep resemblance, that when we trace a beechtree or a squirrel back to its individual begin- 
ning we find a fertilized egg-cell, which divides and re-divides, the body of the plant or animal being built up by continued division, arrangement and differentiation of cells. But important as these resemblances between plants and animals are, the divergence is very profound and expresses one of the great cleavages in evolution.

It came about through the invention of chlorophyll by some Protists - a chemical and physiological achievement of the highest magnitude, which made the life of plants possible, and, through them, that of animals and man. In the complex "photo-synthesis" by which plants build up complex carboncompounds from the raw materials of water, air and earth, chlorophyll plays an indispensable part. The still widely prevalent ignorance of this fundamental process of the living world is perhaps the greatest example of the slowness with which the discoveries of science become generally recognized.

"Most plants derive the carbon they require from the carbon dioxide of the air, while only a few (green) animals have this power; all the others depend for their carbon supplies on the sugar, starch, fat, etc., already made by other animals or by plants. As regards nitrogen, most plants take this from nitrates and the like, absorbed along with water by 
the roots; whereas animals obtain their nitrogenous supplies from the complex proteids formed within other organisms. Most plants, therefore, feed at a lower chemical level than do animals, and it is characteristic of them that, in the reduction of carbon dioxide and in the manufacture of starch and proteids, the kinetic energy of sunlight is transformed by the living matter into the potential chemical energy of complex foodstuffs. Animals, on the other hand, get their food ready-made; they take the pounds which plants have, as it rere, accumulated in pence, and they spend them. For it is characteristic of animals that they explosively convert the potential chemical energy of food-stuffs into the kinetic energy of locomotion and other activities. In short, the great distinction-an average one at bestis that most animals are more active than most plants.

Changing the point of view a little, we may notice that, because of their mode of nutrition, trpical animals are bound to be active and locomotor either in whole or in part. Similarly we may say that the plantcell, by shutting itsclf up in a wall of cellulose, instead of fully oxidizing this substance, and perhaps also by less efficient elimination of nitrogenous waste, doomed itself to fixity 
and to sleep. Yet something of the animal impulse of the ancestral Protists lingers in the plant, and something of the vegetative tendency of the ancestral Protist lingers in the animal.

We have dwelt for a little on this elementary question of the distinctions between plants and animals, because it is the fundamental illustration of a bifurcation that has recurred many times in the evolution of living creatures. Living implies two great processes - of repairing and wasting, of building up and breaking down, of construction and disruption-more technically, of anabolism and katabolism. Given a typical plant and animal of equal weight, both living normally, we might safely say that the animal lives much more nearly up to its income than the plant does. If we express the vital ratio of anabolism to katabolism as $\frac{\mathrm{A}}{\mathrm{K}}$ for the plant and $\frac{a}{\kappa}$ for the animal, we may safely say that $\frac{\mathbf{A}}{\mathbf{K}}$ is always much greater than $\frac{a}{\kappa}$. In the plant the numerator is

"aiways large in proportion to the denominator. In the animal there is a relative preponderance of katabolic processes. 'Thus 
at point after point in the history of organisms the evolving Proteus has had to face the alternatives of two possible regimes precisely corresponding to the alternative between Plant and Animal in the earliest days.

The Cell-Cycle.-When we take a survey of a representative set of unicellular organisms-amœbæ, foraminifers, sun-animalcules, infusorians, gregarines, and simple algæ and fungi as well, we reach, almost by inspection, a rough and ready tripartite classification into very active and very passive forms, with amøboid forms midway. At one extreme are the highly active infusorians, such as the widely diffused free-living slipperanimalcules, or the widely diffused parasitic trypanosomes (one of which causes sleepingsickness); at the opposite extreme are quiescent forms, in which the life seems to sleep; between the two the amœboid forms have evolved along a via media-a compromise between extreme activity and extreme passivity.

If we go deeper than mere inspection and study the life-history of the very simplest forms, such as some of the primitive Proteomyxa and Myxomycetes, we get a new light on our classification. For in these lifehistories we find, for instance, that amœboid 
forms become encysted, that the encysted stage gives rise to active flagellate spores, and that these sink down again into amœbæ. The three chapters in the life-history of the simplest forms are, as it were, prophecies of each of the three groups-Infusorians, Rhizopods, and Gregarines. In other words, the most primitive organisms pass through a cycle of three phases, one of which is accented by each of the three main groups of Protozoa. And while each main group is characterized by one dominant phase of cell-life-flagellate, amœboid or encystedthere are often transient hints of other phases. An infusorian may have its encysted chapter, a gregarine its amceboid stage, and a rhizopod may begin as a mobile flagellate spore; for each group, while accenting one phase of the cycle, retains reminiscences of the others.

The conviction that the triple division really means much, grows stronger when we pass from the unicellulars to the cells that compose the higher animals. For they, too, may be rationally classified along the three great lines. There are active ciliated or flagellate cells in most animal types-the flagellate cells of sponges, the "flame-cells" of the lower worms, the ciliated epithelium lining our air-passages, being three familiar illustrations. The white blood corpuscles 
are obviously comparable to amøbæ. Pas-sive encysted cells are illustrated in some forms of connective, skeletal and fatty tissue. Thus the physiological classification of the Protozoa is verified in the histology of the higher animals, and is further corroborated in the study of their diseases. In a certain kind of "sore throat" the ciliated cells of the windpipe sink into an amceboid phase, cchoing a nomal change in the life-history of the simplest Protists. The young ovum is often arıoboid, the mature ovum is encysted; the typical spermatozoon is flagellate, but there are some exceptional amœboid forms. Finally, the same cell-cycle is not only recognizable in the reproduction of the lower plants, but is plain in the higner cryptogam, and vestigial in the flower. And the deep significance and historical importance of the lines of differentiation indicated by the cell-cycle become more evident still when we recognize that the three phases correspond to the three possibilities of relatively preponderant anabolism, relatively predominant katabolism, and a compromise between these two.

The Brginning of A Body.-The simplest organisms are single ceils physiologically complete in themselves; they leave off where higher creatures begin, that is to say, in a 


\section{GREAT STEPS IN EVOLUTION $8 \tilde{z}$}

unicellular state; they do not form "bodies." Here we have perhaps the greatest gap and the greatest step in organic nature, that between single-celled and many-celled organisms. It is very interesting to inquire into the beginning of a "body." What are the possibilities?

We know of some simple units that have a habit of coalescing into composite masses, of others in which the nucleus divides over and over again within the cell so that multinucleate organisms are formed, and of others again that break their definition, and do their best to get beyond the unicellular state, by forming loose colonies. It was probably in the third of these ways that body-making began. Certain simple organisms, unable fully to complete that division into two or more separate units which normally occurs at the limit of growth, bridged what Agassiz called "the grectest gulf in organic nature." It was perhaps through some weakness that the daughter-units, formed by division of the mother-cell, remained associated, instead of drifting apart in individual completeness. But out of this weakness - if weaknessstrength arose, the strength of animals with a body.

Beginning of Death.-In a startling phrase-the immortality of the Protozoa- 
Weismann called attention to the fact that unicellular organisms are not subject to natural death in the same degree as higher animals are. They may be killed, of course, in many ways, but they do not normally die. Even against microbic infection many of them seem proof; they digest the virulent intruders, as do the phagocytes which form our body-guard. But the point is, that in natural conditions, where inter-crossing, for instance, is readily feasible, they appear to be exempt from that natural death which in the higher organisms is due to the slow mounting-up of physiological arrears.

How is it that these simple pioneer organisms are exempt from the penalty all other flesh is heir to? The answer is twofold. On the one hand, being relatively very simple, in a strict sense without a "body"-they are able to sustain with persistent success the rital equation between waste and repair. On the other hand, their common mode of reproduction, by dividing into two or more units, is inexpensive and not attended with any loss of life. For although the individual A disappears in giving rise to $\mathrm{B}$ and $\mathrm{C}$, its daughter-cells, we can hardly speak of death when there is nothing left to bury. On the one hand, we reach the idea that death was the price paid for a body; on the other hand, 
we see that in the simplest forms of life immortality has not even yet been pawned for love. No?

The Origin of Sex.-In many of the unicellular organisms there is a kind of sexual reproduction, in the sense that two cells fuse to become one, just as ovum and spermatozoon do in higher creatures. In many cases, moreover, the two cells which fuse are dimorphic, as is well illustrated in the bellanimalcule, Vorticella, where a small, active, free-swimming (we may say male) cell unites with a fixed individual of full size, which may be called female. This is one line of approach to the origin of sex, and it may be noted that the male and female cells illustrate the antithesis we have already discussed between relatively more anabolic and relatively more katabolic types.

The next stage in the problem is to account for the familiar fact that in almost all organisms with bodies there are special reproductive cells, or germ-cells-ova and spermatozoa-quite distinct from the ordinary body-cells. This is an economical improvement on the method of starting a new life by a sexual over-growth or by the liberation of buds. Moreover, the peculiarity of true germ-cells is that they do not share in building up the "body," and that they 
retain an organization continuous in quality with the original germ-cell from which the parent arose. They are thus not very liable to be tainted by the mishaps which may befall the "body" which bears them. And again, in the life-history of the germ-cells, and in the mingling of two of them of different experiences in fertilization, there is apparently opportunity for new organic permutations and combinations - variations in short. Perhaps there is some subtler advantage still in the process which ensures that each new life usually begins in a unification of two inheritances.

The third aspect of the problem is that most multicellular organisms are males or females. The former liberate male elements, which are usually actively motile; the latter form, and usually liberate, more passive eggcelis or ova. In the lower reaches of the animal kingdom there is seldom much difference between males and females; indeed, it is often impossible to distinguish the two sexes without a microscopic examination of the reproductive organs. It is obviously at this level, and not with the highly specialized sex dimorphism of peacock and peahen, ruff and reeve, lion and lioness, man and woman, that the problem should be first studied. The problem is partly solved by con- 
sidering the simplest expressions of the sexdifference, as we see it, for instance, in Volvox, an interesting colonial Infusorian, which well illustrates a body in the making. It is a beautiful rolling ball of ciliated cells, and these component units are connected by protoplasmic bridges. From the ball of cells reproductive units are sometimes set adrift, which divide to form other colonies without more ado. But in other conditions, when nutrition is checked, a less direct mood of reproduction occurs. Some of the cells in the ball become large, well-fed elements - the ova; others, less anabolic, fade from green to yellow, divide and re-divide into many minute units-the spermatozoa. The large cells of one colony are fertilized by the small cells from another. Here we see the formation of dimorphic reproductive cells in different parts of the same organism. But we may also find Volvox balls in which only ova are produced, and others in which only sperms are produced. The former seem to be more vegetative and nutritive than the latter; we call them female and male organisms respectively; we are at the foundation of the differences between the two sexes.

Again we would state our thesis that all through the animal series, from active Infusorians and passive Gregarines, to feverish 
Birds and sluggish Reptiles, we read alternatives or antitheses between activity and passivity, between liberal expenditure of energy and a more conservative habit of storing. This primarily depends on the ratio between disruptive (katabolic) processes and constructive (anabolic) processes, and we regard the sexes as expressions of the same contrast within a given species. And do not kindred yet contrasted forms, like goat and sheep, wasp and bee, butterfly and moth, seem as it were but the extreme expression of the same individual and sex contrasts carried farther, upon the plane of species, of genus, of order, or of class?

According to this view the deep constitutional difference between the male and the female organism, which makes of the one a sperm-producer and of the other an egg-producer, is due to an initial difference in the balance of chemical changes. The female seems to be relatively the more constructive, whence her greater capacity for organic sacrifices in maternity; the male relatively the more disruptive, whence his usually more vivid life, his explosive energies in action. In short, the sexes express a fundamental difference in the rhythm of metabolism.

This initial difference not only leads to the primary functional distinction between male 
and female, but it also determines, either from the start, or after maleness and femaleness have been partly established, what particular expression will be given to a whole series of secondary character's, - both structural and functional, - whether a masculine or a feminine expression.

The Beginnings of Brains.-In most sponges and coelenterates (such as jelly-fish, sea-anemones and coral polyps) the body has radial symmetry. That is to say, it is the same all round, it has no right nor left, it can be cut into symmetrical halves along many different vertical planes. This kind of symmetry is well suited for sedentary life, like that of sea-anemones, which wait for food to come within the scope of their stinging and grasping tentacles; or for an easygoing life, like that of jelly-fishes, which live in the very uniform environment of the open sea where all directions mean very much the same.

For conditions of more active and strenuous life, however, where it is important to chase the food, to flee from enemies, to pursue mates, and so on, radial symmetry is unsuitable, and it is replaced by bilateral symmetry. This acquisition of head end and tail end, of right side and left side, was doubtless of enormous importance, both in itself 
and in its consequences, which include our knowing our right hand from our left.

It is likely that certain "worms" were the first animals definitely to abandon the more primitive radial symmetry, to begin moving with one part of the body always in front, to acquire head and sides. And if one end of the body constantly experienced the first impressions of external objects, it seems reasonable to suppose that sensitive and nervous cells would be most developed in that much-stimulated, and otherwise over-educated, head region. But a brain always arises from the sinking in of ectodermic cells from the surface of the embryo, and its beginning in the cerebral ganglion of the simplest "worms" is thus in part explained. It is difficult to over-estimate the importance of the establishment of an anterior brain a chief motor and sensory and co-ordinating nerve-centre - and the consequent evolution of a head.

The Beginnings of Behaviour. - Jennings has shown that some unicellular animals "behave" in a very definite way. They are not mere automata which rush about as long as their spring keeps unrolling, and they are more than the mere slaves of stimulus. There are some, it is true, which seem to have only one kind of reaction to every kind 
of stimulus, only one answer to every question, but there are others whose behaviour is at a higher level, illustrating what may be called "the method of trial and error." They "try" one kind of reaction after another, until, in some cases, they give the effective response.

But while we cannot doubt that the beginnings of behaviour are to be found in the Protozoa, new possibilities must have opened up whenever head-brains were established. For this centralizing of the nervous system must have meant a new integration, a more unified control, of the whole organism.

We cannot attempt to summarize the discernible steps in the evolution of behaviour, but we wish to press home the fact that what we are so familiar with to-day is the long result of time. We see behaviour rising, along one line, to its wonderful instinctive expressions. We see it rising (whether further or along another line is still under discussion) into intelligent expression where there is perceptual inference. Finally, in man, with his conceptual inferences, intelligent behaviour becomes rational conduct.

Progress along many Lines. - In his interesting "Evolution of Plants," Dr. Scott refers to the important fact that at a time so remote as the Devonian period, when there 
were no backboned animals higher than fishes, a very high level of organization had been reached by the plants. There were in those days ferns and horsetails, club-mosses and Pteridosperms, and many other plants of high degree; what has happened since has been specialization rather than great advance. It is true that the fern-like Pteirdosperms gave rise to the world-wide Mesozoic Cycadophytes, and, in still later times, to the true Flowering Plants, but there was no great new organic invention like that of the seed, for which the flower is but the protean birth-robe. Since that, progress has been in the intensive colonization of the earth and in detailed adaptations, vegetative and floral, manifold and exquisite.

In thinking of this, we must remember, in the first place, that while the Devonian period is inconceivably remote, there was an equally inconceivable stretch of ages before it, during which there must have been many a great step among plants as well as among animals. In the second place, the fact that plants have made no such very great advance since the Devonian period, whereas animals have risen by stride after stride to higher and higher levels of organization, is congruent with the deep contrast between plants and animals to which we have already referred. 
It is not merely that plants in their structural relations remain about the level of Coelentera among animals; it is that they are on an entirely different line of evolution. Plants and animals are incommensurable and antithetic.

If we take a series of sedentary animals, such as zoophytes or alcyonarian corals, we find, as in plants, a wealth of variety within narrow range, an exhausting of the possibilities of ramification and colony-making, a great development of hard supporting parts, and many nice adjustments to slight environmental peculiarities. They and the plants have a similar kind of beauty - expressing the dream-smiles of their sleep-like life.

How different this is from what we see among the free-living animals - which made one important step after another. Keeping to backboneless animals for the moment, let us notice some of the great acquisitionsbilateral symmetry, a head-brain, specialized sense-organs, a body-cavity, a segmented body, muscular feet, a renewable external armour, muscular jointed appendages, and so on. Or let us think of particular cases such as the extraordinary development of the respiratory system in insects, where ramifying tubes carry air to every nook and cranny of the body, so that the blood can hardly ever 
become impure, and a climax of vital activity is attained. The story of the evolution of Invertebrates is a succession of great achievements. Among Vertebrates they were even greater.

The Ascent of Vertebrates. - It is a profitable exercise to draw a long ascending slope, with perpendiculars dropped from various points to the base line, registering the evolutionary ascent of Vertebrate animals. What are the impressive facts? (1) Life has been creeping or pressing upwards for many millions of years. (2) Great specializations occur at every level, but there is also beyond doubt a progressive differentiation and integration. (3) This is particularly true of the nervous system, and is of course a condition and expression of the gradual increase of intelligent behaviour. Life becomes richer and freer. (4) Increased individuation makes reproductive economy possible. Parental care increases, and the number of offspring decreases. There is an emergence of the finer feelings, and fondness is sublimed in love. (5) There has been an interesting peopling of the earth, an establishment of faunas distinctive of the shore, the open sea, the deep sea, the fresh waters, and the air. Amphibians mark the important transition from water to dry land; the ancient Ptero- 
dactyls mark the mastery of the air in which Birds and Bats are now most at home. But hardly less impressive is the possessing of every nook and corner. Many a species has only a niche, but it is its own. (6) Following from the masterful, detailed colonization of the heavens and the earth and the watcis under the earth, there is the realth of consummate adaptation-of a creature to its surroundings, to its food, to its habits; of the unborn young to the mother and of the mother to the unborn young; of the sexes to one another; and of the internal architecture of the body, whether in the fit adjustment of the proportions of parts, or in the minute structure of a bone. Every creature is a bundle of adaptations. Indeed, as Weismann says of the whale, "When we take away the adaptations, what have we left?"

It is instructive to look into the matter in detail, and to notice, for instance, what types made particular acquisitions. Hag fishes and lampreys (Cyclostomes) were the first animals with skulls; fishes were first with jaws; amphibians gained fingers and toes, true lungs, a voice, and a mobile tongue; reptiles first show the important antenatal robes (or foetal membranes) called the amnion and the allantois, and the crocodile was the frst creature with a four-chambered heart; 
birds and mammals are the only warmblooded animals, and they show a great heightening of brain-development; in all mammals except a few primitive forms there is an extremely important and usually prolonged intimate connection between the mother and the unborn young.

The Ascent of MaN.-As this final achievement of Vertebrate evolution will be discussed by Dr. Arthur Keith in a special volume of this Library, we need not do more than refer to a few points of general evolutionary interest.

The real distinctiveness of man from his nearest allies depends on his power of building up general ideas and of controlling his conduct in relation to ideals. He has many structural peculiarities, it is true, but the differentiating qualities are in language, thought and conduct, and in the finer brain associated with these.

The "Descent of Man" is the expansion of a chapter in the "Origin of Species." In other words, the evidences of man's origin from an ancestral type common to him and to the higher apes, are the same as those used to substantiate the general doctrine of descent. As Owen allowed long ago, there is an "all-pervading similitude of structure" between man and the anthropoid apes; the 
bodily life is closely similar; the human body is a rich collection of vestigial structures; some of the fossil remains are nearer the anthropoid type; man's individual development is in some ways like a recapitulation of his presumed ancestral history.

There is a fine ring in the closing words of "The Descent of Man":-

"We must, however, acknowledge, as it seems to me, that man, with all his noble qualities, with sympathy which feels for the most debased, with benevolence which extends not only to other men, but to the humblest living creature, with his God-like intellect which has penetrated into the movements and constitution of the solar systemwith all these exalted powers-man still bears in his bodily frame the indelible stamp of his lowly origin."

Man's antiquity is to be measured not in centuries but in millennia. It is perhaps 150,000 years since he used stone weapons in Europe against mammoth and rhinoceros, hyæna and lion, and these weapons were not the work of novices. No fossil remains of man have been found except in Post-Tertiary (Diluvial) deposits, but there are several reasons for believing that his origin was very much earlier. Thus, for instance, it is certain that he did not arise from any of the 
known anthropoid apes (gorilla, chimpanzee, orang and gibbon), but from a stock common to them and to him; therefore it is likely that. the human stock had diverged before the time when the anthropoid apes are known. to have been established as a distinct family, namely in the Niocene.

It is possible that man arose as a mutation, as an anthropoid genius in short, but the factors that led to his emergence are all unknown. We must remember, however, that the stock of Primates to which he is zoologically affiliated is marked by great intelligence, and that we find illustrated amongst them some very significant habitsof whiting half erect, of using sticks and stones, of building shelters, of living in familics, of co-operating in bands, and of talking a good deal. The anthropoid apes are not social, but many monkeys are, and there can be little doubt that man was from the first distinchvely social. "Man did not make society; society mace man."

The lneertainties as to man's pedigree and antiguity are still great, and it is undeniably diffentt to discover the factors in his cmergence and ascent. Therefore, while holding firmly to the general conclusion to which the facts ail point, we do well to trat the problem with all reverence, especially 
when we reflect on the greatness of the result of this last great step in organic evolution. For "What a piece of work is a man! How noble in reason! how infinite in faculty, in form and moving how express and admirable! in action how like an angel! in apprehension how like a god!"

A chapter can merely hint at the great steps in evolution, and we must leave the reader to develop the subject. For ilhis is certain that we cannot appreciate the fact of evolution, or form a sound judgment in regard to its factors, unless we think of the age-long process in some detail and recognize at once the grandeur and the difficulty of each of its greater uplifts.

Evolution as Retrogressive: Deterioration AND Parasitisir.-Of "Degeneration: a chapter in Darwinism," Sir Ray Lankester many years ago wrote a whole volume, compact yet readable: still, even to-day, the old optimism of political progress too largely colours the public mind; so, despite knowledge and care, all save the most pessimistic of us tend sometimes to speak, and it may be even write, as if evolution necessarily implied progress, and as if the surviving fittest were also the best, in its ordinary sense, of better than mere good. Hence the need of frankly facing some of 
those ugly chapters of natural history which follow the decline of so many forms of life, even high and beautiful ones, into degenerations well-nigh incredible, into parasitisms even loathsome. For one thing, even the most thoroughgoing creationist and Paleyan of old must have had some qualms in ascribing the intricacies of parasitism to special creation, or its pains and enfeeblement, so varied and so widespread among all the higher animals, to beneficent design; thus the evolutionary parasitologist has had it practically all his own way, yet has also cured us, with his gruesome lists of pestiferous creatures and lurking dangers, of that dream of this as the best of all possible worlds to which a too facile evolutionism has been wont to incline. Species of all manner of groups, he shows us, may fall into parasitism, the simplest bacteria and lower fungi, the more active and long supposed innocent Protozoa above all-so that for a generation past the vast field of pathology has seemed well-nigh divided between bacteriologist and parasitologist proper. It is among the Vertebrates, which only fall into parasitism in the rarest cases, that infestation is most frequent. Fishes may even swarm externally with trematodes and parasitic crustaceans, internally with cysts and intestinal 
worms without number. A vivid impression of the prevalence of parasitism is afforded by the capture, not infrequent at a channel zoological station or by fisher folk anywhere, of the huge and majestic sunfish, Orthagoriscus mola; and by picking off with forceps into museum bottles his crowds of uninvited passengers - the tuft of barnacles upon his back, the biting isopods like enormous fleas upon his skin, the trematodes sucking like leeches upon his eyes; and within to find not only his alimentary canal crammed with worms more than with food, and his liver changed from its natural brown almost into the likeness of a tangle of white worsted, of which each thread is a tapeworm. Neither frog nor lizard, serpent nor bird, escapes; indeed birds are peculiar sufferers, witness the too common "gapes" of poultry, a choking of the windpipe by threadworms, and the numerous parasitic worms which Mr. Shipley's labours have discovered in the well-nigh sacred grouse. Of ticks the shepherd is only beginning to know the full dangers, as of fleas man himself. Apart from bacterial and protozoan pests, as yet beyond counting, man is debited by the parasitologist with at least sixty species; some reckon twice as many. The amazingly varied methods of Nature for the diffusion 
of parasites are among the very strangest disentanglements of the web of life, but into the stories of these adventures in search of mischief we cannot enter here: enough if we note the stupendous rate of multiplication by which the many chances against finding the proper host are constantly met; thus the common tape-worm of man has been calculated to produce eighty-five million ova during its two years' existence.

It is an interesting inquiry whether the large numbers of so-called species of threadworms, tape-rrorms and other parasites, are not, in many cases at least, mere modification forms, whose diagnostic characters are directly induced by the peculiarities of their respective hosts. The question is, of course, one for the experimental observer.

Again, even parasitism must not be vieved too pessimistically. It is, after all, not the interest of the parasite to kill its host, or even to deteriorate its life too seriously; moreover the host becomes more or less adapted to its wonted guests, and probably correspondingly immune to the irritant poisons which many parasites have been shown to excrete. The rapid disaster which parasites so often bring about seems rather when introduced into some new and unaccustomed host; as probably in the case of sleeping sickness. 


\section{GREAT STEPS IN EVOLUTION 105}

Again, parasitism may pass on one side towards more and more complete mutual adaptation, witness the symbiosis of alga and animal in certain sea-anemones, or the admirable permanence of that co-operation of short-lived alga and transient mould which enables the resultant lichen sometimes to outlive the very tree which bears it. Galls, again, afford many instances of a parasitism which is reaching equilibration.

Thns in many ways we must not consider parasites as simply aberrant, nor their peculiarities as unique. These become intelligible products of evolution when we realize them as perhaps the extreme cases of the determination of organism by environment. From the analysis of this relation, especially in these extreme cases of parasite and host, the theory of evolution might almost have been predicted, since, if the details of environment and of organism be, as here, obviously and precisely adapted one to the other, change in the former must either be followed by the extinction of the latter, or by its modification in the requisite details. To understand the modus operandi of this, Weismann invokes the needful germinal variation of the germ-cells, and Dohrn his "principle of functional change" - his reminder that every living tissue, however 
specialized, retains traces of all the functions of protoplasm, and that therefore any one of these may be indefinitely increased by favourable conditions, and the specialized function similarly reduced to a trace. Our notion of specialization becomes thus associated with a corresponding possibility of simplification, and our idea of progress thus becomes complemented and checked by the possibility of degeneration, and this from any stage of the ascent of life. The first of these views is the neo-Darwinian; while the second savours of neo-Lamarckianism; but here, happily, is a case in which the recent admirable eirenicon of Lloyd Morgan, Osborn and Baldwin (discussed in Chapter Vl) may be conveniently applied. According to this, the modifications of the individual in response to environment, to use and disuse, in themselves non-heritable though they may be, may yet serve as the nurse and shield and selective vantageground for germ-variations in the same direction. With this two-fold process at work, in germs and in developing adults, the frequent development of parasitic shoots upon the tree of life becomes a less perplexing marvel.

Another interest of this subject is the way in which it invites that comparison of the 
natural and the social world which has always been so fascinating, and, as we maintain from opening to close of this volume, also so fruitful. The naturalist and physician almost forget that the word parasite was originally a social epithet; but the many critics of human society are using the comparison more and more frequently, of course often in mere vague abuse, but sometimes keenly also. Notable in this connection is the collaboration of Professor Massart, a biologist of Brussels, with M. Emile Vandervelde, now widely known beyond the Belgian parliament as one of the foremost of the popular tribunes of Europe; and their "Parasitism, Organic and Social" (1895) will still be found suggestive to naturalist and sociologist alike.

Without entering upon matters so controversial as a volume so named inevitably raises, we may profitably note the fresh light which the study of parasitism throws upon that till lately accepted and still mainly predominant body of economical and social thought, that of the modern industrial age-its political economy for the group, its teaching and ideal of success for the individual. For thus instead of calling this one or that of our more successful fellows by the ugly name of parasite, we may 
more safely begin by recognizing this very tendency in ourselves. For who does not at times look forward to a more peaceful, a more prosperous and assured period, in which, storms and trials over, we are to settle down, snug, cosy'and warm, there to eat of the fat, and drink of the sweet, and to enjoy what may remain to us of life? And what parent but wishes for his child a safer, easier, richer life than his own? Little wonder, then, that the political economist, who has for the most part but massed popular opinion into his pretentious but inchoate would-be science, has treated this scheme of life as the natural one, and confirmed his public more and more into it as the practical one as well. For your woulu-be practical man, slave to that wildest, strangest, most impossible of all theories - the theory that there are no theories-ever falls victim to the surface plausibility of the crudest theory going.

Whereas the student who has seen crustacean larvæ in all the activity of their youth, bright-eyed, free-swimming, and thereafter settling down into barnacles upon the rock, or, seeking food and safety at the expense of their larger and stronger active kindred, settling further down into mere blood-bags, mere egg-bags, "sans eyes, sans ears, sans 


\section{GREAT STEPS IN EVOLUTION 109}

everything," has before him a naturesymbol, one worth thinking about, and that carefully, even furiously also. For here it turns out that the teaching of the economists who have identified comfort with progress have been so far right in unifying them, no doubt; only they have been forgetting that such progress tends to be bought too dearly. Their gospel of "getting" on" is not necessarily getting on; and hence their much preached and yet more prayed for "success in life" so often turns out the very reverse of success in living.

Contrariwise, our bio-sociology tends to justify the so-called "unpractical." It is essentially the free-living and self-supporting creatures that really get on, that evolve in the best sense. So the idealist adventuier who loves to meet the "bright eyes of danger," who goes out to seek love and face death, lias true success in life, brief though it be; and this not merely from the "romantic" point of view the philistines fancy confined to novels, but from that rising? standpoint of evolutionist realism of which morals in one age, religion in anocher, and now art in our own, have each been the presage. Thus in facing the ugliest facts of lowest life we see them give way to the noblest hopes of our own evolution. In 
education, then, let us not fear to apply this escape from economics of the baser sort, that science falseliest so called; and thus have done with the current obsessions of the money-world, of most ease with least labour, of getting something for nothing; perhaps above all, of that secking after the assured life of petty, sedentary functionarism, which is becoming a main curse of civilizationwe now see why.

Out in the fields, on hill, at sea, facing the buffetings of wind and wave, working with our fellows, and there content neither with strength nor skill alone, but seeking exercise for both, here is the best life of evolving manhood: as of old, so for ever, let townlings dream as they may. And how to combine this fundamental vividness of rustic life with the subtler, yet it may be even more strenuous life of productive urban culture, is, perhaps, the main problem before the evolutionist. In modern everyday phrase this task is, in fact, already opening before us; already we are seeking to advance rural development here and town-planning there; we have next to co-ordinate both into regional renewal. Given this incipient view and policy of human life, as consciously evolutionary, in exchange for the passing one-of successful life as sessile, uncon- 


\section{GREAT STEPS IN EVOLUTION 111}

sciously degenerative, and as far as possible, parasitic - the field of effort opens. Hygiene, engineering and irrigation, agriculture and forestry, and all such strenuous careers are already opening perspectives lately undreamed by youth, struggles for existence nobler and more sustainedly strenuous than those of war. Practically, the control of the ice-lands and of the tropics, the amendment of nature-and above all, speculatively, the distinction between ascending and deteriorative progress - thus alike become more clear. 


\section{CHAPTER IV}

VARIATION AND HEREDITY: THE SPRINGS AND CHANNELS OF EVOLUTION

What Orcanic Evolution Implies-Heredity and Variation - Why Like Tends to Beget Like-Organic Changes Analyzed-Darwin's Position in regard to TariationsKiodern Study of Yariations-The Mutation Theory -Merdelism-Causes of Variation.

What Organic Evolution Inplies.-Organic evolution is racial change along a definite line. It is for the variety or species, breed or race, what embryonic development is for the individual - a mode of becoming. Its continuity is sustained by a succession of generations, whereas in development the continuity is obviously one of personal identity. Evolution implies three things: $(a)$ raw materials in the form of variations, or organic changes of some sort; (b) an arrangement for securing the hereditary entail of some of these; and (c) a directive mechanism for securing consistency and effectiveness of racial change. The importance of $(c)$ will vary with what is provided by $(a)$ and with the degree of persistence allowed by (b).

Heredity and Variation. - Heredity is 
the genetic relation between successive generations, and an inheritance includes all that an organism is, or has, to start with, in virtue of its hereditary relation. We cannot compare organic inheritance to a patrimony; for the organism and its inheritance are, to begin with, one and the same. Nor do we any longer think of heredity as a power or a principle, as a fate or a force; we study it as a genetic relation, which is sustained by a visible material basis, namely the germcells; as a relation of resemblances and differences which can be measured and weighed, or in some way computed.

The hereditary relation is such that like tends to beget like, while at the same time opportunity is afforded for the individual new departures which we call variations. Both the tendency to persist and the tendency to diverge are included in the hereditary relation, so that it is confusing to make an absolute antithesis between heredity and variation. Heredity, seen in its fullest sense, is the larger concept, and includes both inertia and divergence, both continuance and change. Whatever be the terms used, there are two complemental facts: that like tends to beget like, yet that every new creature has in some way an individuality of its own. 
Why Like Tends to Beget Like. - The fundamental hereditary relation is such that like tends to beget like, and the reason for this is found in the fact of germinal continuity. As long ago as 1875, Galton pointed out that there is a sense in which the child is as old as the parent; for when the parent's body is developing from the fertilized ovum, a residue of unaltered germinal material is kept apart to form the reproductive cells, one of which may become the startingpoint of a child. This idea has been independently expressed and more fully developed by Weismann, who states it thus: "In development a part of the germ-plasm [i.e. the essential germinal material] contained in the parent egg-cell is not used up in the construction of the body of the offspring, but is reserved unchanged for the formation of the germ-cells of the following generation." In many cases the future reproductive cells are visibly set apart at a very early stage before the division of labour in body-making has more than begun; in other cases where the future reproductive cells are not visible till much later, we argue by analogy that they are reproductive cells because they have not shared in bodymaking, but have kept intact the protoplasmic equipment-the full inheritance- 
of the original fertilized ovum. Thus the parent is rather the trustee of the germplasm than the producer of the child. In a new sense the child is "a chip of the old block." The clarifying and corroboration of this doctrine of germinal continuity has been one of the most important steps of post-Darwinian biology. It enables us to understand why like tends to beget like; and it also suggests, what is hardly less important, that the new departures or variations, which we have spoken of as individual, are really expressions of the changeful vitality of the undying germ-plasm. As Bergson puts it: "Life is like a current passing from germ to germ through the medium of a developed organism. . . . The essential thing is the continuous progress indefinitely pursued, an invisible progress, on which each visible organism rides during the short interval of time given it to live."

Organic Changes Analyzed.-Great progress has been made in recent years in studying the individual peculiarities of plants and animals, in registering their amount and their frequency. The collection and analysis of these "biometric" data are of fundamental importance, for the Darwinian method of interpretation is like that of Lyell, throwing the light of the present on 
the darkness of the past; and it is only when we know securely what changes are going on now that we can legitimately argue back to what may have occurred in remote antiquity.

Facts bearing upon variations have been gathered so industriously of late that assimilation has hardly kept pace with accumulation; and one evidence of this is to be found in the confusing ambiguity of the terms used by various biologists. The term "variation" is used in reference to at least three readily distinguishable kinds of organic change, and the term mutation is also used in three senses. The terminology will require to be standardized by some International Congress of Biologists; but pending this, let us do what we can in trying to get the ideas clear.

When we compare a number of members of the same species-men, ruffs, garter-snakes, sticklebacks, snails, brambles, buttercups, pansies, and so on - we find that they differ from one another. These differences can be measured and registered under the title "observed differences," which commits us to no theory whatever.

But these "observed differences" require further analysis before a statement of them can be very useful. Indeed a statement of 
them without analysis is very apt to lead to biological fallacy. Many of the differences may be wrapped up with sex, and these can be readily sifted out from the slumped total. Others may be wrapped up with age, and these can also be analyzed out. Others are due to something unusual in the "nurture" in the wide sense; that is, they are the direct results of peculiarities in surrounding influences and of peculiarities of habit. Such changes in the bodies of plants and animals are extrinsic, not intrinsic, in origin; they are acquired, not inborn. They are technically called "acquired characters," or much more clearly "modifications." They may be defined as structural changes in a part of the body, directly induced by peculiarities of use or disuse, or by some change in surroundings and nurture generally, which transcend the limit of organic elasticity and thus persist after the inducing conditions have ceased to operate. No convincing evidence of their transmission has as yet been forthcoming.

Now the point is that when we subtract from the total of observed differences all that can be regarded as individual modifications, we have a very interesting remainder, which we thus define off as inborn or germinal variations. They are intrinsic, not extrinsic; inborn, not made. We cannot 
causally relate them in a direct way to peculiarities in habits or surroundings; they are often distinct at birth or even hinted at before birth; they are rarely alike even among forms whose conditions of life are uniform. They are in many cases, if not always, transmissible. They form the raw material of evolution.

Darwin's Position in regard to VariaTIONS.-Darwin recognized two kinds of hereditary variations, in addition to those extrinsic changes which we now call modifications. In the first place he recognized large "single variations" or "sports," which occur rarely and result in conspicuous divergences from the type of the species. In the second place he recognized slight "individual variations," which are practically ubiquitous, distinguishing child from parent, brother from brother, cousin from cousin. Both of these kinds of variations were called "indefinite" and "spontaneous," to distinguish them from what he somewhat unfortunately called "definite variations" - the direct result of environmental and functional peculiarities. These correspond to what we now call modifications, and it must be noted that Darwin believed in their occasional transmissibility.

Leaving aside the question of the possible 
racial importance of modifications, it is of interest to notice Darwin's view of the relative importance of "single variations" and "individual variations." The former correspond in a general way to what we now call "discontinuous variations," "mutations," "saltatory variations"; the latter to "continuous variations" or "fluctuations."

Darwin was much interested in the former class, "sports" as he sometimes called them; but-true to the influence of Lyell-he came deliberately to the conclusion that the minute ubiquitous fluctuations were by far the more important. The criticism of Fleeming Jenkin, Professor of Engineering in Edinburgh, that single large peculiarities would be likely to be swamped by inter-crossing, had so much weight with Darwin that he ceased to attach importance to the larger divergences, and found his raw material in the smaller fluctuations. "The more I work," he said, "the more I feel convinced it is by the accumulation of such extremely slight variations that new species arise." We shall return to this question, but we may note in passing (1) that there is no reason to believe that "single variations" necessarily occur singly, the fact being that numerous sports in the same direction sometimes occur simultaneously; (2) that some of the discontinuous 
variations that have been studied have proved themselves to have remarkable staying power in inheritance, being anything but liable to swamping; and (3) that we have not, even to this day, sufficient knowledge of what Darwin never seems to have doubted, namely the degree of heritability of the minute fluctuations. It was probably a false step on Darwin's part when he turned so fully away from discontinuous variations.

Modern Study of Variations.-One of the great steps of progress in evolution lore since Liswin's day has been what we see, for instance, in Dr. J. A. Allen's pioneer measurements of American birds (1871), in Bateson's "Materials for the Study of Variation" (1894), and in the pages of the journal called "Biometrika" - the recording and registration of the variations that do actually occur in nature. A few results may be noted.

It has been clearly shown that Darwin did not in the least exaggerate the available supply of raw material. "Even Darwin himself," as Wallace says, "did not realize how much and how universally wild species vary." It has been proved that great variation is as frequent in wild as in domesticated animals. The fountain of change is even more copious than was dreamed of.

Another important fact has come out 
clearly, especially from the pioneering work of Galton, that there is often a proportion between the frequency of a particular variation and the amount of its deviation from the mean of the character in question. Let us take Wallace's illustration, which makes this point clear at a glance: Among measurements of 2,600 men, taken at random, there is 1 of $4 \mathrm{ft} .8 \mathrm{in}$. and 1 of $6 \mathrm{ft} .8 \mathrm{in}$; 12 of $5 \mathrm{ft}$. and about 12 of $6 \mathrm{ft}$. 4 in.; i.e. equal numbers at equal distances from the mean of $5 \mathrm{ft}$. 8 in. In other words, when the frequency and the magnitude of the variations are registered, they often show what is calied the Normal Curve of Frequency.

This tedious task of registering the variations that occur may seem far from life-lore, but a little consideration and a little actual registration-of buttercup petals, of length of bird wings, of brittle-star arms, of jelly-fish canals, or the like - will convince the student that biometrics may lead him into the very heart of the matter. If the registration of the dimensions of a particular character be carried on year after year in similar material, and show a consistent increase in the asymmetry or skewness of the curve, this must mean that the species is moving in a definite direction as regards the particular character measured. Similarly, the persistent occur- 
rence of a well-substantiated double-humped curve-not the result of modificational effects-may vividly bring home the fact that the species is dividing into two subspecies. Thus, by a statistical path, we are brought face to face with the most vital of all facts - l'évolution créatrice.

The rapidly growing body of facts in regard to variation is also confirming what Darwin called the "correlation of variations." He pointed out that the whole organization is so tied together during its growth and development that, when slight variations in any part occur, and are transmitted, and are accumulated by natural selection, other parts of the structure may also undergo change, apparently irrespective of any advantage. The whole framework is so knit together that if one member suffer change others suffer with it.

The idea of correlation suggests that the organism often changes as a unity in many parts at once, and not like a machine that is perfected piecemeal by the accumulation of many little patents independent of each other. Thus a variation important in the present may bring in its train one that is destined to be important in the future, and a variation too small in itself to be of value may be carried over the dead point into effective- 
ness because it is correlated with another variation of greater momentum or vital value.

Another result of modern studies on variation requires to be stated very cautiously. Evidence is accumulating to show that organic structure may pass with seeming abruptness from one position of equilibrium to another. Changes of considerable amount sometimes occur at a single leap. These brusque changes are called "discontinuous variations," or sometimes "sports," and, in certain cases, "mutations." There is nothing new in the suggestion that evolution may sometimes have been by leaps and bounds, for this was a favourite idea of Cuvier's evolutionist contemporary and antagonist, Etienne Geoffroy Saint-Hilaire; and it was also a pet heresy of Huxley's. There is nothing new in recognizing that discontinuous variations do occur, for they correspond to Darwin's "single variations" or "sports." What is new is that we are beginning to accumulate facts in regard to their frequency and their heritability.

Sir Francis Galton compared organic structure to a polygonal model, so shaped as to stand on any one of its sides. "The model and the organic structure have the cardinal fact in common, that if either is disturbed without transgressing the range of its sta- 
bility, it will tend to re-establish itself, but if the range is overpassed, it will topple over into a new position; also that both of them are more likely to topple over towards the position of primary stability than away from it."

The Mutation Theory. - In 1900 Professor Hugo de Vries of Amsterdam published under the title "The Mutation Theory" an account of his very interesting and important experiments and observations on the origin of species in the vegetable kingdom. The most striking of his conclusions was that species arise from one another by discontinuous leaps and bounds, as opposed to a continuous process. Whereas Darwin relied on the action of selection on minute individual variations or fluctuations, De Vries believes that these have nothing to do with the origin of species, which appear "all at once" by mutations. Let us quote some of his characteristic statements.

"By the mutation theory I mean the proposition that the attributes of organisms consist of distinct, separate and independent units. These units can be associated in groups, and we find, in allied species, the same units and groups of units. Transitions, such as we so frequently meet with in the external form both of animals and plants, are as com- 
pletely absent between these units as they are between the molecules of the chemist."

"The adoption of this principle influences our attitude towards the theory of descent by suggesting to us that species have arisen from one another by a discontinuous, as opposed to a continuous, process. Each new unit, forming a fresh step in this process, sharply and completely separates the new form as an independent species from that from which it sprang. The new speeies appears all at once; it originates from the parent species without any visible preparation, and without any obvious series of transitional forms."

"The mutation theory is opposed to that conception of the theory of selection which is now prevalent. According to the latter view the material for the origin of new species is afforded by ordinary or so-called individual variation. According to the mutation theory individual variation has nothing to do with the origin of species. This form of variation . . cannot even by the most rigid and sustained selection lead to a genuine overstepping of the limits of the species and still less to the origin of new and constant characters." "Of course every peculiarity of an organism arises from a previously existing one; not, however, by ordinary variation, but by a 
sudden though minute change. It is perhaps appropriate to compare such a change with a chemical substitution."

"The name I propose to give to this 'species-forming' variability is Mutability - a term in general use before Darwin's time. The changes brought about by it, the Mutations, are phenomena as to the exact nature of which we understand very little so far. The best known examples of such mutations are the so-called spontaneous variations (the 'single variations' of Darwin) by which new and distinct varieties arise. They are also termed, fitly enough, sports. In spite of the fact that they occur fairly often, they are usually not noticed until the new form has already appeared, when of course it is too late to study the phenomenon of its origin experimentally. These new forms can be sought for in cultivated species, which are seldom of pure origin; as well as in Nature. But as yet we have no power of inducing them at will. It is my belief that all the simple characters of animals and plants arise in this way."

"Under the general term variation, then, are included two distinct phenomena: mutability, and fluctuation or ordinary variation."

"The methods of artificial selection correspond to these two types of variability. 
Ordinary variation, which is also known as individual, fluctuating or gradual variation, is always present; and it can be described in terms of perfectly definite laws which have now been fairly completely formulated. It provides the breeder with material for his improved races. On the other hand, he has to deal with mutations which do not need repeated selection, but, at the most, must be kept free from admixture, and which almost always breed true from the first."

In support of his theory, Professor de Vries has relied mainly on the sudden and repeated leaps and remarkable subsequent constancy exhibited by the progeny of a stock of evening primrose, Enothera lamarckiana, which he found growing in a wild state near Hilversum in Holland. But many other instances of mutation are adduced, the oldest and most accurately described being the origin of the cut-leaved variety of the greater celandine, Chelidonium majus laciniatum, which occurred suddenly in 1590 in the garden of an apothecary at Heidelberg, and has been constant ever since. The evidence of mutations in the animal kingdom is only beginning to be gathered, and there are few satisfactory cases known outside of experimental stations. There are, however, many species, e.g. of birds, which differ from 
their relatives in features similar to those which arise as mutations in experimentai breeding.

The issue at present seems to be this. The distinctive characteristics of a species may arise in one of two ways, either (1) by the accumulation of fluctuations, or (2) suddenly by mutation. In support of the first theory there are the numerous cases where species are connected by inter-grades. In support of the second theory there is experimental evidence, showing that many characteristics remain integral and refuse to blend. Patient work will be necessary before we can decide as to the relative importance of fluctuations and mutations.

Mendelism.-One of the most important of recent biological discoveries has been the "law of heredity," stated in 1865 by Gregor Johann Mendel (1822-1884), an AustroSilesian abbot, who experimented for many years on crossing different varieties of garden peas. His great paper, communicated to the Natural History Society of Brünn, remained practically unknown till 1900, when De Vries in Holland, Correns in Germany, and Tschermak in Austria independently, and almost simultaneously, reached experimental results closely resembling Mendel's. This led to a rediscovery of the buried paper and to a 
period of very active experiment, in connection with which Bateson, Castle, Cuénot and their collaborateurs have been especially prominent.

Mendel worked chiefly with the edible pea, P'isum sativum, which has many well-marked varieties and is habitually self-fertilized. When he crossed a giant variety of 6 to 7 feet with a dwarf variety, $\frac{3}{4}$ to $1 \frac{1}{2}$ feet high, the offspring were all tall. The character of tallness which appeared in the hybrid generation $\left(\mathrm{F}_{1}\right)$, to the exclusion of dwarfness, was called by Mendel the "dominant" character, the other being "recessive."

The tall cross-bred peas were left to selffertilize, which corresponds to close inbreeding in animals, and in their progeny there. were talls and dwarfs in the average proportions of $3: 1$.

When the dwarfs of this $\mathrm{F}_{2}$ generation were allowed to self-fertilize, their offspring $\left(\mathrm{F}_{3}\right)$ were all dwarfs, and further generations bred from them were also all dwarfs. They inay be called pure recessives, being "pure" as regards dwarfness.

But when the talls of the $\mathrm{F}_{2}$ generation were left to self-fertilize, their offspring $\left(\mathrm{F}_{3}\right)$ were of two kinds: one-third of them (pure dominants) produced talls only; two-thirds of them (impure dominants) produced talls: 
and dwarfs in the $3: 1$ proportion. Thus the $\mathrm{F}_{2}$ generation, resulting from the self-fertilization of the cross-bred forms or hybrids $\left(\mathrm{F}_{1}\right)$, consisted of 25 per cent. pure dominants, $\tilde{5} 0$ per cent. impure dominants, and 25 per cent. pure recessives.

The results may bo expressed in a scheme:

\begin{tabular}{|c|c|c|}
\hline Parental generation & Tall variety & Dwarf varicty \\
\hline $\begin{array}{l}\text { First filial (hybrid) } \\
\text { generation }\left(F_{1}\right)\end{array}$ & $\begin{array}{l}\text { all the } \\
\text { ferti }\end{array}$ & $\begin{array}{l}\text { Ill: self- } \\
\text { ielded }\end{array}$ \\
\hline
\end{tabular}

Secondfilial (inbred) $\quad 25 \%$ Talls $\quad 50 \%$ Talls $25 \%$ Dwarfs generation $\left(\mathrm{F}_{2}\right)$ (pure dominants) (impure dominants) (pure recessives)

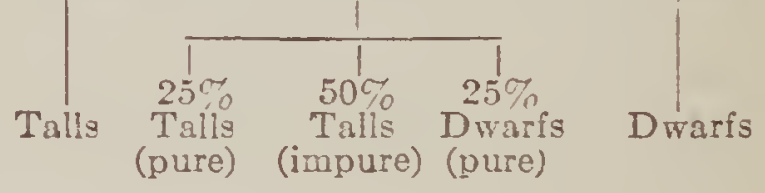

Or, using $\mathrm{D}$ for the forms with the dominant character, $\mathbb{R}$ for the forms with the recessive character, and $D(R)$ for forms with the dominant character expressed and the recessive character latent, the facts may be expressed in a more generalized way thus (after Punnett):-

Parents

First filial generation $\left(F_{1}\right)$

Second filial generation $\left(\mathrm{F}_{2}\right)$

Third filial generation $\left(\mathrm{F}_{3}\right)$

Let us take as an illustration from among animals, one lately well illustrated in the 
admirable Evolutionary Exhibition of the British (Natural History) Museum. When the peculiar "waltzing mice" are crossel with normal mice, the offspring $\left(F_{1}\right)$ are all normal. The waltzing habit is recessive. 13ut when the offspring are inbred, their progeny $\left(F_{2}\right)$ are normal mice and waltzing mice in the proportion of $3: 1$. The recessive waltzers of this generation might be sold as pure waltzers; with others of their kind they will produce only waltzers for as many generations as one likes to breed them. But the normals of the same generation turn out to be of two kinds - though they are all alike in appearance: one-third of them (pure dominants) will yield only normal mice; the other two-thirds (impure dominants) will split up again, when inbred, into normal mice and waltzing mice in the old proportions of $3: 1$. Another form of the scheme may be used:-

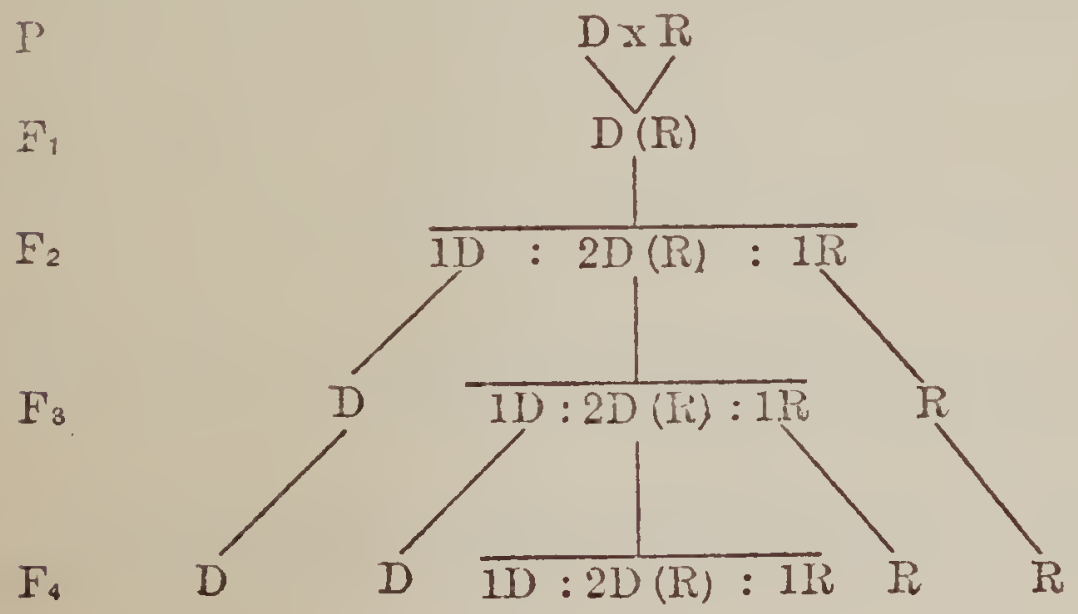


It is interesting now to inquire into the occurrence of this remarkable mode of inheritance, which is seen when the parent forms have opposite or contrasted characters which do not blend. The striking fact is the diversity of the organisms in which it has been demonstrated in the short period since 1900, e.g. in mice, rats, rabbits, guinea-pigs, cattle, poultry, canaries, snails, silk-moths; in beans, maize, wheat, barley, stocks. Another striking fact is the great variety of characters to which it applies, e.g. shades of colour, peculiarities of fur and feathers, abnormal features like extra toes, subtle qualities like "broodiness" in hens, early ripening or immunity to rust in wheat, and so on.

Let us give a few examples, arranged in parallel columns.

\section{Animals}

Dominant character.

Hornlessness in cattle. Normal short hair in rabbits and guineapigs

Short tail in Manx cat (somewhat imperfectly).

Normal movements in Waltzing in mice. mice.
Recessive character. Presence of horns. Long "Angora" hair.

Normal length of tail. 


\section{VARIATION AND HEREDITY 133}

Crest in poultry. Rose comb and Pea Single comb. comb.

Extra toes.

Normal four toes.

Broodiness.

Absence of this instinct.

Unbanded shell in Banded shell. wood-snail.

\section{PuAnts}

Dominant character. Recessive character.

Peas:-

Tall stems.

Dwarf stems.

Yellow cotyledons. Green cotyledons.

Brown-skinned seeds. White seeds.

Round seeds.

Wrinkled seeds.

Wheat:-

Absence of awn.

Presence of awn.

Rough and redchaff. Smooth and white chaff.

Keeled glumes.

Flinty endosperm. Susceptibility to rust.

Barley:-

Two-rowed ears. Six-rowed ears.

Nettles:-

Markedly dentate Slightly dentate leaves.

Rounded glumes. Floury endosperm. Immunity to rust. leaves.

So far we have stated facts-the results of experiment-but Mendel also suggested an 
interpretation or rationale of the facts. He made the supposition that the generative cells or gametes produced by the cross-breds $\left(\mathrm{F}_{1}\right)$ are of two kinds, each kind bearing only one of the two contrasted or alternative characters, which, as we have seen, do not blend. He supposed also that the two kinds are produced in approximately equal numbers. Now if each of the hybrids of the $F_{1}$ generation produces in both sexes 50 per cent. of its germ-cells bearing the dominant character and 50 per cent. bearing the recossive character, then, if fertilization be fortuitous, 25 per cent. of the fertilized eggcells will bear only the dominant character, 50 per cent. will bear both the dominant and the recessive character (only the former being expressed or well expressed in development), and 25 per cent. will bear only the recessive character. This is called the theory of the segregation of pure gametes, and it is the corner-stone of Mendelism. A scheme will make it clearer:-

Mrale Cells.

Female Cells.

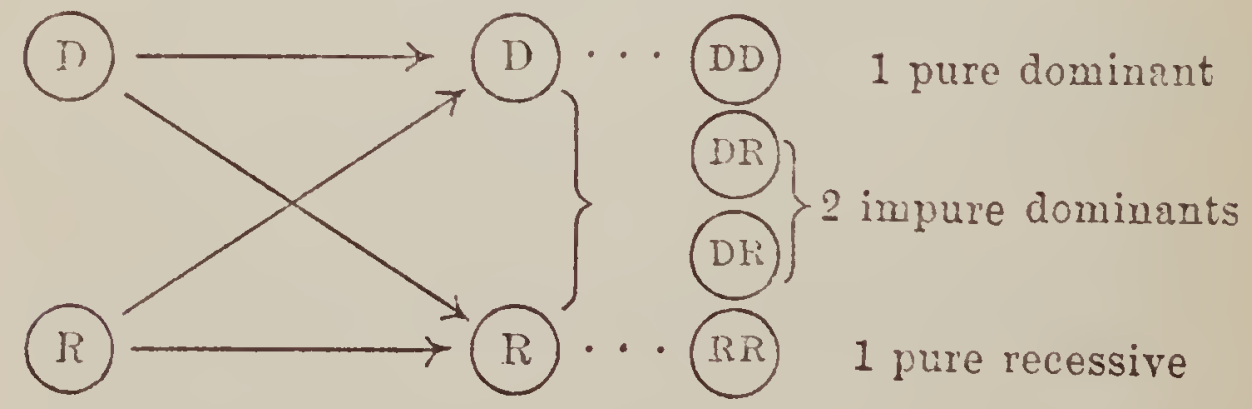


Mendel's simple theory explains the definite proportions $1 \mathrm{D}+2 \mathrm{D}(\mathbf{R})+1 \mathrm{R}, \mathrm{ob}-$ served when $D$ and $R$ are crossed. It has been tested in various ways, for instance, by crossing $\mathrm{D}(\mathrm{R})$ with $\mathrm{D}$ or with $\mathrm{R}$, when, as the hypothesis demands, equal numbers of $\mathrm{D}(\mathrm{R})$ and $\mathrm{D}$, or of (DR) and $\mathrm{R}$, are obtained. In his exceedingly clear exposition of Mendelism (1905), Professor R. C. Punnett, himself a productive investigator, states the characteristic Mendelian result thus: "Wherever there occurs a pair of differentiating characters, of which one is dominant to the other, three possibilities exist: there are rccessives which always breed true to the recessive character; there are dominants which breed true to the dominant character and are therefore pure; and thirdly, there are dominants which may be called impure, and which on self-fertilization (or inbreeding, where the sexes are separate) give both dominant and recessive forms in the fixed proportion of three of the former to one of the latter."

Bringing the theoretical interpretation into prominence-that is, the theory of gametic segregation, Professor Bateson, the leader of the Mendelian school in Britain, says: "The essential part of the discovery is the evidence that the germ-cells or gametes produced by cross-bred organisms may in respect of given 
characters be of the pure parental types, and consequently incapable of transmitting the opposite character; that when such pure similar gametes are united in fertilization, the individuals so formed and their posterity are free from all taint of the cross; that there may be, in short, perfect or almost perfect discontinuity between these germs in respect of one of each pair of opposite characters." This idea of the segregation of the dominant and the recessive characters in two different sets of germ-cells is the essence of Mendelian theory.

Before passing from this important and fascinating subject, we may emphasize two points. There is no dubiety in regard to the clear cases of Mendelian inheritance. Cases that seem to be non-Mendelian may turn out to be Mendelian-disguised by the complexity of the contrast, by interaction between different pairs of characters, and by what is called incomplete dominance-but there is no mistaking the phenomena of Mendelian inheritance in their typical expression. The certainty of the matter is evident from the success with which the principle has already been used in prediction and in practice. On the other hand, there are also many heritable characters which blend, and do not conform to the Mendelian 


\section{VARIATION AND HEREDITY 137}

mode of inheritance. In illustration we may refer to hybrid trout, half-bred sheep, and mulattoes.

Application to Evolution Theory.Like Weismannism, which has for one of its foundations the idea of germinal continuity, Mendelism conceives of the hereditary relation in the strict sense, i.e. not as between the bodies of parent and offspring, but between the parental and the filial germ-cells.

Like Weismannism, which has for another of its foundations the idea of determinants or representative particles constituting the mosaic of inheritance, Mendelism regards the organism as built up of a number of definite, separably heritable characters.

Mendelism has thrown light on at least certain kinds of variation, those which are due to the addition or omission of one or more definite elements. As Bateson puts it: "With the development of the inquiry it has become clear that variation, in so far as it consists in the omission of elementary factors, is the consequence of a process of 'unpacking.' The white sweet pea was created in the variation by which one of the colourfactors was dropped out. Such variation is not, as it was formerly supposed that all variation must be, a progress from a lower degree of complexity to a higher, but the 
converse. When from a single wild type man succeeds in producing a multitude of new varieties, we may speak of the result as a progress in differentiation: but we must recognize that the term is only applicable loosely, and that the obvious appearance of increased complexity may in reality be the outcome of a process of simplification." Similarly, "reversion occurs when the sum total of the factors returns to that which it has been in some original type." The return may be brought about by the omission of an element or by the addition of a missing element. If certain kinds of variation may be called "unpacking," reversion is repacking.

In discussing the bearing of Mendelism on the theory of evolution, Bateson makes three important suggestions. (1) "One has only to glance over trays of birds' skins, the portfolios of a herbarium, or drawers of butterflies and moths, to discover abundant 'species' which are analytical varieties of others," i.e. differing in the presence or absence of definite factors. "The principles of heredity we trace in our experimental breeding are operating throughout the natural world of species." (2) The fact of discontinuity in variation, whether it be called mutation or something else, is undoubted, but hitherto there has 
been "nothing to indicate how or when it was determined. We now see that the discontinuous variations are in the main the outward manifestations of the presence or absence of corresponding Mendelian factors, and we recognize that the unity of these factors is a consequence of the mode in which they are treated by the cell-divisions of gameto-genesis." (3) "The notion that a character once appearing in an individual is in danger of obliteration by the inter-crossing of that individual with others lacking that character proves to be unreal; because in so far as the character depends on factors which segregate, no obliteration takes place. The factors are permanent by virtue of their own properties, and their permanence is not affected by crossing. . . ." Moreover, he continues, "The conception of Evolution as proceeding through the gradual transiormation of masses of individuals by the accumulation of impalpable changes is one that the study of genetics shows immediately to be false. Once for all, that burden so gratuitously undertaken in ignorance of genetic physiology by the evolutionists of the last century must be cast into oblivion. For the facts of heredity and variation unite to prove that genetic variation is a phenomenon of individuals. Each new character is 
formed in some germ-cell of some particular individual, at some point of time."

The issue at present seems to be this, that there are characters which blend when crossed, and others which segregate when crossed. Patient work is necessary in order to test these two groups and to discover what is the criterion of blending and alternating respectively. In his interesting work on "Hereditary Characters," Dr. Charles E. Walker maintains the thesis that racial characters tend to blend and that individual characters are transmitted in an alternative or Mendelian manner.

OrIGIN OF VARIATIONS.-Since variations form the raw materials of evolution, it would be satisfactory if we could conclude this chapter by stating how they arise. But that is quite impossible at present. We know very little that is certain in regard to the originative factors in evolution. We must still confess, with Darwin: "Our ignorance of the laws of variation is profound." It may be of interest, however, to notice some of the suggestions that have been made in regard to this fascinating problem.

There are variations which mean augmentation, or diminution, or re-arrangement of already existing qualities. Now, if the 
hereditary qualities are carried by representative particles in the germ-cells, we can in a measure understand the origin of the kind of variation referred to; for extraordinarily intricate permutations and combinations go on in the microcosm of the germ-cells. Particularly in the process of maturation is there what we might call a shuffling of the cards-even a throwing away of half of the pack. In fertilization, again, paternal and maternal contributions form a new unity. Perhaps there may be, as Weismann supposes, a struggle between rival hereditary items.

But there seems to be another kind of variation, qualitative rather than quantitative, substantive rather than architectural, when something distinctively new appenrs. What can be said as to their origin? Weismann has suggested that the oscillations and changes in the blood and other nutritive fluids may stimulate the germ-plasm to a new departure. It may also be that important changes in the environment may saturate through the body and provoke the germplasm to vary. There are other "may be's.'

With all recognition and appreciation of the work and thought above summarized, we cannot but think that the secret of varia- 
bility lies yet deeper, in the very nature of the living organism itself. It has been a Proteus from the first; changefulness is its most abiding quality; in short, the essence of the creature is its imnate creativeness. 


\section{CHAPTER V}

\section{SELECTION}

Huxlcy on "The Quintessence of Darwinism"-Analytic Abstract of "The Origin of Spccies" (Variation under Domestication - Artificial Selection - Variation under Natural Conditions - Struggle for Existence - Natural Selection)

The Case for Natural Selection-Direct Evidence of Natural Selection-Imolications of the Concept of Natural Selection-Different Kinds of Selection (Sexual Selection Germinal Selection)-Family and Group Selection-Auxiliary Hypothesis of Isolation-Eugenics as a Renewal of Evolution.

DARwIN's achievement in "The Origin of Species" was twofold. In the first p'ace, he presented the evidences of the fact of evolution so forcibly and so fairly that he made evolutionists of the great majority of his readers. Indeed, he made the world "think in terms of evolution." In the second place, in his theory of Nature's sifting of hereditary variations he gave a causal interpretation of the age-long process of Becoming. He made the evolution idea current intellectual coin; but his success in making the fact clear and credible was in part due to his discovery of one of the chief factors. 
Huxley ON "The Quintessence OF DARwinism." - Huxley made this distinction between fact and factors very plain in his essay "On the Reception of the Origin of Species" in Darwin's "Life and Letters." He first states the grounds of his own agnostic position (up to 1858) with respect to the doctrine of evolution as promulgated by Lamarck, Robert Chambers, and even Spencer: "Firstly, that up to that time the evidence in favour of transmutation was wholly insufficient; and, seconally, no suggestion respecting the causes of the transmutation assumed, which had been made, was in any way adequate to explain the phenomena."

He goes on to say:-

"The suggestion that new species may result from the selective action of external conditions upon the variations from their specific type which individuals present-and which we call "spontaneous" because we are ignorant of their causation-is as wholly unknown to the historian of scientific ideas as it was to biological specialists before 1858 . But that suggestion is the central idea of the 'Origin of Species,' and contains the quintessence of Darwinism. . . That which we were looking for, and could not find, was an hypothesis respecting the origin of known 
organic forms which assumed the operation of no causes but such as could be proved to be actually at work. We wanted, not to pin our faith to that or any other speculation, but to get hold of clear and definite conceptions which could be brought face to face with facts and have their validity tested. The 'Origin' provided us with the working hypothesis we sought. . . .'

Of "the quintessence of Darwinism," then, a brief account is needed, and this may be best given by following as closely as possible upon the lines of the magnum opus itself, although the full title of this- "The Origin of Species by means of Natural Selection, or the Preservation of Favoured Races in the Struggle for Life," is its own best and briefest summary.

Analysis of "The Origin of Species." -After mentioning that his first light upon the origin of species was derived from his early distributional studies, Darwin points out that "a naturalist, reflecting on the mutual affinities of organic beings, on their embryological relations, their geographical distribution, geological succession, and such other facts, might come to the conclusion that species had not been independently created, but had descended like varieties from other species. Nevertheless, such a 
conclusion, even if well founded, would be unsatisfactory unless it could be shown how the innumerable species inhabiting this world have been modified so as to acquire that perfection of structure and co-adaptation which justly excites our admiration." Again, "It is therefore of the highest importance to gain a clear insight into the means of modification and co-adaptation. At the commencement of my observations it seemed to me probable that a careful study of domesticated animals and cultivated plants would offer the best chance of making out this obscure problem. Nor have I been disappointed: in this and in all other perplexing cases I have invariably found that our knowledge, imperfect though it be, of variation under domestication affords the best and safest clue." It was therefore with variation under domestication that he began his book.

Variation under Domestication.-A comparison between the individuals of a cultivated or domesticated "variety" shows a greater degree of variation than there obtains between the individuals of a wild species or "variety." "The higher variability of domestic productions is to be ascribed to the less uniform conditions of their upbringing, perhaps in part to excess of food.' 
Exposure to new conditions must be continued for generations to set up any great variation; but this, once set up, continues indefinitely. Changed conditions may directly influence the whole organization of the creature or certain parts alone; or they may act indirectly through the reproductive system. With respect to the direct acion, the nature of the organization seems to count for more than that of the conditions. The effect on the ofispring may be definite: e.g. size may depend upon the amonnt of food, colour upon quality of food, thickness of skin and hair upon climate, etc. But indefinite variability is a much commoner result of changed conditions, and has probably played a more important part in the formation of our domestic races. The reproductive system is peculiarly sensitive to very slight external changes. Many plants and animals will not reproduce in donestication, even though individually vigorous; others, though weak and sickly, breed freely. Hence we need not be surprised at the reproductive system acting irregularly and producing variations. But that variation is not exclusively associated with sexual reproduction is demonstrated by the case of plants "sporting" through bud-variation. Such cases, moreover, prove that the nature 
of the organism counts for more than the conditions.

Changed habits, e.y. changes in the degree of use or disuse of a part, produce an inherited effect, witness the lighter wingbones and heavier leg-bones of the domestic duck, or the enlarged udders of cows.

Variations are often definitely correlated: thus short-beaked pigeons have small feet; hairless dogs have imperfect teeth; and blue-eyed white tom-cats are deaf. Hence selection of any one character will probably modify others indirectly.

Although the laws of inheritance are mostly unknown, it seems that probably most, if not all, characters tend to be inherited. There is no satisfactory evidence to support the popular idea that domestic varieties revert to the primitive stock when they run wild. Reversions occasionally occur in domestication, but there is no general tendency to lose what has been gained - apart, of course, from breeding with wild stocks, or with other domesticated ones.

Except in being less uniform than natural species, in often differing more widely in a single part, and in being fertile when crossed, there are no well-marked distinctions between our domestic races and the so-called true species of a genus. The many breeds of 
dogs and cattle may have arisen from more than one species; but probably those of horses and fowls, and clearly those of rabbits, ducks and pigeons, are each descended from a single wild species. At least a score of varieties of pigeon might be chosen which differ so thoroughly, internally as well as externally, that an ornithologist, treating them as wild birds, would be compelled to grant them specific, and even distinct generic rank. Yet, since all these have indisputably arisen from the wild rock-dove, it is clear that naturalists who admit a unity to such domestic races, which professed breeders have often laughed to scorm, should in turn be cautious before deriding the unity of wild ones.

Artificial Selection.-How, then, have domestic races been produced? By external conditions or habits alone? One of their tell-tale features is in exhibiting adaptations, not to their own good, but to man's use or fancy. We know that all the breeds were not produced in their present state of perfection, and the key is man's accumulative selection. Nature gives successive variations; man adds them up, making for himself useful breeds. Skilful breeders speak of the organization as plastic and under control, and have effected great changes within our 
own generation. Unconscious selection, which results from every one trying to possess and breed the best individuals, is even more important. The accumulation of change which man effects explains why we so often cannot recognize the wild parent stocks of our cultivated plants, while its absence in countries inhabited by uncivilized man explains why these never yeid plants worth immediate culture. Man's power of sclection is facilitated by keeping large numbers, in which variations are more likely to occur. Facility in preventing crosses is also of importance, e.g. in the case of pigeons as contrasted with cats; some species are, however, less variable than others, e.g. the goose.

Variation umder Natural Conditions. - Individual differences arise eren in the ofispring of the same parents and tend to be inherited; hence they afiord material for natural selection to act on and accumulate, precisely as they would for human selection. (It may be that genera with large numbers of slightly different species-e.g. rose, bramble and hawkweed-owe their protean character to their variations being of no service or disservice, and consequently not being acted on by natural selection.) In determining whether groups of similar forms 
should be ranked as species or as varieties, the opinion of naturalists of sound judgment and wide experience is the only guide, yet this lacks unanimity: for example, of the polymorphic genera (i.e. rich in species with a small range of differences) in the British flora alone, Bentham reckons 112 species, but Babington 251. Wallace has shown that no certain criterion can be given by which to define his own convenient working categories of Malayan buttcrflies and moths, viz. variable forms, local forms, subspecies, and representative species. As De Candolle concluded from his monograph on oaks (in which he shows at least two-thirds of his 300 species to be provisional), "so long as a genus is imperfectly known and its species founded upon a few specimens", they seem clearly limited; but, "just as we come to know them better, intermediate forms flow in and doubts as to specific limits augment." The terms variety and species are thus arbitrarily applied to indefinable groups of more or less closely similar individuals. Common species that range wide and are much diffused are those which vary most. The species of the larger genera in each country vary more frequently than the species of the smaller genera. The species of large genera present strong analogies with 
varieties, which suggests that they originated as such.

Struggle for Existence.-The term "struggle for existence" is used in a large: and metaphorical sense, including depend. ence of one being upon another, and embracing (which is more important) not only the life of the individual, but success in leaving progeny. From the high (geometrical) rate of increase of all organic beings (even the slow breeders requiring only a few more years to people a whole district) struggle inevitably follows, either one individual with another of the same species, or with the individuals of a distinct species, or with the physical conditions of life. It is the doctrine of Malthus applied with manifold force to the entire animal and vegetable kingdoms, for in this case there can be no artificial increase of food and no prudential restraints from marriage.

The checks to increase are very obscure. Eggs or young animals generally suffer most, and plants, mostly as seedlings, both from germinating on ground already occupied and from animals. The amount of food, of course, gives the extreme limit of numbers; very frequently, however, the check is given by the attacks of enemies, as on game by "vermin." Changes of climate play an 
important part, and periodical seasons of extreme cold have destroyed as many as fourfifths of the bird of an observed area. Epidemics, too, may occur. In many a species a large stock of individuals is often essential to its continuance.

Complex and unexpected checks and relations exist between organic beings which have to struggle together; witness the profound alteration of the flora and fauna of a heath when planted with Scots pine, these again being wholly dependent upon the exclusion of cattle. But in several parts of the world insects determine the existence of cattle. Again, red clover depends for fertilization upon the humble-bees, these upon immunity from the attacks of field-mice, and thus indirectly upon the number of cats, Hence no bees, no clover, and the more cats, the more clover.

The struggle will almost invariably be most severe between the individuals of the same species, for they frequent the same districts, require the same food, and are exposed to the same dangers. In the case of varieties of the same species, the struggle will generally be almost equally severe, and we sometimes see the contest soon decided (as in the case of varieties of wheat or of sweet pea, of the mountain sheep or of the 
medicinal leech). Similarly, the struggle between species of the same genus will generally be more severe than between the species of distinct genera. This is illustrated by the inevitable replacement of the black rat by the brown, or of the large cockroach by the small. The structure of every organism is related to that of all others with which it competes, from which it escapes, or on which it preys; witness alike the teeth and talons of the tiger, or the legs and claws of the parasite clinging to his hair. The albumen of a seedling favours its struggle with plants already growing around it. Darwin goes on to speak of two "canine animals" struggling with each other in a time of dearth; of mistletoe versus mistletce on the same branch; of mistletoe versus other fruit-bearing plants; of a plant on the edge of the desert in days of drought; and then says, "In these several senses, which pass into each other, I use, for convenience' sake, the general term of Struggle for Existence."

Natural Selection.-How will this struggle for existence act in regard to variation? Can the principle of selection, so potent in the hands of man, apply under Nature? Most efficiently; for, when we bear in mind the constant occurrence of variation, with the strength of the hereditary tendency, 
also how infinitely close and complex are the mutual relations of organic beings to each other and to their physical conditions of life, and consecuently what infinitely varied diversities of structure might be of use to each being under changing conditions of life, can it be thought improbable, seeing that variations useful to man have undoubtedly occurred, that other variations, useful in some way to each being in the great and complex battle of life, should occur in the course of many generations? And if such do occur, can we doubt (remembering that many more individuals are born than can possibly survive) that individuals having any advantage, however slight, orer their fellows would have the best chance of surviving and of procreating their kind? On the other hand, we may feel sure that any variation in the least degree injurious would be inevitably destroyed.

This preservation of favourable and this destruction of injurious variations are called natural selection, or, less metaphorically, the survival of the fittest, the one term referring mainly to the process, the other to the result. The probable course of natural selection may be understood from the case of a country undergoing change of climate. The proportional numerical strengths of its species 
will be changed; some will probably become extinct; and these changes will seriously affect the others. Immigration of new forms might also occur, with further serious disturbance; or, where this is impossible, there will be places in the economy of Nature which might be better filled up. In such cases slight changes in structure or habit which in any way favoured the individuals of any species, by adapting them better to their altered conditions, would tend to be preserved, and natural selection would have free scope for its work of improvement. Moreover, changed conditions increase variability.

As man produces great results by his artificial selection, what may not natural selection effect? Man selects only for his own purposes, Nature for the good of the creature itself; man on the more external characters (he has become more adventurous since Darwin's day), Nature on the whole machinery of life; man irregularly and imperfectly for a short time, Nature by consistent accumulation during whole geological periods. Natural selection is daily and hourly scrutinizing, throughout the world, the slightest variations, rejecting those that are bad, preserving and adding up all that are good, silently and insensibly working, when- 
ever and wherever opportunity offers, at the improvement of each organic being in relation to its animate and inanimate conditions of life. It may operate on characters which we are apt to consider of very trifling importance, and its accumulation of small variations may set up unexpected correlative changes. It may affect the egg, the seed, or the young as easily as the adult; it may adapt the structure of young to parent and of parent to young; and in social animals it may adapt the structure of each for the benefit of all. In the later editions of the "Origin" a brief account of sexual selection is given at this point.

The theory of natural selection is then illustrated by particular instances. Thus Darwin pictures the formation of swift varieties of wolves, much in the same way as greyhounds have been evolved by man. Or, again, he refers to the secretion of nectar by flowers, its use to insects, the action of these in carrying the fertilizing pollen, its advantage in intercrossing, and the resultant finely adjusted adaptation of flower and insect to each other through the preservation of their respective advantageous variations.

Circumstances favourable for the pro. duction of new forms through natural selecw 
tion are great variability, large numbers of individuals, the complex effects of intercrossing, isolation in confined areas (yet probably still more an extension over continental areas, especially if oscillating in level), and considerable lapse of time. But the lapse of time by itself must not be supposed to do anything (as if the forms of hife were undergoing change by some innate law), but merely to afford increased opportunity for variation and environmental change. Extinction, to which rare species are on the way, is the last word of natural selection.

The divergence of character brought about by artificial selection in domestic brecds is efficiently paralleled in Nature, since the more diversified the offspring of each species, the more they will seize on diverse places in the economy of Nature, and so increase in numbers. The greatest amount of life can be supported by increased diversification of structure, each species being adapted to a particular set of conditions. This divergence of character, with extinction of intermediate forms, explains the difficulties of classification - of making a genealogical tree which will express the facts of the case and represent diagrammatically "the great tree of life, which fills with its dead and broken branches 
the crust of the earth and covers the surface with its ever-branching and beautiful ramifications."

Dariwin's Summary. - The preceding summary of the classical statement of the doctrine of natural selection should be supplemented by reference not only to the original work, to the corroborative labours of its author, to the able independent treatise ("Natural Selection") of Wallace, and to the synthetic treatments of the whole subject of evolution given by Haeckel in his "Generelle Morphologie," and by Spencer in his "Principles of Biology," but to the enormous mass of exposition, argument and illustration accumulated by subsequent writers, commencing with Hooker and Asa Gray, Huxley and Haeckel, but soon becoming too numerous for mention. We indicate, however, a few convenient recent summaries in the "Bibliography" at the close of this volume.

But while we must avoid the error of supposing that the last word on natural selection was said by Darwin, or that there is not still abundant opportunity both for reflection and research in regard to it, we must be clear as to the essential simplicity of the general theory. Darwin himself summed it up in a couple of sentences: "As many more individuals of each species are born than can 
possibly survive, and as, consequently, there is frequently recurring struggle for existence, it follows that any being, if it vary however slightly in any manner profitable to itself, under the complex and sometimes varying conditions of life, will have a better chance of surviving, and thus be naturally selected. From the strong principle of inheritance any selected variety will tend to propagate its new and modified form."

There are here three main propositions:-

(1) Variability is a fact of life. Variations are of frequent occurrence, and some of them are certainly transmissible.

(2) Living creatures are very prolific. The majority die young. There is a ceaseless struggle for existence and the web of interrelations is such that even minute variations may determine survival.

(3) If variations occur in the direction of increased fitness, if the variations are transmissible, and if there is discriminate selection with reference to these variations, then the possessors of the fitter variations are bound to be favoured with longer life and larger families-with survival, in short. If this is kept up consistently, then new adaptations and, probably with the help of some form of isolation, new species, will arise.

The Case for Natural Selection.-The 
theory of natural selection has the marks of a good theory-it works well as an interpretative formula in the most varied cases, it has proved itself a useful instrument of research, and it has even been made the basis of successful prediction. Darwin himself was under no misapprehension as to the logical position of his theory-that its strength was in its interpretative value, not in its direct evidence. In a letter to Bentham in 1863, he writes: "The belief in natural selection must at present be grounded entirely on general considerations-(1) on its being a vera causa, from the struggle for existence and the certain geological fact that species do somehow change; (2) from the analogy of change under domestication by man's selection; (3) and chiefly from this view connecting under an intelligible point of view a host of facts." Given variability, a high rate of increase, the struggle for existence, the web of life, the observed fact that most living creatures die young-it seems to most naturalists to follow that natural selection is indeed a vera causa and the survival of the fittest a reality.

Direct Evidence for Natural SelecTION.-One of the interesting steps of progress since Darwin's day has been the attempt to secure definite evidence of the 
operation of natural selection. The theory works well as an interpretation, but what we need is actual proof of discriminate selection, actual evidence that survivors do survive in virtue of particular qualities. A few examples of this in present-day experience will give strength to the belief that similar processes occurred, as Darwin suggested, throughout the past.

It is interesting to note that so strong a selectionist as Weismann considers that natural selection can be proved only indirectly. He says: "A direct estimation of the relative protective value of the two colours [of a Sphingid caterpillar] is altogether out of the question. The survival of the fittest cannot be proved in nature, simply because we are not in a position to decide a priori what the fittest is." As Mr. E. S. Russell remarks: "This is a significant admission from the protagonist of pure Darwinism, but he admits too much. It is true we cannot decide a priori what the fittest is, but we can discover by observation and experiment whether or no protective colouration has selective value. A case in point is given by Mr. A. P. di Cesnola in a short but highly interesting paper in 'Biometrika' for 1904 .

"It is well known that the "praying 
Mantis,' Mantis religiosa, occurs in Italy in a green and a brown form. The former is usually to be found on green grass, the latter on herbage browned by the sun. Mr. Cesnola tied down among green herbage twenty green Mantis, and among withered grass a similar number of brown individuals. After seventeen days they were all alive. He also tethered twenty-five green Mantis among brown herbage, and they were all dead after eleven days. The converse experiment was also made, forty-five brown Mantis being exposed on green grass, and of these only ten survived at the end of seventeen days. Most of the Mantis were killed by birds; five of the green ones were killed by ants. Here, then, is a proof, quite conclusive though the numbers are small, of the selective value of the protective colouration of both races of Mantis. If green Mantis and brown Mantis be exposed on green grass, the green ones will survive rather than the brown, the death-rate will be selective. Such a simple experiment gives more solid support to the view that protective colouration is due to natural selection than any accumulation of probabilities."

It is of enormous importance that cases similar to the above should be accumulated, so that stability may be given to the theory 
of natural selection by actual evidence that the survivors survive and the eliminated are eliminated because of some differentiating peculiarity or peculiarities. Hence a few more examples may be given.

Poulton fastened 600 pupæ of the tortoiseshell butterfly to nettles, tree-trunks, fences, walls, and so on. At Oxford, the mortality was 93 per cent., and the only pupæ that survived were on nettles, where they were least conspicuous. In the Isle of Wight, the elimination was 92 per cent. on fences, as against 57 per cent. among nettles. Here, again, there was definite evidence of discriminate elimination.

Professor Crampton's very careful research on the pupre of a Saturnid moth, proved discriminate elimination, and yielded also this interesting result, that the selected characters (for the most part concerned with dimensions and proportions) were not sich as would have appeared to be directly or indirectly "useful" to their possessors, though they were demonstrated to have the high utility of determining survival-which is indeed, for the evolutionist, the final criterion of utility.

Professor Bumpus took 136 benumbed house-sparrows into his laboratory, where 72 revived and 64 succumbed. There were general differences-of a somewhat subtle 
sort-between those that revived and those that succumbed. General stability of structure was the essential characteristic of the former.

The fine researches by which the late Professor Weldon proved discriminate elimination in shore-crabs, and by which Professor Karl Pearson proved a selective death-rate in man, are of the highest importance, but they require more exposition than we can give here.

We may round off this section with two simple observations whose picturesqueness may emphasize our present point.

Professor Davenport, of the Carnegie Institution for Experimental Evolution, had 300 chickens in a field, 80 per cent. white or black and conspicuous, 20 per cent. spotted and inconspicuous. In a short time twenty-four were killed by crows, but only one of the killed was spotted.

Finally, a kindred and recent field observation of our own. In a heavy snowstorm at Johannesburg in August 1909, many hundreds of trees were destroyed by the weight of snow on the branches. It was interesting, after the storm, to notice that the elimination was in a marked degree discriminate. The trees that suffered most were the imported Australian trees, such as 
the Blue Gums and Black Wattles, quickly growing, with soft wood, and with abundant foliage that caught the snow. On the other hand, the deodars from the Himalaya mountains, constitutionally adapted to let the snow slide from their pendulous branches and acicular leaves, had hardly a twig broken.

Implications of the Concept of Natural Selection.-As a naturalist of very rich experience Darwin realized the complexity of the evolution problem more than most naturalists have done, and a careful study of his sentences makes it quite clear that when he used phrases like "struggle for existence" and "natural selection," which have acquired by familiarity a somewhat hard and mechanical sound in our ears, he had a singularly rich concrete content in his mind.

"Nothing is easier," he said, "than to admit in words the truth of the universal struggle for life, or more difficult-at least I have found it so-than constantly to bear this conclusion in mind." . . "I use this term ['struggle for existence'] in a large and metaphorical sense, including dependence of one being on another, and including (which is more important) not only the life of the individual, but success in leaving progeny." "Nature may be compared to a surface on which rest ten thousand sharp wedges 
touching each other, and driven inward by incessant blows." .. " It may be metaphorically said that natural selection is daily and hourly scrutinizing throughout the world the slightest variations." . . . "Battle within battle must be continually recurring with varying success; and yet in the long run the forces are so nicely balanced that the merest trifle would give the victory to one organic being over another."

What we wish to suggest is, that Darwin's characteristic fundamental idea of the intricacy of interrelations in the web of life, lies below the idea of the struggle for existence, and therefore below the idea of natural selection. Unless we appreciate the fundamental natural history fact of the reb of life, we cannot rightly understand how slight differences can be of critical moment in determining survival. The entanglements are so intricate that a slight variation may be of survival-value to its possessor.

There is another consideration which Darwin had certainly in mind, and which, like that just explained, has often been lost sight of since. It is illustrated, for instance, by the researches of Bumpus and of Crampton on the survival of sparrows and pupæ respectively. The point was, that the survivors seemed to survive, not because of 
single peculiarities, but because of their general stability and efficiency. As we have already hinted, we must still admit what Darwin admitted more than fifty years agothat it is extraordinarily difficult to say precisely why one species has been victori. ous over another in the great battle for life. Part of the difficulty is to be found in the fact that there is seldom a simple issue.

As Russell puts it:-

"We should think of each creature as being, as it were, the point of intersection of a number of selection processes, of as many processes as there are significant characters; and since the significance of characters must change with the development and growth of the organism and with every alteration in its environment, so the sum of selection processes to which the organism is subjected must be an ever-changing one."

"The survival or non-survival of the organism will be determined by the resultant of all these selection processes, and though the exact manner of it be extremely complex, it will be the most generally efficient organism which will on the average survive. Its characters will be such as have remained 'useful' throughout its life, such as have adapted the organism to the generality of life-conditions under which it has lived.' 
Different Kinds of Selection.-There are two main modes of natural selection. There is the ordinary "lethal selection," which works by the discriminate elimination of the relatively less fit; and there is "reproductive selection," which works through the increased and more effective reproductivity incident on the success of the more fit. When Darwin says "natural selection acts by life and death . . . by the survival of the fittest and by the destruction of the less well-fitted individuals," he describes lethal selection, and many use the term natural selection in this sense only. But when Weismann says: "Those that are best adapted in colour will secure the most abundant food and will reproduce most prolifically, and they will thus have a better prospect of transmitting their usual colouring to their offspring," he is obviously describing reproductive selection.

Karl Pearson draws a distinction between "secular selection," which is Darwin's natural selection, and "periodic selection," which is less easily detected. The difference is this: in the ordinary process of natural selection a change in the mean value of the selected character must be effected from one generation to another. But it might also happen that the extreme deviations from the 
mean-e.g. the giants and the dwarfs-were cut off, while the mean value of the character, e.g. the average stature, remained unchanged. This is "periodic selection," whose reality Weldon proved in the case of one of the snails: it can be detected by the diminution in the extent or range of variability.

There are other extensions of the selection-idea. Thus in social insects like ants, where community competes with community, we see an adumbration of the intersocietary struggle and selection which we are familiar with in mankind. There is also some measure of "struggle of parts within the organism," as Roux called it, i.e. between competing organs and tissues and cells; and where there is rapid multiplication of elements and discriminate destruction there must be a definite selective process. There is also a well-known struggle between potential ova, clearly illustrated in Hydra and Tubularia, reminding us of the struggle between sister queen-bees. There is a kind of struggle among the hundreds of spermatozoa in their race towards the ovum. Allowing a margin for chance, the most vigorous and sensitive spermatozoa will tend to succeed and this will be for the advantage of the species. We are quaintly reminded of the race between drones to overtake the queen-bee in her 
nuptial flight. There is also sexual selection and germinal selection, which may be conveniently considered in separate sections.

Sexual Selection.--In extension of his theory of natural selection Darwin proposed a theory of sexual selection to account for the frequent occurrence of markedly contrasted secondary sex-characters, familiar in cases like peacock and peahen, stag and hind. There are two modes of this sexual selection: the combats between rival males and the preferential mating where the female chooses or seems to choose.

The issue is clearer in the case of the combats of males. For when the younger or weaker candidates are killed, or expelled from the herd, or left unmated, there seems little reason to doubt the discriminateness of the elimination.

As to preferential mating, there is no doubt that the males, especially among birds, sometimes show off their varied attractions, but, as Wallace has consistently maintained, there is very little convincing evidence that the female chooses a partner out of a number of suitors. Still less is there evidence that she chooses because of any particular excellence in colour or in song or in dance. In some cases, however, there is evidence that certain males are left unmated, and that 
these are inferior in attractiveness. In the mysterious case of spiders, the fastidious female sometimes kills a suitor who does not adequately please her; as well as afterwards, it may be, the one who does.

Since Darwin's day many of the supposed cases of preferential mating have broken down rather badly under criticism, but there are still many facts to go upon. It seems clear that the suitors are sometimes highly excited, and that their displays-often more reflex than deliberate-impetuously excite the female and overcome her coyness - a character which, as Groos points out, is of no inconsiderable racial value. In some passages Darwin seems to credit the female with a high degree of "taste" or æsthetic fastidiousness; but he was probably on safer ground when he wrote, "it is not probable that she consciously deliberates; but she is most excited or attracted by the most beautiful, or melodious, or gallant males." We do not know very clearly what choosing may mean to a hen-bird; but even when she seems to choose some slight improvement in colour or song or dance, the probability is that she is simply surrendering herself to the male whose tout ensemble has most successfully excited her sexual interest.

Germinal Selection.-In 1895 Weis- 
mann suggested that the concepts of "struggle" and "selection" might be usefully extended to the individual items which compose the germ-plasm, or, what comes to the same thing, the inheritance. If we suppose, as there are many reasons for supposing, that the physical basis of inheritance in the germcells is composed of a multitude of representative vital particles which are able to feed, grow, and multiply, then it is conceivable that fluctuations in the nutritive supply of the germ-cells, and inequalities in the vigour and assimilating power of the hereditary constituents, may result in an intra-germinal struggle and selection.

The general idea is a familiar one, that nothing succeeds like success; and vice versa. A strengthened representative item or determinant in the germ-plasm will nourish itself more abundantly than its neighbours. "It may get into a permanent upward movement, and attain a degree from which there is no falling back." On the other hand, a weakened determinant will have less power of attracting nutriment, and will tend to go downhill. If it be the determinant of something useful, then the ordinary process of natural selection will eliminate the individual that develops from the impoverished germ-cell; if it be the determi- 
nant of something useless natural selection will not interfere, and the determinant will continue getting weaker every generation.

The theory of germinal selection is, of course, an hypothesis, dealing like Mendel's theory of gametic segregation with the invisible, but it may be nevertheless useful in enabling us provisionally to formulate a number of very puzzling facts, and in suggesting experimental work, on which, eventually, we must base our conclusions as to these abstruse questions.

According to Weismann, germinal selection helps us to understand the dwindling away of organs which have sunk below the level touched by ordinary natural selection; the occasional exaggeration of organs beyond the limits of demonstrable utility, as may be illustrated in artificial conditions by the six feet long tail-feathers of some Japanese cocks; the occurrence of definitely directed, appropriate, and simultaneous variations, and much more besides. It plays into the hands of personal selection; or, as Weismann more elegantly phrases it, "it supplies the stones out of which personal selection builds her temples and palaces: adaptations."

Family and Group Selections.-Though Darwin did not wholly overlook this (indeed in at least one notable passage he expresses 
it) there is no doubt that the general tone and treatment of Darwinism, even hitherto, has been deeply coloured by the acute individualism of Darwin's and the preceding age. We may therefore restate here the concluding thesis of our own "Evolution of Sex" (1889), since elaborated in various ways by Drummond, by Kropotkin and others. It is that the general progress both of the plant and the animal world, and notably the great uplifts (see Chapter III above), must be viewed not simply as individual but very largely in terms of sex and parenthood, of family and association; and hence of gregarious flocks and herds, of co-operative packs, of evolving tribes, and thus ultimately of civilized societies - above all, therefore, of the city. Huxley's tragic vision of "nature as a gladiatorial show," and consequently of ethical life and progress as merely superposed by man, as therefore an interference with the normal order of Nature, is still far too dominant among us. It threatens even to-day to confuse the nascent science, and still more to wreck the incipient art, of Eugenics, in fact to encourage and defend that massacre of the innocents which is expressed in the deathrate of every community; and to extend this to a corresponding view of legislation and government. Here, in fact, is opening the 
greatest practical controversy of our science, in comparison to which all others have been but academic-that ultimately between the Herodian and the Magian view and treatment of the child, and between essential renewals of the Cæsarist and of the Christian ideals of the community, upon our modern spiral. Iet since this is a modern spiral, we must harmonize this controversy; we must seek the due correlation of the ideals of organic and of psychic selection. For this we need above all some clearer vision of the ideals of evolution-Olympian for the body, Parnassian for the spirit, and even morein fact, an evolutionist hope and aim not only for the life of the individual, but increasingly for the uplift of the race and of the community. On the way towards this, selective consciousness and conscience are indispensable, love as individual, love as social; and with these sacrifice also, it may be of love or of parenthood itself. Nor is the social control a mere choice between Draconian harshness on one hand and shallow philanthropy on the other; for these are but rival cruelties, that to the individual, this to the race. To determine, then, the ideal goal and the true process of selection for our own species, is thus the supreme problem and task which are opening before us as evolutionists. 
Auxiliary Hypothesis of Isolation.We have already referred to the occurrence of particular species on particular islands in the Galapagos Archipelago, and there are a great many similar cases which suggest that isolation means something in evolution. The red grouse is peculiar to Scotland, but it has doubtless been derived from the closely-related stock of the Scandinavian willow grouse. While the zoologist has lately distinguished an Orkney vole and a St. Kilda wren, every one knows the Shetland pony, the Highland cattle. There are said to be eighty species of the land-snail Cerion in the Bahamas, and Gulick records over 200 species of the land-snail Achatinella in the various valleys of the Sandwich Island Oahu.

Many evolutionists-Wagner, Weismann, Gulick, Romanes, Jordan, and others-have worked at the idea of Isolation, as a directive factor in evolution; and Romanes maintained that it was a sine qua non in the origin of new species. The term must not be thought of in any narrow sense; it includes all the means which restrict the range of intercrossing within a species: geographical barriers, such as arise when a peninsula becomes an island; temporal barriers, such as arise when the members of a species reach sexual maturity at different times of year; habitudinal bar- 
riers, when a species splits into two or more castes with different habits of life; physiological barriers, such as arise by some variation in the reproductive organs; and psychological barriers, which rest on profound antipathies.

What probably happens is this: a successfully vigorous and adaptive species spreads; the several contingents become isolated from one another; and, if different variations spring up in several or all of the contingents, then, other things being equal, isolation will favour the origin of distinct species. "I do not doubt," Darwin said, "that isolation is of considerable "importance in the formation of new species." It may be of some importance in preventing intercrossing, but it is much more likely that it works by bringing about close inbreeding, which develops prepotency or stability of type.

In the human world, the manifold range of individuality presented by regions favourable to family, village, and clan isolations, such as Scotland or Norway, Greece or Palestine, thus becomes intelligible. Again, in that deterioration of the cities of the plain, which is so frequent throughout history, so evident to-day, we may increasingly fear an organic factor underlying the obvious social ones-that of reversion through intercross- 
ing; as when the highly individualized races of pigeon sink back to the comparative uniformity of the ancestral rock-dove. Yet from this apparent regression, really a profound and intimate panmixis, a thoroughgoing cross-fertilization, who shall say what new variations may arise, what new selections also-even what evolving guidance of these?

Eugenics as a Renewal of Evolution. - Thus we return to man as transformist, a discussion already opened in Chapter II, but this time appearing in a fresh perspective. It is admitted by all inquirers into the origins of civilization on one hand, into the origins of cultivated plants and of domesticated animals on the other, that practically all these familiar and indispensable companions of man are of prehistoric origin, and have risen along with him, as he with them. But now the corollary of this: imagine the immensity not only of patient labour, but of selective skill, which are comprised within the steps from wild grasses to cereals, from crab-apple and wild olive to the vast and fruitful groves which must assuredly have covered the prehistoric cultivation terraces of old, stretching as these did throughout the Mediterranean region from Portugal to Syria-thence through Asia Minor to Persia, to Korea itself. One has 
taken the pains to calculate the actual capital value of these ancient Mediterranean terraces, and brings out the marvellous, yet credible, result that the actual economic wealth of this remote prehistoric world far exceeded that of the Mediterranean to-day; and this not merely in its agriculture, or with roads and railways thrown in, but with the existing cities as well! Here then is a view of the early human past very different from the picture of groping brutishness, of promiscuity and struggle with which nineteenth-century anthropology was too much obsessed; for if we seek the modern representatives of these old cultivators and selectors, these breeders and arboriculturists, at their best we must seek them at the very highest growing-point of our own civilization to-day. For with all respect to the great mechanical inventors, and the masters of the physical sciences who have accompanied them, we claim a higher primacy in science for Darwin and his peers, and this alike as regards vision of the universe, as in organic not merely physical evolution, and in potential and forthcoming, if not yet fully actual contribution to the service and uplift of man. In short, these prehistoric transformists of wild life into cultivated fruitfulness and domesticated use, had already among them 
their Darwins and Vilmorins, their Gartons and Burbanks; with the one important difference-that these achieved immeasurably greater practical results than have as yet their modern successors.

Again, is it likely that those who could transform the lurking, wolfish depredator into the trusty guardian of their flocks, the wild cattle into patient ox and gentle cow, the wild horse into the Arab, neglected their own breeding as we and our progenitors have done-or even misunderstood it as all historic aristocracies have done? True, we have not their history in the letter, yet we have much of it in the spirit; that of the folk-tales and fairy tales, of which the most childlike and sympathetic of the sciences is steadily recovering the values and the meanings; and these old child-tales are even returning towards their social and vital applications-above all that of presenting the ideal of love as the quest of life which our fathers called romantic, which we now call eugenic and think modern. Whereas out of all this recovery of the golden age and of the ancient garden of fruitful labour, does there not emerge the idea that its guardians, so much wiser and happier than we knew, had thought not only for the simpler creatures they cared for and ruled and elevated, but 
for themselves and for each other?--in short, that our modern Eugenics, latest-born even among the evolutionary sciences, may yet be among the very oldest; and that now once more, at the opening of that new epoch of world-consciousness and world-activity which is involved no less thoroughly by the evolution theory than was the passing industrial age by the advance of mechanical science, the ancient evolutionary past is being again reborn? 


\section{CHAPTER VI}

ORGANISM, FUNCTION AND ENVIRONMENT:

IN RELATION TO EVOLUTION

The Conception of Life-The Evolution Idea, its History -Theories of Evolution, Classified-Relations between Organism and Environment-Indirect Importance of Modifications-The Rôle of Function-The Living Organism-Theories of Vitalism-Initiation into Psychology.

The Conception of Life.-The definition of life is the last, not the first, question for the student of Biology. What we have to do first is to study the actual happenings, the changes, the movements, the activities that go on under our eyes. It is only after we have given careful study to the actual fact of living-which is a process, a dynamic relation - that we can profitably inquire into the particular secret of the agent.

By many who have begun at the wrong end-wrong from the point of view of scientific method-the conception of Life, the organism's secret, has to be left as a mystery, or is mistaken as an entity. By others it is thought of in terms of chemical substance, like the "elixir" or "quintessence" of old, or again in terms of modes of energy, 
which are "physical" or "vital," to different schools, of materialistic or idealistic leanings respectively, albeit physical rather than biological in either case. Our present point is that before inquiring into the secret of the organism- "Life" in the innermost and organismal sense-we must seek a deeper appreciation of the process of living. What then is this? On the one hand there is the Environment in its action upon the organism; and on the other the Organism in its reaction to and action upon the environment; the dynamic relation, in its twofold aspect, is called Function.

The Evolution Idea: its History.Before we seek to relate the various theories of evolution factors that have been suggested to the three categories of Biology-Organism, Function, Environment-it may conduce to clearness to consider for a little the general "doctrine of descent."

While it is true, as Professor Osborn puts it, that "Before and after Darwin" will always be the "Ante et post urbem conditam" of biological history, it is also true that the general idea of organic evolution is very ancient. Several of the Greek philosophers looked upon Nature as having developed, and as being still in process of change. Aristotle seems to have recognized an ascending 
series from polyp to man and an age-long movement towards increased perfection. Static conceptions, however, prevailed, with some rare exceptions, through the long interval between Aristotle and Bacon, who was one of the first to think definitely about the mutability of species. But after the Renaissance it was among the "philosophers," not among naturalists, that the evolution idea began again to live and move. The first naturalist to give a broad and concrete expression to the evolutionist doctrine of descent was Buffon (1707-1788). Erasmus Darwin (1791-1802), Charles Darwin's grandfather, was another firm evolutionist, probably influenced by Buffon, and it is very interesting to observe how much of the argument in his "Zoonomia" might stand to-day. Lamarck (1744-1829) was above all thoroughgoing in his evolutionism; and Haeckel rightly speaks of his "Philosophie Zoologique" as "the first connected and thoroughly logical exposition of the theory of descent.'

Besides the three old masters, as we may call them, Buffon, Erasmus Darwin and Lamarck, there came other quite convinced pre-Darwinian evolutionists - Treviranus, Etienne Geoffroy Saint-Hilaire, Groethe, Robert Chambers, and many others. Dar- 
win refers to thirty-four more or less evolutionist authors in his Historical Sketch, and the list might be added to. Especially when we come near 1858 do the numbers increase, and we must never forget that Herbert Spencer not only marshalled the arguments for Evolution in a very forcible way in 1852, but applied the formula in detail in his "Principles of Psychology" in 1855. We must also remember that the genetic view of nature was insinuating itself in regard to other than biological orders of facts, here a little and there a little, and that the scientific temper had ripened considerably since the days when Cuvier laughed Lamarck out of court.

We have inserted this historical reference to pre-Darwinian evolutionists, since it is important to shake ourselves free from all creationist appreciations of Darwin; but it would be a perversion of history to suggest that he simply entered into the labours of his predecessors. In point of fact, he knew very little about them till after he had been for years at work. Let us ask rather how it was that Darwin succeeded in winning a world-wide acceptance of the evolution idea, where so many others had failed!

Because, in the first place, he had clear visions-"pensées de la jeunesse, exécutées 


\section{FUNCTION AND ENVIRONMENT 187}

dans l'age mûr" - which his indocile refusals to submit to outworn university curricula had made possible, which the "Beagle" voyage made fuller and more vivid, which an unrivalled British doggedness made ever more positive and real-visions of the web of life, of the fountain of change within the organism, of the struggle for existence and its winnowing, and of the spreading genealogical tree. Because, in the second place, he put so much grit into the substantiation of his visions, putting them to the proof in an argument which is of its kind-direct demonstration being out of the questionquite unequalled. Because, in the third place, he broke down the opposition which the most scientific had felt to the seductive modal formula of evolution, by bringing forward a more workable theory of the process than had been previously stated. Nor can we forget, since questions of this magnitude are human and not merely academic, that he wrote, in his mingled simplicity and condescension, so that all men could understand.

Theories of Evolution, Classified.So far the generai doctrine of descent; but some of the pioneers did more than apply the evolution idea as a modal formula of becoming: they began to inquire into the 
factors in the process. How are their theories related to the three categories- Organism, Function, Environment?

To some the fundamental fact is the living Organism-a creative agent, a striving will, a changeful Proteus, selecting its environment, adjusting itself to it, self-differentiating and self-adaptive-Life dominating nature, master of its fate.

To others it has always seemed that the emphasis should be laid on Function-on activity and practice, on use and disuse, on doing and not doing.

To others, again, what counts for most is the Environment. This wakes the organism to action, feeds it or starves it, gives it new experiences or imprisons it within the old. Environment prompts the organism to selfexpression, yet moulds it and prunes it, punctuates its life, and finally puts in the full stop, of death.

Let us take some historical illustrations. There is no doubt that Buffon laid great emphasis on Environmental influences-especially of climate and food-as direct transforming factors.

The central idea of Erasmus Darwin's evolutionism was Functional: that wants stimulate exertions and that these result in improvements, which subsequent generations 
make better still. This was Lamarckism before Lamarck, as his grandson pointed out.

Lamarck agreed with Buffon in maintaining that external conditions directly moulded plants, but differed from him in denying this for animals, "for environment can effect no direct change whatever upon the organization of animals." In so doing, despite the obvious exaggeration, we must credit him with clear recognition of the relative passivity of the vegetative life, the relative activity of that of the animal. The central idea of his theory, however, was the cumulative transmission of functional modifications: "Changes in environment bring about changes in the habits of animals. Changes in their wants necessarily bring about parallel changes in their habits. If new wants become constant or very lasting, they form new habits, the new habits involve the use of new parts, or a different use of old parts, which results finally in the production of new organs and the modification of old ones." But beyond this he clearly insisted on the inward urge or effort of the organism to realize its inmost wants, and to express this in change of habits and even of structure.

Treviranus (1776-1837), whom Huxley ranked beside Lamarck, was on the whole like Buffon in attaching chief importance to 
the influence of a changeful environment, both in modifying and in eliminating. But he had another deep idea, which Goethe shared, of an inherent formative impulse in the creature. "In every living being there exists a capability of an endless variety of form-assumption; each possesses the power to adapt its organization to the changes of the outer world, and it is this power, put into action by the change of the universe, that has raised the simple zoophytes of the primitive world to continually higher stages of organization, and has introduced a countless variety of species into animate Nature."

But it is in Goethe that we find the fullest expression of the idea of the innate tendency of a living creature to fuller self-realization. At the same time he held with Lamarck that "the way of life powerfully reacts upon all form," and with Buffon that the orderly growth of form "yields to change from externally acting causes."

The main idea of Goethe, of an inherent growth force, has constantly reappeared, notably among the American palæontologists: witness Cope's "bathmism"; and now among the whole rising generation of vitalists, German and other. The anatomist and systematist, the chemical and physical physiologist, have been, and still are, wont 


\section{FUNCTION AND ENVIRONMENT 191}

to reject this; and not without reasonthat of the positivism of science, which rightly shrinks from the acceptance of abstract entities and causes. Undeniably, whatever may be our sympathy for these manifold suggestions of vitalist evolutionism, they are still too much open to Molière's ridicule, as of explaining the effect of opium by its "dormitiveness."

We need not continue these historical illustrations, but the important point is this, that some naturalists, such as Buffon, emphasized the importance of the Environment; others, such as Lamarck, laid the main stress on Function; others, such as Goethe, discerned that, after all, the moving spirit in the drama of evolution is the Organism. It may be said without dogmatism that the adequacy of an evolution theory is in proportion to its recognition of all the three categories, which give, in point of fact, the three aspects of life.

Surely, whatever may be the limits of Darwinism, its superiority to preceding evolution theories was in part that it got nearer to seeing life whole. The Organism was appreciated: it is the fountain of change; it is aggressive, insurgent, even riotous, in its multiplication; it struggles, it even chooses. Rightly or wrongly, Function was 
also appreciated: use and disuse have their organic consequences, and for Darwin these were, at least in part, transmissible. Simillarly the Environment was appreciated, alike in moulding and in pruning. Finally was added the idea of Nature's environmental and adaptive sifting-the essentially new and triumphant doctrine of Natural Selection.

The post-Darwinian scepticism as to the transmission of functional and environmental modifications might seem to involve a denial of the evolutionary importance of anything but the varying organism and the winnowing environment; but what it really means is that the previous appreciation of the evolutionary importance of function and of environment was not subtle enough. We ask, therefore, wherein the importance of function and environment may consist, if there is no direct transmission of the individual modifications which they undoubtedly produce. This involves a careful inquiry into the relation between organism and environment.

Relations between Organism and EnVIRONMENT.-(1) It is impossible to separate living creatures from their surroundings. To do so in fact is to kill them; to do so in theory is to turn biology into necrology, a vice which has always too largely infested 
our science, paralyzed its thinkers, sometimes even skeletonized or mummified them. There is an endless diversity in environments, and some of them are most extraordinarythe iceberg, the hot spring, the mountain top, the abysses of the ocean, the cave, the interior of another creature-but for each kind of organism there is an indispensable minimum of supplies and influences, apart from which it cannot develop, or grow, or continue to live. This is the fundamental relation of living things, that of constant and normal environmental dependence.

(2) But surroundings are changeful and the living creature changes with them. In many cases, where the external changes are regularly recurrent, like seasons and tides, the organism falls into step with them; so that there are internal rhythms, punctuated by external periodicities. The latter may come to be needed only as the liberating stimuli, or trigger-pullers, of the former. Experiments show that some young tropical acacias are hereditarily wound up, as it were, to a twelve hours' day and night-times of leaf-expansion and leaf-closure. The cold of winter is probably the stimulus rather than the efficient cause of the brown stoat becoming the white ermine.

(3) To some of the irregular changes in its 
surroundings the living creature is able to adjust itself temporarily. The warm-blooded bird or mammal can within limits adjust its heat-production and heat-loss so that the temperature of the body remains the same whether that of the environment rises or falls. In the case of many of these transient adjustments there remains no abiding result that can be detected.

(4) Insensibly, however-for it is all a matter of degree-we pass to cases where the responses to environmental change last for a considerable time. Sun-burning on a summer holiday, increase in the size of a muscle after a course of exercises, the blanching of the banked-up celery are familiar allustrations. The bodily change has taken a firmer hold than in the case of transient adjustments, but it is still a passing change. Like a bow unstrung the organism rebounds, approximately to its previous state.

Semon has recently propounded a theory - of the "Mneme" - which is of interest in this connection. The general idea of it is, that when living matter is affected by a stimulus, its quality cannot be the same as it was before the stimulus. Even a bar of iron is not quite the same after it has been once struck; how much more a living creature which is specialized towards gaining and 
garnering experience. There is always some. residual effect; this Semon calls an "cngram," and the sum of the engrams of a liv-. ing creature is its "Mneme"-its organic lore, its bodily and sub-conscious memory we may practically say.

The "Mneme" may have particular importance in cases where penetrating stimuli, like those of the seasons, recur periodically, re-vivifying and re-enforcing the previous accumulations of experience. Along this line of thought, Semon, and following him Francis Darwin and others, may be said to be returning towards a position again essentially Lamarckian, for thus the results of experience may be conceived as accumulating from generation to generation, even although, as Weismann maintains, individually acquired bodily modifications may not be entailed as such. The effects of an often repeated stimulus may saturate through the organism by nerve paths and protoplasmic bridges and the fluent blood; what then precludes them, in some cases at least, from reaching even the germ-cells in their recesses?

In this connection, it is only just to recall the remarkable speculative insight of the late Samuel Butler, that most convinced and argumentative of Lamarckians, who, more or less simultaneously with Hering in Prague, 
propounded a generation ago much the samo doctrine of "Organic Memory," as that which we now owe to Semon. Haeckel too has expounded much the same doctrine; and no doubt in increasingly clarified form it must henceforth be reckoned with.

(5) Insensibly, again-for it is all a matter of degree -we pass from the temporary dints impressed upon the organism by the environment to those that last. There are many cases in which the novel conditions provoke a structural change from which there can be no rebound, the limit of organic elasticity having been passed. These lasting changes are technically called "modifications" or "acquired characters." A tree may be permanently blown out of shape; over-exertion at high altitude may strain the heart beyond repair; a man may be tanned for life by the tropical sun.

(6) Quite different from the last are cases where some change in the environment of the parent provokes a variation in the offspring. The best instances, as yet, are to be found in the experiments carried on for many years by Tower on beetles of the genus Leptinotarsa, which he subjected to unusual conditions of temperature and humidity, when the male and female reproductive organs of the parent were at a certain stage 


\section{FUNCTION AND ENVIRONMENT 197}

in their development. The body of the parent exhibited no modification, but the external influence, saturating through the body, was sometimes operative on the germcells and thus on the offspring. In some cases there were remarkable changes in colour and markings, and even in minute details of structure. And there was no reversion to the parental condition.

(7) Another "organism-environment" relation is that implied in the struggle for existence, which in its widest and truest sense includes all the reactions of living creatures to their surroundings and difficulties. The physical world is careless of life; one living creature presses upon another, competes with another, devours another. Thus, while the environment is a stimulus, it is also a sieve. It has an eliminating action which, as we have seen, is often discriminate; it sifts and winnows; the result is extinction for some, but adaptation, and this it may be a degree more perfect, for others.

(8) But we must not think of the matter too fatalistically, as if organisms were always like helpless fishes, around which the environmental net closed, only the little ones getting through the meshes. True, they cannot by taking thought increase or decrease their 
stature, even to save their lives; yet they are fertile in device, persistent in endeavour. Even the worm will turn; even the plant will answer back. Living creatures are agents; they thrust as well as parry; they act on their surroundings, modifying them; they are ever seeking out new environments, and conquering them.

The foregoing analysis has sufficiently shown that the range of relations between the living creature and its surroundings is a very complex one,- of functional dependence, of periodic punctuation, of transient adjustment, of more lasting adjustment, of permanent modification, of variational stimulus, of elimination or selection, up to active initiative upon the organism's part. The evolutionary import of these relations is no doubt even more intricate than we can yet see. The old theories of direct adaptation in response to altered environmental conditions, or as the result of use and disuse, were much too simple. But there has also been far too great simplicity in the view too long prevalent in the generation after Darwin, and to some extent even to-day, that each species must, so to speak, wait with folded hands, until fit variations emerge, whether these be "spontaneous" (i.e. unexplained), or arise in course of shufflings of 
qualities and properties that undoubtedly must occur in the history of the germ-cells.

Indirect Importance of Modifications. - The interesting suggestion has been made, independently by Mark Baldwin, Lloyd Morgan, and Osborn, that useful "modifications" may serve as the fostering nurses of "variations" in the same direction. We quote from Lloyd Morgan a brief statement of this idea: "Suppose that a group of plastic organisms is placed under new conditions. Those whose innate plasticity is cqual to the occasion are modified and survive. Those whose plasticity is not equal to the occasion are eliminated.... Such modification takes place generation after generation, but, as such, is not inherited.

But any congenital variations similar in direction to these modifications will tend to support them, and to favour the organism in which they occur. Thus will arise a congenital predisposition to the modifications in question."

"The plasticity still continuing, the modifications become yet further adaptive. Thus plastic modification leads, and germinal variation follows; the one paves the way for the other."

"The modification, as such, is not inherited, but is the condition under which 
cr.ngenital variations are favoured and given time to get a hold on the organism, and are thus enabled by degrees to reach the fully adaptive level.'

Yet another consideration. Although we do not know of any case of the transmission of a modification as such, or even in a representative degree, we, of course, agree with Weismann in admitting that modifications may have secondary effects on the germcells, and thus on the offspring. In this way "nurture" may come to have a racial importance. Nor can we forget that the environment of mammalian mothers is bound to have an influence on the unborn young, which shares the maternal life so closely. Apart from the "mysterious wireless telegraphy of antenatal life," there is a sharing of the diffusible substances carried by the blood.

The Rôle of Function.-We cannot go back to the cruder forms of the Lamarckian theory, and believe that the giraffe lengthened its neck by stretching it; yet we must beware of taking too simple a view of what function implies. What are the certainties? We know that development-the expression of an inheritance demands functional as well as environmental stimuli. Practice makes an organ possible. Without exercise 


\section{FUNCTION AND ENVIRONMENT 201}

it will not develop fully. Again, we know that changes in function have great individual importance. By force of smiting one becomes a smith. Even if there be no multiplication of muscle-fibres after the more strenuous function began, each fibre is larger and worth more. Contrariwise, disuse means deterioration; when we rest too much we rust. No one has ever doubted the individual importance of functional modifications. Further, although the transmission of a functional modification remains unproved, the secondary and indirect results may influence the germ-cells and the offspring. It is idle to say that what living creatures do or fail to do has no racial importance. Another certainty is that by its activity a living creature, being no mere puppet of fate, may alter the whole situation. This, again, may have evolutionary interest, even if it ends fatally. Admitting all this, can we say more?

The Living Organism.-The secret of Life is baflling to the human intelligence, refusing to be formulated. Often the conception of Life has seemed to biologists to be within reach, and then it is perhaps farthest away. It recedes as we approach. Yet, though intelligence fails, do we not at times come nearer to it through sympathy? Words- 
worth, Emerson, Meredith, these and many other Nature-poets are perhaps the truest, because deepest, biologists of us all.

It is partly in the intrinsic difficulty of the problem-vital activity being something between mechanical causality and our conscious purposing-and partly in the way that science ever takes on the colour of its time, that we must look for an explanation of the historical oscillations of biology between the mechanistic interpretations of the living organism and the vitalistic appreciations of it. Now it is a machine and again it is a spirit, now an automaton and again a free agent, now an engine and again an entelechy. The pendulum of thought continues to swing.

Despite the fact that as yet no vitalist writer has succeeded in making himself and his nomenclature really intelligible to any other, and that the frequent gibes at vitalistic metaphysics and mysticism remain largely justified, we confess that the modern movement of vitalism has our increasing sympathy. It affects our evolutionism to this extent at least that we feel compelled to recognize the persistence of some originative impetus within the organism, which expresses itself in variation and mutation, and in all kinds of creative effort and endeavour. 
There are two sides to all doctrines of vitalism-a negative side which argues towards the impossibility of holding to the purely mechanistic interpretation, and a positive side which attempts some further elucidation of the life-mystery.

As an outspoken statement by a competent physiologist and physician of the vitalist position, on its critical side, we may take Dr. Haldane's recent British Association address (Dublin, 1908). "In Physiology, and Biology generally, we are dealing with phenomena which, so far as our present knowledge goes, not only differ in complexity, but differ in kind from physical and chemical phenomena; and the fundamental working hypothesis of Physiology must differ correspondingly from those of Physics and Chemistry." . . " The physico-chemical theory of life has not worked in the past and never can work. As soon as we pass beyond the most superficial details of physiological activity it becomes unsatisfactory; and it breaks down completely when applied to fundamental physiological problems, such as that of reproduction.'

Theories of Vitalism.-A constructive and comprehensive endeavour to formulate a cioctrine of vitalism is that of Dr. Hans Driesch's recent Aberdeen Gifford Lectures, 
in which the author, working from his standpoint as an experimental embryologist, advances technical proofs of the "autonomy of life," and of its specific distinctiveness from the not-living. He advances an elaborate threefold argument to show how the interpretation of a living creature as a machine breaks down, both in regard to its functioning and its development; and he seeks to show that it is necessary to postulate an immaterial autonomous factor, or "entelechy" which punctuates the transformations of energy that go on within the body. This "entelechy" is the living creature's innermost secret, in fact its directive soul.

Another clear and comprehensive exposition of a theory of Vitalism will be found in Bergson's "Creative Evolution." Bergson dwells on the close resemblance between the life of the organism and our own personal experience. We change without ceasing; the organism is in a state of ceaseless flux which we call metabolism. Both have the mysterious quality of "durée" - but duration in more than the merely physical and chronological sense; for what he means by it is "the continuous progress of the past which gnaws into the future and which swells as it advances." "Our personality shoots, grows and ripens without ceasing. Each of its moments 


\section{FUNC'IION AND ENVIRONMENT 205}

is something new added to what was before. We are creating ourselves continually." So of an organism it may be said that "its past, in its entirety, is prolonged into its present, and abides there, actual and acting." "Continuity of change, preservation of the past in the present, real duration-the living being seems, then, to share these attributes with consciousness. Can we go farther and say that life, like conscious activity, is unceasing creation?"

Bergson answers this question by an emphatic affirmative. The spontaneity of life is manifested by a continual creation of new forms. "A hereditary change in a definite direction; which continues to accumulate and add to itself so as to build up a more and more complex machine, must certaiily be related to some sort of effort, but to an effort of far greater depth than the individual effort, far more independent of circumstances, an effort common to most representatives of the same species, inherent in the germs they bear rather than in their substance alone, an effort thereby assured of being passed on to their descendants. There is an original creative impetus in life, which passes from generation to generation of germs, is sustained right along the lines of evolution among which it gets divided, and is the 
fundamental cause of variations, or at least of those variations that count."

We see, then, how Bergson psychologizes life without needing to invoke the "spiritual influx"-too much a "deus ex machina"which is demanded by Wallace, to explain the genesis of man's higher faculties, and indeed to explain the other great steps in evolution. Metaphysical and abstract though his interpretation remains, too shadowy as it is for the needs of the working naturalist, we must recognize that here is a fresh and forceful re-statement of the essential thought of Lamarck, of Goethe, of Robert Chambers, of Butler, and of later vitalists; in fact, of all who have most deeply felt the supreme importance of the organismal factor in evolution. More even than this, here is a new conversion of the philosopher into the biologist, and when we recall the enthusiasm with which the late Prof. William James proclaimed himself as the disciple and exponent of Bergson, we see how fruitful may be this re-opening alliance of the abstract with the concrete thinker. Again, as in Spencer's day, our biology and our psychology have to be correlated and unified anew, and all towards the philosophy of evolution. Still, with all respect to the philosophers, who have taken this great step 


\section{FUNCTION AND ENVIRONMENT 207}

towards becoming naturalists, we cannot but feel that the next step in progress must depend upon how far we naturalists can in our turn become something of psychologists and even philosophers.

It is a matter of common sense and experience, which we are all verifying any and every day for ourselves, that the psychologically-minded person can and does see farther into life, and sees more aspects of it, than the most skilled mechanic, be he the inventor of machines or the discoverer in physics. After all, the biologist cannot be content until he becomes something more than a physicist and chemist, an anatomist, systematist and so on: beyond its structures and reactions, life has an aspect of behaviour, and that is, after all, the main one. As he grasps this, he becomes a biopsychologist, and starts upon fresh quests; at first, no doubt, and properly, armed capà-pie with brass instruments and copper wires. Faithful to his physico-mechanical upbringing, he measures reaction-times, he plots curves, he again reassures himself that there is nothing more in Life. But one day danger and opportunity arouse him; another love or sorrow awakens him altogether-not most probably to any mystic vision such as vitalists are credited with by their opponents, 
usually far too generously, we suspect, but at any rate to make the discovery still so rare for men of science, albeit an open secret to plain folk, that beyond the often measurable bio-psychoses of the psychological laboratory there are psycho-bioses, often immeasurable, in the greater world-laboratory of life. After this initiation, a new and before-unsuspected thought-world opens; and within this begins the real controversy, of reconciling the claims and methods of orderly science with these deepest, yet most incontestable, data of experience. In such ways the enduring contrast, or at least the bias, of the mechanistic and the vitalistic training and temperament may be continued upon a higher spiral, with results ever more fruitful, yet in principle already in viewfrom one side that of carrying physical and chemical, structura! and functional inquiries onwards to new triumphs of analysis; but also, from the other side, that of tracing the psychic process deeper and deeper, into the very germs and origins of life. In a mord, then, it is for the mechanistic biologist to cease from scoffing at the vitalist as a "mere mystic," and to set about mastering psychology until he can turn scientific clearness upon his vagueness. Till then he but lays himself open to a counter-sneer from the 


\section{FUNCTION AND ENVIRONMENT 209}

mystic, and a worse nickname-that of "necrologist."

Initiation into Psychology.- How is the biologist, trained in the dissecting-room, the laboratory, the museum, the herbarium, or even in the garden or the field, to get at the psychological point of view, even when he begins to feel that he here has something to learn, that he in fact requires it, if he is to be a biologist indeed? Even in Bergson, much more in the German vitalists, there is too much of the intangible. Let him begin with Darwin himself, and he may soon feel, that like many an admiring disciple before now, he has not grasped the fully rounded thought of his own master. With rare exceptions, like Lloyd Morgan for instance, what naturalist of us all is not far more at home with Darwin when he is in his field watching his earthworms, in his garden watching the bees, in his greenhouse among his insectivorous or moving plants, or in his study writing "The Origin of Species," than when already as a youth upon the "Beagle," he was keenly collecting data which eventually formed the foundation of his "Expression of the Emotions in Man and Animals," a masterwork of comparative psychology; or, as a grandfather in his easy-chair, keenly and kindly watching the 
daily growth of his child-playmate, and so laying foundations for that great science of mental embryology still best known by its fit and homely name of child-study? A naturalist, too, has a respect for embryology: let him, then, take as guide the foremost of American mind-embryologists, President Stanley Hall (see the American Darwin Centennial volume, "Fifty Years of Darwinism"), who after creating a very paradise for the guild of brass instruments, and long and leading services to child-study, has of later years applied himself to the no less fruitful and perhaps even more important field of Adolescence; that magic Dionysiac moment of human metamorphosis, in which wisdom and folly, madness and genius strive for mastery, and ferment out from within the issues of each maturing life, in passion or apathy, virtue or vice, social service or crime, health. or insanity. For him as for Darwin "the soul of man is no whit less the offspring of animals than is his body. Our psychic powers are new dispensations of theirs. The ascending series of gradations is no more broken for the psyche than for the soma." Following Darwin still, his " method is always and everywhere objective and observational, never subjective or introspective. . . The true ultimate knowledge of our psyche is 


\section{FUNCTION AND ENVIRONMIENT 911}

the description of all developmental stages from the amœba up; and those move most surely among the altitudes who have most carefully explored the depths in which the highest human powers originate. Emotions are best studied in their outward expressions of gesture, will is investigated by the study of behaviour, intelligence by massed instances of sagacity, and not by analysis under old rubrics.'

With example like this of Darwin's, an.l guidance like this of Stanley Hall's, no biological brother need fear to enter the school of psychology, as we ourselves have done, albeit also tardily. From its many and ever-widening outlooks new views appear; on one side, perhaps, a glimpse of how to clear up the vagueness of current vitalisu, and in any case many ways of mellowing the crudeness of current mechanism. 


\section{CHAPTER VII}

EVOLUTION THEORIES IN THEIR SOCIAL ORIGINS AND INTERACTIONS

Evolution theories: their history from social side-Limitations yet advantages of social outlooks-From sucial progress to naturalist outlook-Science in its relation to labour-Science in Philosophy, Education and Life-The natural sciences once more-Summary of preceding argiment-Education through nature-occupations to vocations -Rustic and urban as contrasted in thought-Needed renewal of rustic point of view.

IN the introduction we saw that the doctrine of evolution was on one side a generalization from science after science-from astronomy and geology, even sooner and more plainly than from zoology and botany; from philology and other human sciences also. We saw the faith in evolution arising, less consciously, no doubt, but perhaps all the more deeply; and through the social transformations of its age. The generation of culminating political revolution in France, that of the culmination of the industrial revolution in England, have thus expressed themselves through Lamarck and Darwin more 
clearly than either thinkers ever dreamed, or than their respective exponents and disciples have realized.

The wealth of first-hand observation from which Darwin and his successors generalized their conviction of "the all-sufficiency of natural selection" was thus a less simple and child-like discovery of Nature than it seemer; it was a new and modern selection from the wealth of Nature's aspects and interests. For, when all is said and done, "the eye sees only what it brings with it the power of seeing." What are Lamarck's interpretations of the effects of use and disuse, his assured insistence upon the interior freedom of the organism to realize its inmost capacities, but the new step in social progress through abandonment of outworn orders of society, the freedom opening before new ones? "La carrière ouverte aux talents" is pure Lamarckism; so again the splendid overassurance of the Napoleonic epic, that "every French soldier carries a marshal's baton in his knapsack." But the colder business view so characteristic of English thought came to prevail over such political and military exaggerations; the ideals of mechanical efficiency and of individual and financial success rising above the ruins of liberal aspirations and of imperial achievements as they 
have so often done. Hence a view of evolution essentially mechanical, in terms of the division of labour, the cumulative patenting and the like, which were gradually evolving the express locomotives or the manufacturing plant of Darwin's day, and now the flying-machine in our own. Hence, too, views essentially competitive and commercial, albeit of various shadings, Irom old-fashioned individual efficiency to cheaper and cheaper undersellings, with advantages here from advertisements more and more brightly and seductively coloured, there from deceptive imitations more and more subtly wrought. "Competition is the life of 'Trade": then why not also the trade of Life? Yet with all this freshness and vigour of economic application, there has prevailed in the main, and still prerails, a naïve forgetfulness of the social origins of these naturalists' discoveries.

Similarly in neo-Darwinian times. With united and real respect for Weismann, for whose work one of us has once and again acted as translator and editor, the other yet ventures to urge one of the very few criticisms which that wide and fair-minded and subtle thinker seems never to have considered: the striking social parallelism of his own theory of the germ-plasm, of the ovum's 
strict inheritance, with the thought of contemporary Germany; with the victories and hegemony of Prussia, the renewed claims of its aristocracy also; and, above all, with its doctrine of race, political and anthropological combined. The intermediate step between this ruling Prussian world of action and Weismann's ascendancy in speculative biology is indicated by the widely diffused doctrine of Count Gobineau, consciously and avowedly bio-social as this has been. All these movements alike have now found eloquent, though hardly scientific, expression in Houston Stewart Chamberlain, whose contemporary vogue in Germany is thus earned and explained.

Limitations yet Advantages of Soctal Outuook.-But the reader may ere now be saying: If this be true, if biological doctrines be even half as much projections of their social age as is here suggested, what becomes of the independent scientific value they have claimed, and which we are asked to grant? Is your science merely a new anthropomorphism? - and if so how does it differ from the mythological accounts of Nature it claims to displace?

The answer is not so difficult as it seems, the result not so unsatisfactory after all. The independence of the doctrines of any 
science from the social life, the prevalent thought of the generation in which they arise, is indeed a fiction, a superstition of the scientist which we would fain shatter beyond repair; but the science itself becomes all the sounder for recognizing its origins and its resources, its present limitations and its needs of fresh light from other minds, from different social moulds. Robinson Crusoe made an excellent survey of his island, and felt a legitimate scientific assurance of its thoroughness, a corresponding personal pride also; but when Friday came, bringing with him a widely different tradition of culture, his fresh survey not only enriched his master's at many a point, but taught him, indeed each of them, its relativity as well. Here indeed is the practical criterion of scientific conclusions, their verifiability by diverse minds. So far then from sneering at Lamarck as an impassioned son of the revolution, at Darwin as a shrewd and prosperous modern Englishman, at Weismann as a German ennobled, and so on, we begin to see how, just as "it takes all kinds of people to make a world," so it must also to give anything like a full account of it, to clear these partial accounts up into a science. A science is one of the most collective, most historic, of products; and most social there- 
fore, though the custodians of its heritage be as yet few.

There is a time for everything, and since philosophy, or any portion of it worth calling generalized science is (or at least should be) the ripened fruit of experience, the retirement of the student and philosopher from the noise and turmoil, the delay, hourly pressure of the world, is as necessary and as legitimate a process as is setting apart the milkpan to let the cream rise. The mistake arises when we begin to think of this isolation as the sole essential, and overlook that all the cream we get comes from the cow, and from such pasture as we can give her. The qualities and defects of the retiring biological philosopher thus become apparent. Take Mr. Spencer for choice. After an education unusually scientific, an experience unusually practical, including participation in the greatest constructive activities of his day, both as railway engineer, as mechanical inventor, and in its theoretic discussions also, as editor and as economist, he takes more and more general views, first as leader-writer, then as essayist, and thence abstracts himself into his long and devoted cloistered life as philosopher. But after all, how little in essential thought does his reasoned philosophy get beyond its initial statement in his 
sporadic essays?-and how largely are these, in qualities and in limitations alike, the expressions of his boyish and his youthful education, his professional experiences?

From Social Progress to Naturalist OutLOoK.-Once more, then, we insist upon the progress of evolutionary science as from social progress to its naturalist application. In our opening chapter we put this plainly enough, but as it were once for all; thence passing as naturalists into the field, and as biologists into the laboratory and study. Darwin is again the example of this lifehistory of the naturalist. Malthus once grasped and applied, he drew no more drafts upon political economy, consciously at least; and his many disciples and continuators have been no more conscious of their stoutly utilitarian economics than was M. Jourdain of his prose: though of course it has been none the less there all the time. Wallace, indeed, practically alone among Darwinians, and more divergent and original than his generous loyalty has ever allowed him to realize, has kept in touch with the movement of economic thought, and that in later and less canonical schools especially; he has striven to throw light upon other puzzles and controversies, from political to psychological, from geographic to religious; but 


\section{EVOLUTION THEORIES}

thereby, despite services to evolutionary biology second only to Darwin's own, he failed to widen the interests of fellow-workers henceforth specialized, and perhaps rather intensified their reluctance to venture beyond their immediate problems. They too were doubtless so far right in this: their reexamination of Nature in the light of the Darwinian theory has been a great task. But now on many sides fresh chapters of evolutionary study are opening, and there are many workers who feel free, even constrained, to relate and unify the phenomena of development of plants and animals and man, the intricacies of structures and functions, variations and discases, amid which have lain our various individual trainings as organic evolutionists, with those of other evolutionists, not only the cosmic, but the social. Hence, then, the planning of this little book-which starting with the social origins of biological evolution theories, next naturally gives its main bulk to the biological theories themselves, but increasingly suggests the fruitful parallel of organic and social evolution; and now, as it draws towards conclusion, it argues with more and more insistence for the conscious renewal of this, as a working partnership henceforward. 
Science in its Relations to Labour.Note here another difference between the opening treatment of this parallelism and that with which we now draw to a close. Biological evolution as projection of a social philosophy, be this conscious or unconscious, and the resultant renewal of Nature studies as observant and inductive in the field, are alike the expression of that wisely passive mood in which, with naturalist as with poet, "we see into the life of things." But man is born to labour also; his hands have made him wise; the complex brain not merely or mainly growing up in vacuo or in abstracto nor even in encyclopædia, as one school of educationists after another has falsely thought and wrongly applied, but as we now begin to see and to apply, in intimate interaction also with the skilful and strenuous hand. Science, no less than fine art, is essentially of the working class. Like art it is craft-experience, craft-skill, craft-initiative, for the scientist more reflective, as for the artist more impassioned. Science is always obscrving, inquiring-blundering therefore also - with the prentice; is in fact a perpetual apprentice; yet skilled, and that a degree beyond the customary journeyman-speculative, experimental, inventive, with the best. Furthermore, Science is experienced, critical, 
comprehensive, with the master, and hence of such service to his large undertakings. True, the working world around us, bound all day to the wheel of labour, is hypnotized more even than is the middle class by nominal wages in money instead of real wages in life; more even in its brief leisure than the upper class by fair abstractions and fine words; and so it has lost sight of its outstanding artist leaders, its pioneering scientist ones, as they of each other. Hence as yet when new leaders emerge amid its ranks it is as amateur barristers, or amateur financiers, for the most part. Still, the reunion of arts and sciences with labour "is comin' yet for a' that," and with it a new age of social evolution, and of corresponding impulse to evolution theory also.

Scinnce in Philosopir, Education, and LIFE.-Of this incipient renewal of philosophy with social life the discussion of pragmatism is an example; but for our purpose its change of stress, from passive knowledges to active purposes, is more obviously expressed in the coming in of manual training to-day after that of scientific instruction yesterday. To-morrow we shall realize that more of free and creative art is needed to redeem industry from its mammonism and its drudgery, as science from formalism 
and cram; thereafter, with the unison of all three will come education indeed; artistic, scientific and practical; heart, head, and hand; and each calling out the others to fuller expression and development.

Concretely, how can this dream of individual development so important for the progress of science, the reading of evolution, be actually applied and brought about? So far as the sciences are concerned-and these are commonly esteemed the most difficultthe principles of its applications are ciear. While the services of each science to practical life are constantly insisted on, and in no danger of being overlooked, we far more often and readily forget the rise of each science from practical life. But the historic beginnings of geometry with measurement are again in progress in the schools. Those of astronomy with navigation have long been well taught to the sailor youth, and now the boy scout is learning, like his pastoral ancestors, to find his time by the sun, his way by the stars. Nor is this a matter of clementary education merely; here lies the main progress of research also, that higher education of the individual and the race together. Thus the problems of daily life, the emergencies of practice, called out the highest powers and achievements, from Archimedes of old to Kelvin yesterday. 
For fuller illustration-whether we state on principle more abstractly (as the rise of science from practice)-or more concretely (experimental science as proletarian experience and initiative), we cannot do better than bring to these tests some of these great leaders of science, whom the uninitiated still practically think of as magicians and wizards, much as they did of their predecessors of old. Take, then, Kelvin and Lister. Leaving aside the too common London populace view, to whom these names are impressive merely as Lords, albeit a little lower than the brewers; or the more educated London view, which would appreciate them as successive Presidents of the Royal Society, it is plain that a more real and biographic understanding of the one is as the farthest ranging of the mathematical and the experimental physicists, both pure and applied, and of the other as the renewer of modern surgery. Biographically, we understand Kelvin better in his lifelong environment of Glasgow; but only fully as we see its significance, for one thing as the great fiord of the iron shipbuilders, with their consequent dangers of deranged compass and the like, whence a well-known example of Kelvin's experimental solutions. Here, too, arose James Watt, with his Pro- 
methean control of new energies; and here fitly also in turn Kelvin to control the yet subtler and more potent spark of electricity with inventions, each a literal masterpiece of craft subtlety and of manual skill. Kelvin, whom in illustrious old age the world delighted to honour, was thus as truly the master-smith of Glasgow as had been Watt before him; so the spacious physical laboratories of every university in the world today are still above all the local extensions of William Thomson's cellar-workshop.

So Lord Lister is not to be understood primarily even as surgeon-in-chief: his place in history, immortal though it be, is also humble, humbler even than that of the plebeian branch of the profession, the barber's. For he with his antiseptic surgery is "the shepherd with his tarbox by his side"; more simply still, since full shepherd-craft is far beyond his ken, he is the "tar-boy," who waits upon the shepherd, ready to put on his dab of antiseptic wherever needed. So Pasteur was not essentially a magnate of the Legion of Honour, the member of two Academies at home, and of all abroad; not even primarily the great chemist. He was a tanner's son, born and bred, that is, amid the greatest and oldest of antiseptic processes, and developing and applying it all his life. 
More generally, in character and experience he was a Jura peasant, with all the French peasant's tenacious and tireless industry, his manifold minute economies. One rare advantage he had, and this it was which made him the world's master-peasant-the daintiest ultra-feminine eye for dirt, and as its direct and woman-like application a super-housewifely passion for cleaning. How, out of these simple conditions, these homely and humble antecedents, came discoveries and applications revolutionizing industries, agriculture, medicine, and through Lister surgery (for Lister is Pasteur's tar-boy), we have tried to tell elsewhere.

So, again, the botanist is in the university as the representative of the old herbalist, the wise woman gathering her simples. Linnæus, with his world-museum, his proudly entitled "System of Nature," albeit traveller and scholar, is essentially and traditionally a head-pharmacist, the most orderly on record of that necessarily tidiest and most careful of guilds. Jussieu, of the natural system which replaced the pharmacists' inevitably more artificial one, was the king's gardener, the man of living flowers, charged to keep the queen and her ladies in bouquets, and so getting a free hand to vary them, and an intelligent and questioning audience 
sometimes to explain them to, whereby indeed botany came into fashion. Of botany there are always these two schools-the pharmacist's and the gardener's; so its professors belong essentially to one or other, sometimes partly to both, but never thoroughly: that is too much to ask. The zoologists then? These are hunters; first out after big game with its dangers, its trophies; after birds too, and their plumage. Sometimes there comes to one the vision of St. Hubert, and then he lays aside his gun, and takes up his notebook or his camera. Darwin was one of these from his Beagle days at any rate; but before that, he was plainly of the hunter type-in fact, a born truant, the stuff true poachers are made of.

Other naturalist-hunters come down to smaller and smaller deer, next to their fleas and midges, and now to-day are hunting out the parasites within these, and to some purpose. Other naturalists, again, are fishermen, increasingly expert, their huts and pools growing into zoological stations, their nets searching the sea from its surface-plankton to abyssal dredgings; and these from Arctic to Antarctic. Plainly then, the natural sciences grow up along with practical life and ever learn from it anew. 


\section{Summary of Preceding Argument.}

Collecting now all the threads of this long discussion towards a fuller grasp of the studies of evolution, the result is plain enough. Since we cannot but project our human thought, our social progress, upon Nature, let this be more than that of past or passing phases and groups, but of the incipient social order as well, of Society at its very best, since here is the growingpoint of our own evolution. Yet we must test all anew in the field; for by our fresh glimpse of theoretic light, the whole world must be reviewed afresh, and our new light ray tested in its turn for all it may be worth, as well for all it can reveal. The true Darwinian is thus not he who longest swear's by the word of the master, and stretches some classic adaptations, say of flower and insect, towards its breaking point, but he who with a social philosophy advanced beyond that of Darwin's teacher, Malthus, goes forth anew into the field. For one this bettered social theory may be Marx's, for another Ruskin's, for another Gobinean's, Nietzsche's, and so on: each is actually yielding its biological result. Most obviously perhaps, Galton's, since his studies have been again of the population question, but in what new light! And with what fresh 
results and impulses: here with biometrician disciples, there with no less active Mendelian antagonists!

Yet, as we have seen, it is not enough to be students even of Man and Nature; we must also take our part in the world of action, if we would understand the action of life. The scientist has affirmed this intensely in his insistence on field work, on museum work, on laboratory work: but still too narrowly; even with zoological stations and experimental institutes thrown in. Here no preparation can be too full, too varied in its practicality.

Explore our region here, and any other you may have the good fortune to reach, fully, thoroughly, repeatedly, from hilltop to sea-bottom and back again. Realize your environment, your region through activity also: and this not only as an excursion-field, a playing-field, from ski to dive, it may be as hunting-field in moderate measure, but as work-field also, and above all. Go down into mine and quarry; get some turn at hewing coal, at dressing stone. The anvil, the joiner's shop, the carver's or other studio are all excellent; already coming into use for afternoons at any rate of school winters in town: in summers be out in Nature; sce and touch Nature alive. 
Go out then with the herring-fleet for one summer's holiday at least: work in the fields a spring, a harvest, and tend the horse, as well as hold the plough. Work too in the garden, and this for kitchen as well as for drawing-room; yet also for general beauty as well as detailed use. Above all, and not only for culture's sake but character's, get out with the shepherds, till you know not only something of their work, but of themselves. In each craft, at each level, learn not only something of the immediate work, but of its workers, and of their ideal aims, their culture-spirit, for there is no true work and no true worker without this: then you can choose your occupation, or rather it will choose you, and at such level as you may be fit to rise to, here of its constructive toil and skill, there of its song or story, its science or its art.

RUstic and URban as contrasted in Thought.-Of all the many occupational experiences there are but two main types, those concerned with organic and with physical nature, the rustic and the urban, in a word, the vital and the mechanical. Here is the main contrast of town and country, in their characteristic experiences, their essential occupations; and the resultant interpretative evolutionary stand- 
points which we are seeking will be essentially these two, will be characterized by familiarity with the processes of mechanism and of growth respectively. The town intellect is of course the swifter, the clearer, more precise and definite, the more assertive and authoritative accordingly; hence its characteristic contributions to knowledge and to social progress, and the satisfaction with which it proclaims these, and with which it applies these, doubting nothing, to the education of the rustic world, which undoubtedly comes forward accordingly-but into town. That surviving slow, heavyfooted peasant, behind his plough, or gazing over the fence at his growing corn-what blank stupidity! That shepherd striding back from the snow-drift with the lamb within his plaid-what pretty sentiment! That is what the mechanicals and moneyers and paperists of cities see in these silent servitors of Life.

Needed Renewal of Rustic Point of VIew.-Suppose, however, that they one day become articulate; that Pasteur is not the last thinking peasant, but an initiative one, a forerunner, already followed by the breeders, cultivators, eugenists of previous pages. With such contributions to the work of experimental evolution will there 
not also be forthcoming corresponding contributions to its theory? This will be neither in terms of the mere mechanomorphism of the physicists and chemists, nor of the puzzled mysticism of vitalist philosophers as yet befogged by their urban environments or bewildered by reaction from it. It will be in terms of biology proper, and its processes, of nutrition and reproduction, of metabolism and growth. Each science is but an aspect of the whole, a pictured facet of Nature's unity, but it has its own categories, its own values. No one of the main sciences, be they the objectivephysical, biological, social; or the subjective-ethic, psychologic, æsthetic-is intelligibly reducible into the concepts of any other, those of mechanics, physics, chemistry, despite their long exaggerated pretensions, as little as any-(though their parallelisms may and should be sought; that is a practicable and legitimate inquiry). It tells us nothing of the rsthetic value of scarlet blossom, of golden sunset, of summer green, that these have such and such relations of wave-length, interesting in the physical laboratory though that be. By all means let us correlate brain growth with mind; but the life of intelligence, idealism, imagination, would have none the less its psy- 
chological independence were the chemical formulæ of every brain metabolism published to-morrow.

So then for biology. Its theory of life, of evolution must be in its own terms, of function and form, and free therefore from absorption into the lower physical order, as from exaggeration into the higher ethical and political one. The latter mode of statement is the transcendentalist's old-fashioned fable; the former is a materialistic fable. But to correlate and parallelize the biological with the physical order, as with the social, whenever we can: that is a different matter.

Above all, however, let us as naturalists see that we grasp not only the mechanical and urban point of view but the rustic and physiological one. 


\section{CHAPTER VIII}

THE EVOLUTION PROCESS ONCE MORE REINTERPRETED

The evolution process again reinterpreted-Antithesis of vegetation and reproduction; applications in the plant world-Justification from rustic experience- Evoluticn in the animal kingdom-Summary and conclusions.

Thovgri we must leave that rich mastery of the evolution secret we once hoped for to the successors we would fain send out so much better equipped, can we not meantime be going at least a step or two farther before we leave life's wonder-feast-readers and writers alike? Here, then, in preceding chapters have been offered summaries and interpretations not a few: some are masterkeys, tested by long and world-wide use, others awaiting trial and verification; but most, surely, of some applicability. In conclusion, and not as dogmatically pressed, but suggestively offered, the reader may be interested in some brief outlines of a different reinterpretation of the evolution processone not as yet fully published, still less seriously criticized by other biologists; one suggested at the close of our "Evolution of 
Sex," outlined in scattered papers and lecture syllabuses, and with its beginnings compressed into a too dry abstract at the close of the old "Britannica" article "Variation and Selection," many years ago.

Let us start from the acceptedly known, from Darwin's natural selection, and this of "indefinite" variations, and express the problem before us in the words of Weismann: "We certainly cannot remain at the purely empirical conception of variability and heredity as laid down by Darwin in his admirable work. In the first enthusiasm over the newly discovered principle of selection, the one factor of transformation contained in this principle has been unduly pushed into the background to make way for the other more apparent and better known factors. The first indispensable factor, and perhaps the most important in any case, in every transformation is the physical nature of the organism itself."

This inquiry into the organismal springs of variation must lead us far. For Weismann these have led especially into his subtle studies of the germ-plasm; but obviously also they involve a fresh survey of the leading types of variation as we see them developed by plant and animal forms. Naturalists are no longer so much setting out from the anal- 
ogy of human selection upon domestic animals and cultivated plants, and reasoning from the accumulation of their varietal differences up to what seem to correspond to species or sometimes even genera in Nature, and thence arguing on Lyell's uniformitarian principle, for the analogous cumulative natural selection through geological time, of the characters of larger groups, genera, orders, classes and the rest. We have simply now to group our types of variation, and to consider them from the standpoint of general physiology as far as 'we know it, and independently of these fascinating hypotheses of agriculture and geology.

Vegetation and Reproduction, AND THEIR ANTITHesis.- The largest view of physiology, one peculiarly obvious to the botanist, from the vivid distinctness of flowers and foliage, but denied by none for animals and man as well, is that which treats the functions of living beings as of two main kinds; grouping on the one side respiration, irritability, and all the other actirities of the individual in its self-maintaining life, and then setting over against the whole of these the great function of the species-maintaining life, reproduction. Weismann's main work has been to emphasize this distinction, especially from the side of the intimate morphol- 
ogy of the germ-cells; while some of the best chapters of Spencer's "Principles of Biology" are those in which, after pointing out its intelligibility in terms of the principle of conservation of energy, he elaborates the antithesis of nutrition and reproduction by reference to many plant and animal forms. Yet though the principle is one familiar since the dawn of physiology, its applications are still far from exhausted. "While philosophers are disputing over the government of the world, hunger and love are performing the task," says Schiller; and our "Evolution of Sex" is essentially an elaboration of one great aspect of this theme.

Applications towards Interpretation of the Plant World.-Let us begin with the origin of the flower, which all agree in regarding as a shoot modified for reproduction. But it is also shortened, as compared with a vegetative shoot; then why? By natural selection from two other alternative variations?-one like the vegetative shoot, and the other lengthened farther still? These are imaginable as forms; there is no morphological absurdity about them: yet we may be fairly sure they never existed at all, and so have not been selected. How so? They are excluded by the physiological explanation of inevitable shortening; since 
the organic expenses of the onset of the reproductive function necessarily check the vegetative ones.

Similarly for flower groupings, the "forms of inflorescence." The simplest form is the long flowery stem, each flower with its own stalk, like the foxglove spire; but such fine "racemes" are comparatively uncommon. Often the flower-stalks are arrested, and we have the "spike," as in the mullein, goldenrod; or again it may be the main stem which stops short, leaving the minor stalks to grow and separate the flowers, as in the "umbel" of cowslip (and even primrose), of ivy and of the parsley and hemlock tribe without number. But in one great order, and that significantly one of the most successful in the whole world-flora, the daisy and dandelion order, the axis of inflorescence is arrested in growth until it is a flat disk, and the flower stems have disappeared altogether, so that we have the crowded "head" of flowers, their own individual development greatly reduced, so characteristic of the Composites. This principle of flower-heading is constant in not a few orders otherwise widely distinct, like willows and plantains; and appears here and there among other orders, e.g. in seapinks, and even among labiates and roseworts. It is noticeable that such forms, like 
the Composites themselves, are commonly vigorous and hardy growers, as may reasonably happen, the saving through subordination of the reproductive shoots being applicable to help on the vegetative ones. In the figs, a peculiarly vigorous and varied tribe, the arrest of the inflorescence goes so far as to make this like an inturned glove-finger, a hollow pouch instead of the usual ascending cone, and with the tiny florets inside accordingly.

Now, returning to the individual flower, it is an interesting fact that this process of reduction of the great axis of inflorescence from shoot to head, and thence to fig, is repeated on that small axis of the flower, which the beginner in flower dissection is apt to forget altogether. This, however, may be easily made out as a distinct case, in the buttercup, or best of all, in the magnolia, and the sepals and petals, the stamens and carpels, may all be seen to arise upon this in ascending order, like the young crowded leaves of a vegetative bud. This simple ("hypogynous") arrangement, however, goes farther in the ("perigynous") strawberry, where, instead of a short conical shoot, we have now the axis disk-shaped, recalling the composite head; while even the hollow fig finds its parallel in the many flowers which, 
like rose or daffodil, have become "epigynous," i.e. with their ovaries, now sunk at the bottom of a cup, the arrested and overgrown apex. Passing now to forms so utterly distinct as the fungi, we find the same process repeating itself, the essential reproductive organs sinking from cone to disk, and thence into cup or pouch, like fig and rose, indeed closing up completely.

Now, the farther we go in our studies of flower anatomy, the more we find of this subordination of the vegetative life by the reproductive; witness the reduction of the number of petals, stamens and carpels from indefinite to few. See, however, what all this amounts to. All these changes and others, in fact the most important of floral variations, the big lifts distinctive for the evolution of orders, are thus seen no longer as indefinite, and hence dependent on external selection for their guidance; but, on the contrary, as parallel and definite, since determined through the continued checking of the vegetative process by the reproductive, and thus pressed along parallel and definite grooves of progressive change. But if this be so, the importance we have been taught by Darwin to assign to natural selection becomes greatly changed-from selecting and accumulating supposed indefinite variations, 
to that mainly of retarding definite ones, after their maximum utility has been independently reached!

The same simple conception unlocks innumerable problems of floral morphology, large and small alike, from the inevitable development of angiosperm from gymnosperm (by the continuous subordination in vegetative development of the reproductive carpellary leaf) to the origin of many of the refined minor "adaptations" of the dominant school. Adaptation to insects, to wind also, thus falls from a primary to at most a very secondary place as a factor in the evolution of flowers; for the characteristics usually ascribed to the selective action of wind and insects constantly appear at the extremes of the relatively more vegetative and more floral series which are discernible more or less in every alliance, great and small. Witness among the vast group of monocotyledons, the extremes of the grasses and the orchids respectively; or in a single genus, say Senecio, its weedy groundsels and gorgeous cinerarias.

Justification of the Present Theory In Rustic Experience.-Now this whole theoretic reinterpretation: whence is it? Again from experience. With the resources of a great garden, at any rate with a gardener 
to do all the work for us, we come out at leisure, and notice the flowers, here visited by insects, and there swaying in the wind, and fancy their forms thus fashioned, adapted, selected from without: our town friends are readily convinced of this, and their assent strengthens our convictions and stimulates our researches anew. But when we set about making a garden for ourselves, and labour with our own hands, new perspectives open, fresh points of view appear, above all that of growth; and this-even at its very simplest, the wide growth-contrast of lilies and rushes, of weeds and flowers-reinterprets the differences we formerly ascribed to form-as scientists we thought, as leisure class we now see; and essentially urban at that. For while in our town herbaria we distinguish grasses and orchids essentially by their post-mortem structure, the gardener is the fuller scientist, the true physiologist, knowing their differences as lives; the grass so vegetative that cattle and farm and city all live upon its surplus, the orchids so splendidly floral that we may easily spend upon their culture more than our grass-field can earn.

If this rustic point of view be seized, and the urban and mechanical one correspondingly subordinated, the present theory will 
work itself out just as fully and freshly as did the selectionist game of thought: if not, it remains useless to argue for it. The eye sees only what it brings the means of seeing.

Re-interpretation of the ANimal KingDOM.--Instead then of opening new botanical sections, of which each would really require a chapter, sometimes a whole volume, now dealing with the interpretations of flowers and of fruits, and again with the great peculiarities of habit-evergreens, thorny plants, climbers and so on, let us rather ask: Can any such physiological interpretations be applied to a survey of the animal kingdom? Its problems are obviously far more intricate and varied: yet the result is scarcely less definite or comprehensive. In the outline of our restatement of the cell-theory as a "theory of the cell cycle" (Chapter III) we have already interpreted such main forms of Protozoa as the rhizopods, the gregarines, the infusors, not from without, as the empirically selected products of spontaneous variations among indefinite possibilities, but from within, as simply the preponderatingly amœboid, resting, and motile phases of the cell-cycle, three forms determined by the properties of protoplasm itself.

This conception of life-histories, as physiological and not merely structural, ration- 
alizes our animal no less than our vegetable classifications. Thus the greatest of all steps in morphological progress, that from the unicellular Protozoa to the multicellular Metazoa, is plainly not due to the external selection of the more individuated and highly adapted Protozoan species, but is understood from within, as the union of relatively embryonic and unindividuated cells into an aggregate in which each becomes diminishingly competitive as regards its fellows, and increasingly subordinated to the social whole; while within the body thus developed, a series of cells remains relatively undifferentiated as the essential sex organ, female or male (preponderatingly anabolic or katabolic) as the case may be. And as the natural variations and divergences of plants may be most conveniently summed in terms of vegetative and floral preponderance respectively, so those of animals similarly fall into the broadly recognizable contrast of passive and active, sedentary and errant, pcrpetually renewing itself in every group. Hence the contrast of fixed anenome or coral and swimming jelly-fish or ctenophore, of stony tubeworms and naked creeping or swimming worms, or the contrast, yet series, of fixed crinoid and boring urchin with creeping starfish and active sand-star; or again of passive 
barnacle and active shrimp, of sluggish beetle and nimble gnat; or again within the same orders, as moth and butterfly-always the same dichotomy of passive and active. Here essentially lies the secret of the divergence between ascidian and vertebrate, to take a great difference, or that between toad and frog for a small one; or again this is the main contrast between reptile and bird, Diplodocus and swallow. This lies within the perpetual redifferentiation of these, witness, among reptiles, the sluggish and often colossal tortoises, yet the active and supple snakes; and these (of course) again differentiating anew, here the huge and passive python, and there the small and nimble fer de lance. Once more, for birds, see the contrast of the massive pedestrian dodo with his pigeon cousins; or of giant chickens like the ostrich and emu tribes with exquisite but tiny adults, say the hummingbirds. The kinship of elephant and coney, the contrast of stony glyptodon and gigantic sloth with nimble lemur and agile monkey, and again of bear and dog, of $\mathrm{dog}$ and cat, of sheep and goat, are thus re-interpreted together, no longer as for the early Darwinians as so many machine-like combinations of innumerable indefinite variations externally selected from among yet more innumer- 


\section{THE EVOLUTION PROCESS}

able ones, nor even among a more limited number of ancestral possibilities, but as so many forms thrown from the rhythmic oscillation of the loom of life. Each of these types or species, with its exquisite intricacy of detail and individuality of pattern, its marvellous correlation of organs, is thus a new unity created from within by its own interior play and balance of vegetative and reproductive forces, its inner predominances here of anabolisms and there of katabolisms. Growth and arrest, giant and dwarf, rest and movement, sleep and waking, even female, and male are contrasts all physiologically akin; and this single and simple rhythm of metabolisms, of passivities and activities goes on into compound and recompounding rhythms, like the figures of the pendulograph. The forms of life are thus distinct and definite, because harmoniously unified. They have a certain stability, great or small, yet they are anew transformable, like musical variations, like singing flames. Thus from within are spun and woven and shaped the manifold garments of Life, always simple, though ever more and more Protean. Our clue to the secret of variational evolution thus holds good, is one and the same from the ancient contrast of plant and animal up through the great lifts of evolution, and down 
through its ever recurrent falls; and if it applies equally to the origin of classes and orders, of genera and of species, why not also to the varieties and mutations which naturalists are discussing, for the most part too externally, at the present day?

Summary and Conclusions.-As in plants the species-maintaining functions preponderate over the individual ones, so that from annual to agave the plant must flower although it die, so the same preponderance appears in animals. The "self-interest" in which the utilitarian economists found the all-sufficient spring of action, and which naturalists too long and too uncritically adopted from these (whence Huxley's "gladiator's show"), turns out to be enlightened by family interest, species interest, however sub-conscious. The traditional primary insistence upon the individual competition for food, and the very subordinate and tardy recognition of the importance of sexual and social co-operation, are also traceable to a confusion of thought-that of putting the nutritive factor "in the first place" because it precedes the reproductive in time; whereas the organism enters upon reproduction, and so cedes the preponderance, "the first place," to the species-regarding functions. That increase of the reproductive sacrifice 
which first makes the mammal, and then marks each of its distinctive uplifts of further progress (from monotreme to marsupial, and thence to placental), that increase of parental care, that frequent appearance of sociality and co-operation which, even in its rudest forms, so surely secures the success of the species attaining it, be it mammal or bird, insect or even worm-all these survivals of the truly fittest, through love and sacrifice, sociability and co-operation simple to complex-need far other prominence than they can possibly receive even by some mildewing attenuation of the classic economic hypothesis of the progress of the species essentially through the internecine struggle among its individuals at the margin of subsistence.

Our theory thus furnishes a re-interpretation of the forms attained by plants and animals comparable to that afforded by the received hypothesis (and, if space allowed, traceable into no less refinement of detail), yet with an essentially allied view of the process and factors of organic evolution as a whole. Most briefly stated, the view of evolution thus reached is that of definite variation: its branchings essentially dichotomous rather than indefinite, with progress essentially through the subordination of individual 
struggle and development to species-maintaining ends. The ideal of evolution is thus no gladiator's show, but an Eden; and though competition can never be wholly eliminatedthe line of progress is thus no straight line but at most an asymptote - it is much for our pure natural history to see no longer struggle, but love as "creation's final law."

Natural selection remains still a vera causa in the origin of species; but the function ascribed to it is practically reversed. It exchanges its former supremacy as the supposed sole determinant among practically indefinite possibilities of structure and function, for the more modest position of simply accelerating, retarding or terminating the process of otherwise determined change. It furnishes the brake rather than the steam or the rails for the journey of life; or in better metaphor, instead of guiding the ramifications of the tree of life, it would, in Mivart's excellent phrase, do little more than apply the pruning-knife to them. In other words, its functions are mainly those of the third Fate, not the first; of Siva, not of Brahma. 


\section{BIBLIOGRAPHY}

THIs list of books has been made longer than in most of the volumes of the series, and for three reasons. (1) The scientific study of organic evolution is still very young. There are many uncertainties, there is rapid progress along diverse lines, there are not a few moot and controversial points. We wish to recognize this by giving a representative set of references, indicative of various schools of evolutionists. (2) We have met, personally and in correspondence, a large number of able-minded workers - face to face with evolution problems, e.g. as breeders or as gardeners, as medical practitioners or travellers-who had thought long, and sometimes carefully. over particular sets of facts, but remained entirely unaware that these had been threshed out, not once or twice, but many times over. Not that this refuses value to any new observation or thought, but it suggests that some literary research may be reasonably expected from those who hav' reached what they feel sure is an upsetting conclusion. We hope that this little book and this list will facilitate that research. (3) The problem of Becoming is not particular to any one science. It is social as well as cosmic and organic. Therefore in our list we have not forgotten that Darwinism touches the Humanities.

* Those marked with one asterisk may be the best books for a student to begin with. But the best beginning is alway's where the personal tendril fixes.

** Those marked with two asterisks record important postDarwinian investigations.

It is too difficult to affix marks to suggestive thoughtsshall we say of Bergson, for instance-which may turn out to be of much more value than many concrete studies. The idea of confining "research" to the objective is grotesque.

*** Those marked with three asterisks are "classics."

Barley, L. H.- "Plant-breeding." 3rd Edition, 1904. [A valuable and practical study of variation and selection in cultivated plants.] See also "The Survival of the Unlike." 1896.

Baldwin, J. Mark.- "Development and Evolution." 1902. [Expounds the author's theory of the indirect evolu- 


\section{BIBLIOGRAPHY}

tionary importance of modifications.] See also "Darwin and the Humanities." 1909.

**Bateson, W.- "Materials for the Study of Variation." 1894. [A remarkable collection of data relating to certain kinds of variation, especially important in its evidence of discontinuous variation; a book to consult and to reckon with, rather than to read, but with a stimulating introduction.]

"The Methods and Scope of Genetics." 1908. [An illuminating introductory lecture, suggesting to an educated reader something of the import and the fascination of Mendelian experiments, by which the author has achieved much.]

**___ "Mendel's Principles of Heredity." 1909. [The most important statement of what has been achieved by the experimental study of genetics.]

Bergson, Henri.- "Creative Evolution." 1911. Translation of "L'Evolution créatrice." 1907. [One of the most profound and original contributions to the philosophical consideration of the theory of evolution.]

Botrer, Samdel.- "Evolution: Old and New." 2nd Edition, 1882. [A keen-witted criticism of orthodox Darwinism.] See also "Life and Habit." 1878. [Strong statement of Lamarckian views.] "Luck or Cunning." 1887.

*ClODd, E.-"Story of Creation, a plain account of Evolution." 1888. [A useful introduction.]

"Pioneers of Evolution." 1897. [A very interesting historical sketch.]

CoE, C. C.- "Nature versus Natural Selection." [Extreme position, denying the efficacy of Natural Selection.]

Conn, H. W.- "Method of Evolution." 1900.

Cope, E. D.- "The Primary Factors of Organic Evolution." 1896. [Strong exposition of Lamarckian and bathmist position.] See also "The Origin of the Fittest." 1887.

**Cunnot, L.- "La Genèse des espèces animales." 1911. IA masterly book, giving a fresh and careful account of the present state of kllowledge in regard to the origin of animal species.]

***Darwin, Charles.- "Origin of Species" (1859); "Variation of Animals and Plants under Domestication" (1868); "Descent of Man" (1871).

Divenport, C. B.- "Experimental Morphology." 1897. [A valuable uncompleted treatise on the plasticity and modifiability of the organism.]

"Statistical Methods in the Study of Variation." 2nd Edition, 1904. [A useful introduction to biometrics.] 
**Davenport, C. B.- "Inheritance in Poultry." 1906. [A fine series of experiments in breeding.]

**Delage, Yves.- "L'Hérédité et les grands problèmes de la biologie générale." 1895; 2nd Edition, 1902. [A great book, discussing with scholarship and impartiality the chief problems of biology; Lamarckian on the wholo and against Weismann; with a detailed bibliography.] See also an excellent short book by Delage and Goldsmidt, "Les Théories de L'Evolution." 1809.

DEPÉRET, C.-The Transformations of the Animal World." 1909. [A useful concrete study of the actual history of the past.]

*Doncaster, L.-- "Heredity in the light of recent Research." 1910. [A pithy and clerr introduction.]

Driesch, Hans.- "Science and Philosophy of the Organism." Gifford Lectures in the University of Aberdeen. 2 vols., 1908. [A deep and original vindication of vitalism, difficult for most readers; a fine gymnasium for intellectual athletes.]

Emer, G. H. Th.-_"Organic Evolution." 1890. [Lamarckian and Goethian, with a theory of orthogenesis, or progressive variation along a definite line.]

**Ewart, J. Cossar.- "Penycuik Experiments." 1899. [An account of important breeding experiments bearing on hybridization, reversion, variation, etc.]

"Fifty Years of Darwinism: Modern Aspects of Evolution." Centennial addresses in honour of Charles Darwin before the American Association for the Advancement of Science, 1909. [An exceedingly interesting and valuable series of lectures on Darwinism, by numerous authorities.]

***Galton, Francis.-"Natural Inheritance." 1889. [A classic book, applying statistical methods to the st'udy of inheritance, and expounding important generalizations, such as Filial Regression.]

Geddes, Patrick.- "Variation and Selection" in "Fncyclopædia Britannica," 9th Edition. "Darwinian Theory," "Evolution," in "Chambers's Encyclopædia." "Chapter's in Modern Butany." 1893.

Grddes, P., and Thomson, J. Arthur.- "The Evolution of Sex." 1889. Revised Edition, 1901. [A discussion of sexual selection, the reproductive factor in evolution, the physiological interpretation of sex, and so forth. The general thesis is that maleness and femaleness are expressions of alternatives in the regulated rhythm of metabolism.]

Groos, K.- "The Play of Animals." Translation, 1900. [A very suggestive book, a proof of the biological importanco 
of play, with an important contribution to the theory of sexual selection.]

Golick, J. T.-_Evolution, Racial and Habitudinal." 1905. [Elaborate discussion of isolation as a factor in evolution.]

***HAECKEL, ERNST.- "Generelle Morphologie." 2 vols., 1866. A classic work, to be placed beside Spencer's "Principles of Biology." It is now out of print, but part of it has been recently re-issued.]

"Natural History of Creation." English translation, 1870. A picturesque book that has passed through many editions. The early chapters give a vivid account of the rise of the evolution theory. The statement of "the evidences" had a deserved success in vindicating the validity of the evolution formula.]

*Headley, F. W.- "Life and Evolution." 1906. [Picturesque concrete illustrations of the problems of evolution.] See also "Problems of Evolution." 1900.

Hutтon, F. W.- "Darwinism and Lamarckism." 1899.

Hoxley, T. H.-Article "Evolution" in "Encyclopædia Britannica," 9th Edition.

***___ "American Addresses." (1877.)

Jenkinson, J. W.- "Experimental Embryology." 1909. [A very able treatise on the external and internal factors in development. With a valuable discussion of Vitalism and Driesch's contributions thereto.]

**Johannsen, W.- "Ueber Erblichkeit in Populationen und in reinen Linien." 1903. [Important experiments on beans, barley, etc.; notably on the isolation of "pure lines."] See also "Die Elemente der exakten Erblichkeitslehre." 1909.

Jordan, D. S., and Kelloga, V. L.- "Evolution and Animal Life." 1907. [Very interesting concrete studies of evolution problems.]

KELLOGG, V. L.- "Darwinism To-day." 1907. [A remarkable book, with the frankest and friendliest reconsideration of Darwinism, in the light of post-Darwinian progress, by a thoroughly competent critic. With abundant references to and quotations from recent evolutionary literature.]

KropotKin, P.- “Mutual Aid a Factor of Evolution." 1902. [A valuable account of the inadequately appreciated "other side" of the struggle for existence.]

LANkester, E. RAY.- "The Advancement of Science." 1890. [Important essays on "Degeneration: a chapter in Darwinism," "A Theory of Heredity," "The History and Scope of Zoology," etc.] See also "The Kingdom of Man." 1906. 
*Lock, R. H.--"Recent Progress in the Study of Variation. Heredity, and Evolution." 1908. [A useful introduction to recent researches.]

Lotsy, J. P.- "Vorlesungen über Descendenztheorie." 2 vols. 1907 and 1909. [A scholarly text-book of evolution.]

*Marshali, A. Mrlnes.-."Lectures on the Darwinian Theory." 1894. [An admirably clear and vigorous presentation of Darwinism and of the evidences of evolution.] See also "Biological Lectures and Addresses." 1894.

Marshall, F. H. A.- "The Physiology of Reproduction." 1910. [A masterly work with many bearings on evolution problems.]

Menz, J. T.--"History of Scientific Thought in the Nineteenth Century." 2nd vol., 1904. [The finest exposition of the import and development of "the genetic view of Nature." A work of magistral scholarship and deep insight.]

*Metcalf. - "Outline of the Theory of Organic Evolution." 1904. [A useful introduction.]

**Morgan, C. Lloyd.- "Habit and Instinct." 1896. [The most important book on instinct.] See also "Animal Life and Intelligence" (1890); revised edition, entitled "Animal Behaviour." 1900.

Morgan, T. H.-_Evolution and Adaptation." 1903. [An important critical essay.]

**__-"Experimental Zoology." 1907. [An indispensable account of recent experimental researches bearing on evolution. A worthy supplement to Semper's great work, "Animal Life."]

NAGELI, C. von. - "Mechanisch-physiologische Theorie der Abstammungslehre." 1884. ['The most effective presentation as yet given of the theory of organismal variation in definite directions.]

Osвorn, H. F.- "From the Greeks to Darwin." 1895. [A vivid historical sketch.]

PACKARD, A. S.- "Lamarck, his Life and Work." 1901. [A scholarly account of Lamarck's theory of evolution.]

**Pearson, Karl.- "The Grammar of Science." 2nd Edition, 1900. [The biological part includes an invaluable discussion of evolution problems from the biometrician's point of view.]

Perrier, E. - "Philosophie zoologique avant Darwin." 1884. [A scholarly account of pre-Darwinian evolutionists and generalizers.]

*Puate, L.- "Selektionsprinzip und Probleme der Artbildung. Ein Handbuch des Darwinismus." 3rd Edition, 1903. 
[A scholarly and lucid text-book of evolution, in part Lamarckian.]

**Potlton, E. B.-“Essays on Evolution, 1889-1907." 1908. [Very valuable critical and historical studies, and applications of the theory of evolution to mimicry and protective coloration in insects.]

*__ "Charles Darwin and the Theory of Natural Selection." 1896.

**Przibram.-Experimental Zoology, Part I, Trans. 190 S. [Acute discussion by an expert investigator of the results of experimental embryology.]

*Punnetr, R. C.-“"Mendelism." 2nd Edition, 1905. [An unsurpassed exposition by an expert investigator.]

RADL, EM.- "Geschichte der biologischen Theorien." 2nd Part, 1909. [An able historical and critical discussion of biological theories and of Darwinism in particular.]

Reid, G. Archdall.- "The Laws of Heredity." 1910. See also "The Principles of Heredity." 1906.

Rignano, E.-."Ueber die Vererbung erworbener Eigenschaiten." 1907. [A careful discussion of the question of the transmission of acquired characters.]

Romanes, G. J.- - Darwin and after Darmin." 3 vols., 189297. [A valuable exposition of Darwinism with many original suggestions and criticisms, and with an important discussion of isolation.]

Schnmider, K. C.- "Einführung in die Descendenz-theorie." 1906. [A fresh and lucid statement of the evidences of evolution, with a short account of the chief theories.]

Semon, R.- "Die Mneme als erhaltendes Princip im Wechsel des organischen Geschehens." 1904. [A modernized Lamarchism.]

**Semper, Kart. - "The Natural Conditions of Existence as they affect Animal Life." 1881. [One of the finest and soundest of biological books, with an educative sceptical reserve, discussing in particular the influence of the environment, but before the question of the transmission of somatic modifications had become urgent.]

Beward, A. C. (Editor).- "Darwin and Modern Science." 1909. [A valuable series of essays by representative biologists.]

****Spencer, Herbert.- "Principles of Biology." 2 vols., London, 1866-63. Revised Edition, 1908. [This was, in its time, a macterpiece, a magnificent "materialism," an incomparably acute analysis and re-synthesis of the biology of the day. The re-edition was, in our judgment, less valuable, because it did not really assimilate the progress that had been made.] 
Sterne, Cartes [Ernst Kratse].- "Werden und Vergehen." 3rd Edition, 1886. [A remarkably vivid book giving an account of the great steps in evolution.]

"Die allgemeine Weltanschauungen." 1889. [An interesting account of the old interpretations of the cosmos.].

Sutron, J. Brand.- "Evolution and Disease." 1890. [A very suggestive contribution to the natural history of disease. Comparison of pathological and normal changes of structure.] See also "Introduction to General Pathology." 1886.

Thomson, J. Arthor.- "The Science of Life." 1899. short general survey of the development of biology.] "The Study of Animal Life." [See examples of the web of life, and the chapter on the evolution of evolution theories.]

"Heredity." 1909. [An exposition of the problems of heredity and an estimate of the various contributions, biometrical, experimental and cytological; and with an extensive bibliography.]

*__ "Darwinism and Human Life." 1909. [Six lectures introductory to the study of evolution problems.]

**Tower, IV. L.- "Evolution in Chrysomelid Beetles." 1906. [An important investigation on environmental factors serving as stimuli to germinal variations.]

**Varignt, H. Df.-“"Experimental Evolution." 1892. [An admirable introduction to the experimental study of evolution.]

*Vernon, H. M.- "Variation in Animals and Plants." 1903. [A useful introduction to the study of variation and especially to the biometric point of view.]

**VRIEs, H. De.- "Species and Varieties, their Origin by Mutation." 1905. [A vivid series of lectures expounding the author's mutation theory.]

**_- "The Mutation Theory." Translation. 2 vols., 1910 and 1911. [A detailed account of the author's remarkable experiments and observations on the origin of species in the vegetable kingdom.]

WALKer, C. E.- "Hereditary Characters and their Modes of Transmission." 1910. [A very interesting endeavour to harmonize the results of the Mendelian experiments with the observations of the biometricians.]

"Wallace, Alfred Russel.- "Darwinism." 1889. standard book of great value and interest, e.g. in showing how the author's position differs in certain respects from Darwin's.]

**** 1871. "Contributions to the Theory of Natural Selection.". 


\section{6}

\section{BIBLIOGRAPHY}

*Weismann, Adgust.- "The Evolution Theory." 2 vols., 1904. [Expressing the final convictions of a veteran evolutionist, with a wealth of fact-illustration, which remain, whatever be the verdict as to theory.]

**__ "The Germ-plasm." Contemporary Science Series. 1893.

**__ "Essays on Heredity and Kindred Subjects." 1891-92.

Wrlson, E. B.- "The Cell in Development and in Inheritance." 2nd Edition, 1900. [An indispensable book characterized by its high standard of accuracy and by its maturity of judgment.] 


\section{THE HOME UNIVERSITY LIBRARY of Modern Knowledge}

Is made up of absolutely new books by leading authorities. The editors are Professors Gilbert Murray, H.A.L. Fisher, W. T. Brewster, and J. Arthur Thomson.

Cloth bound, good paper, clear type, 256 pages, per volume, bibliographies, indices, also maps or illustrations where needed. Each complete and sold separately. Per volume. 75 cents.

[Order

\section{LITERATURE AND ART.}

Number]

73. EURIPIDES AND HIS AGE. By Gilbert Murray, Regius Professor of Greek, Oxford.

101. DANTE. By Jefferson B. Fletcher, Columbia University. An interpretation of Dante and his teaching from his writings.

2. SHAKESPEARE. By John Masefield. "One of the very few indispensable adjuncts to a Shakespearean Library."-Boston Transcript.

81. CHAUCER AND HIS TIMES. By Grace E. Hadow, Lecturer Lady Margaret Hall, Oxford; Late Reader, Bryn Mawr.

97. MILTON. By John Bailey.

59. DR. JOHNSON AND HIS CIRCLE. By John Bailey. Johnson's life, character, works, and friendships are surveyed; and there is a notable vindication of the "Genius of Boswell."

83. WILLIAM MORRIS: HIS WORK AND INFLUENCE. By A. Clutton Brock, author of "Shelley: The Man and the Poet." William Morris believed that the artist should toi" for love of his work rather than the gain of his employer, and so he turned from making works of art to remaking society.

75. SHELLEY, GODWIN AND THEIR CIRCLE. By H. N. Brailsford The influence of the French Revolution on England. 
70. ANCIENT ART AND RITUAL. By Jane E. Harrison, LL. D., D. Litt. "One of the 100 most important books of 1913."Nen York Times Revien.

45. MEDIEVAl ENGlish LiTERATURE. By W. P. Ker, Professor of English Literature, University College, London. "One of the soundest scholars. His style is effective, simple, yet never dry."The Athenaeum.

87. THE RENAISSANCE. By Edith Sichel, author of "Catherine de Medici," "Men and Women of the French Renaissance."

89. ELIZABETHAN LITERATURE. By J. M. Robertson, M. P., author of "Montaigne and Shakespeare," "Modern Humanists."

27. MODERN ENGLISH LITERATURE. By G. H. Mair. From Wyatt and Surrey to Synge and Yeats. "One of the best of this great series."-Chicago Evening Post.

61. THE VICTORIAN AGE IN LITERATURE. By G. K. Chesterton.

40. THE ENGLiSH LANGUAGE. By L. P. Smith. A concise history of its origin and development.

66. WRITING ENGLISH PROSE. By William T. Brewster, Professor of English, Columbia University. "Should be put into the hands of every man who is beginning to write and of every teacher of English that has brains enough to understand sense." $-N e$ D York Sun.

58. THE NEWSPAPER. By G. Binney Dibble. The first full account from the inside of newspaper organization as it exists to-day.

48. GREAT WRITERS OF AMERICA. By W. P. Trent and John Erskine, Columbia University.

93. AN OUTLINE OF RUSSIAN LITERATURE. By Maurice Baring, author of "The Russian People," etc. Tolstoi, Tourgenieff, Dostoieffsky, Pushkin (the father of Russian Literature), Saltykov (the satirist,) Leskov, and many other authors.

31. LANDMARKS IN FRENCH LITERATURE. By G. L. Strachey, Scholar of Trinity College, Cambridge. "It is difficult to imagine how a better account of French Literature could be given in 250 pages."-London Times.

64. THE LITERATURE OF GERMANY. By J. G. Robertson.

62. PAINTERS AND PAINTING. By Sir Frederick Wedmore. With 16 half-tone illustrations.

38 ARCHITECTURE. By Prof. W. R. Lethaby. An introduction tc he history and theory of the art of building. 
68. DISEASE AND ITS CAUSES. By W. T. Councilman, M. D., LL. D., Professor of Pathology, Harvard University.

85. SEX. By J. Arthur Thompson and Patrick Geddes, joint authors of "The Evolution of Sex."

71. PLANT LIFE. By J. B. Farmer, D. Sc., F. R. S., Professor of Botany in the Imperial College of Science, London. This very fully illustrated volume contains an account of the salient features of plant form and function.

63. THE ORIGIN AND NATURE OF LIFE. By Benjamin M. Moore, Professor of Bio-Chemistry, Liverpool.

90. CHEMISTRY. By Raphael Meldola, F. R. S., Professor of Chem. istry, Finsbury Technical College. Presents the way in which the science has developed and the stage it has reached.

53. ELECTRICITY. By Gisbert Kapp, Professor of Electrical Engineering, University of Birmingham.

54. THE MAKING OF THE EARTH. By J. W. Gregory, Professor of Geology, Glasgow University. 38 maps and figures. Describes the origin of the earth, the formation and changes of its surface and structure, its geological history, the first appearance of life, and its influence upon the globe.

56. MAN : A HISTORY OF THE HUMAN BODY. By A. Keith, M. D., Hunterian Professor, Royal College of Surgeons, London. Shows how the human body developed.

74. NERVES. By David Fraser Harris, M. D., Professor of Physiology, Dalhousie University, Halifax. Explains in non-technical language the place and powers of the nervous system.

21. AN INTRODUCTION TO SCIENCE. By Prof. J. Arthur Thomson, Science Editor of the Home University Library. For those unacquainted with the scientific volumes in the series, this would prove an excellent introduction.

14. EVOLUTION. By Prof. J. Arthur Thomson and Prof. Patrick Geddes. Explains to the layman what the title means to the scientific world.

23. ASTRONOMY. By A. R. Hinks, Chief Assistant at the Cambridge Observatory. "Decidedly original in substance, and the most readable and informative little book on modern astronony we have seen for a long time." - Nature.

24. PSYCHICAL RESEARCH. By Prof. W. F. Barrett, formerly President of the Society for Psychical Research.

9. THE EVOLUTION OF PLANTS. By Dr. D. H. Scott, President of the Linnean Society of London. The story of the development of flowering plants, from the earliest zoological times, unlocked from technical language. 
43. MATTER AND ENERGY. By F. Soddy, Lecturer in Physicas Chemistry and Radioactivity, University of Glasgow. "Brilliant. Can hardly be surpassed. Sure to attract attention."-Ner York Sun.

41. PSYCHOLOGY, THE STUDY OF BEHAVIOUR. By William McDougall, of Oxford. A well digested summary of the essentials of the science put in excellent literary form by a leading authority.

42. THE PRINCIPLES OF PHYSIOLOGY. By Prof. J. G. MicKendrick. A compact statement by the Emeritus Professor at Glasgow, for uninstructed readers.

37. ANTHROPOLOGY. By R. R. Marett, Reader in Social Anthropology, Oxford. Seeks to plot out and sum up the general series of changes, bodily and mental, undergone by man in the course of history. "Excellent. So enthusiastic, so clear and witly. and so well adapted to the general reader."-American Library Association Booplist.

17. CRIME AND INSANITY. By Dr. C. Mercier, author of "Test Book of Insanity," etc.

12. THE ANIMAL WORLD. By Prof. F. W. Gamble.

15. INTRODUCTION TO MATHEMATICS. By A. N. Whitehead. author of "Universal Algebra."

\section{PHILOSOPHY AND RELIGION.}

69. A HISTORY OF FREEDOM OF THOUGHT. By John B. Burg: M. A., LL. D., Regius Professor of Modern History in Cambridge University. Summarizes the history of the long struggle between authority and reason and of the emergence of the principle that coercion of opinion is a mistake.

96. A HISTORY OF PHILOSOPHY. By Clement C. J. Webb, Oxford.

35. THE PROBLEMS OF PHILOSOPHY. By Bertrand Russell, Lecturer and Late Fellow, Trinity College, Cambricige.

60. COMPARATIVE RELIGION. By Prof. J. Estlin Carpenter. "One of the few authorities on this subject compares all the religions to see what they have to offer on the great themes of religion."-Christian Work and Evangelist.

44. BUDDHISM. By Mrs. Rhys Davids, Lecturer on Indian Philosophy, Manchester.

46. ENGLISH SECTS : A HISTORY OF NONCONFORMITY. By W.B Selbie. Principal of Manchester Colleze. Oxford. 
55. MISSIONS: THEIR RISE AND DEVELOPMENT. By Mrs. Mandell Creighton, author of "History of England." The author seeks to prove that missions have done more to civilize the world than any other human agency.

52. ETHICS. By G. E. Moore, Lecturer in Moral Science, Cambridge. Discusses what is right and what is wrong, and the whys. and wherefores.

65. THE LITERATURE OF THE OLD TESTAMENT. By George F. Moore, Professor of the History of Religion, Harvard University. "A pope lar work of the highcat urder. Will be profitable to anybody who cares enough about Bible study to read a. serious book on the subject."-American Journal of Theology.

88. RELIGIOUS DEVELOPMENT BETWEEN OLD AND NEW TESTAMENTS. By R. H. Charles, Canon of Westminster. Shows how religious and ethical thought between 180 B. C. and $100 \mathrm{~A} . \mathrm{D}$. grew naturally into that of the New Testament.

50. THE MAKING OF THE NEW TESTAMENT. By B. W. Bacon, Professor of New Testament Criticism, Yale. An authoritative summary of the results of modern critical research with regard to the origins of the New Testament.

\section{SOCIAL SCIENCE.}

91. THE NEGRO. By W. E. Burghardt DuBois, author of "Souls of Black Folks," etc. A history of the black man in Africa, America or wherever else his presence has been or is important.

77. CO-PARTNERSHIP AND PROFIT SHARING. By Aneurin Williams, Chairman, Executive Committee, International Co-operative Alliance, etc. Explains the various types of co-partnership or profit-sharing, or both, and gives details of the arrangements now in force in many of the great industries.

99. POLITICAL THOUGHT: THE UTILITARIANS. FROM BENTHAM TO J. S. MILl. By Williaza L. P. Davidson.

98. POLITICAL THOUGHT: FROM HERBERT SPENCER TO THE PRESENT DAY. By Ernest Barker, M. A.

79. UNEMPLOYMENT. By A. C. Pigou, M. A., Professor of Political Economy at Cambridge. The meaning, measurement, distribution. and effects of unemployment, its relation to wages, trade fuctuations. and disputes. and anme propnoale of remedy or relief. 
80. COMMON-SENSE IN LAW. By Prof. Paul Vinogradoff. D. C. L., L.L. D. Social and Legal Rules-Legal Rights and DutiesFacts and Acts in Law-Legislation-Custom-Judicial Precedents--Equity - The Law of Nature.

49. ELEMENTS OF POLITICAL ECONOMY. By S. J. Chapman, Professor of Political Economy and Dean of Faculty of Commerce and Administration, University of Manchester.

11. THE SCIENCE OF WEALTH. By J. A. Hobson, author of "Problems of Poverty." A study of the structure and working of the modern business world.

1. PARLIAMENT. ITS HISTORY, CONSTITUTION, AND PRACTICE. By Sir Courtenay P. Ilbert, Clerk of the House of Commons.

16. LIBERALISM. By Prof. L. T. Hobhouse, author of "Democracy and Reaction." A masterly philosophical and historical review of the subject.

5. THE STOCK EXCHANGE. By F. W. Hirst, Editor of the London Economist. Reveais to the non-financial mind the facts about investment, speculation, and the other terms which the title suggests.

10. THE SOCIALIST MOVEMENT. By J. Ramsay Macdonald, Chairman of the British Labor Party.

28. THE EVOLUTION OF INDUSTRY. By D. H. MacGregor, Professor of Political Economy, University of Leeds. An outline of the recent changes that have given us the present conditions of the working classes and the principles involved.

29. ELEMENTS OF ENGLISH LAW. By W. M. Geldart, Vinerian Professor of English Law, Oxford. A simple statement of the basic principles of the English legal system on which that of the United States is based.

32. THE SCHOOL: AN INTRODUCTION TO THE STUDY OF EDUCATION. By J. J. Findlay. Professor of Education, Manchester. Presents the hisiory, the psychological basis, and the theory of the school with a rare power of suminary and suggestion.

6. IRISH NATIONALITY. By Mrs. J. R. Green. A brillian' :ccount of the genius and mission of the Irish people. "An entrancing work, and I would advise every one with a drop of Irish blood in his veins or a vein of Irish sympathy in his heart to read it."-Nen. Yort Times' Renien 
102. SERBIA. By L. F. Waring, with preface by J.M. Jovanovitch, Serbian Minister to Great Britain. The main outlines of Serbian history, with special emphasis on the immediate causes of the war, and the questions which will be of greatest importance in the afterthe-war settlement.

33. THE HISTORY OF ENGLAND. By A. F. Pollard, Professor of English History, University of London.

95. BELGIUM. By R. C. K. Ensor, Sometime Scholar of Balliol College. The geographical, linguistic, historical, artistic and literary associalions.

99. POLAND. By W. Alison Phillips, University of Dublin. The history of Poland with special emphasis upon the Polish question of the present day.

34. CANADA. By A. G. Bradley.

72. GERMANY OF TO-DAY. By Charles Tower.

78. LATIN AMERICA. By William R. Skepherd, Professor of History, Columbia. With maps. The historical, artistic, and commercial development of the Central South American republics.

18. THE OPENING-UP OF AFRICA. By Sir H. H. Johnston.

19. THE CIVILIZATION OF CHINA. By H. A. Giles, Professor of Chinese, Cambridge.

36. PEOPLES AND PROBLEMS OF INDIA. By Sir T. W. Holderness. "The best small treatise dealing with the range of subjects fairly indicated by the title."-The Dial.

26. THE DAWN OF HISTORY. By J. L. Myers, Professor of Ancient History, Oxford.

92. THE ANCIENT EAST. By D. G. Hogarth, M. A., F. B. A., F. S. A. Connects with Prof. Myers's "Dawn of History" (No. 26) at about 1000 B. C. and reviews the history of Assyria, Babylon, Cilicia, Persia and Macedon.

30. ROME. By W. Warde Fowler, author of "Social Life at Rome," etc.

13. MEDIEVAL EUROPE. By H. W. C. Davis, Fellow at Balliol College, Oxford, author of "Charlemagne," etc.

3. THE FRENCH REVOLUTION. By Hillaire Belloc.

57. NAPOLEON. By H. A. L. Fisher, Vice-Chancellor of Sheffield University. Author of "The Republican Tradition in Europe."

20. HISTORY OF OUR TIME (1885-1911). By C. P. Gooch.

22. THE PAPACY AND MODERN TIMES. By Rev. William Barry, D. D., author of "The Papal Monarchy," etc. The story of the rise and fall of the Temporal Power. 
4. A SHORT IISTORY OF WAR AND PEACE. By G. H. Perris, author of "Russia in Revolution," etc.

94. THE NAVY AND SEA POWER. By David Hannay, author of "Short History of the Royal Navy," etc. A brief history of the navies, sea power, and ship growth of all nations, including the rise and decline of America on the sea, and explaining the present British supremacy thereon.

8. POLAR EXPLORATION. By Dr. W. S. Bruce, Leader of the "Scotia" expedition. Emphasizes the results of the expeditions.

51. MASTER MARINERS. By John R. Spears, author of "The History of Our Navy," etc. A history of sea craft adventure from the earliest times.

86. EXPLORATION OF THE ALPS. By Arnold Lunn, M. A.

7. MODERN GEOGRAPHY. By Dr. Marion Newbigin, Show's the relation of physical features to living things and to some of the chief institutions of civilization.

76. THE OCEAN. A GENERAL ACCOUNT OF THE SCIENCE OF THE SEA. By Sir John Murray, K. C. B., Naturalist H. M. S. "Challenger," 1872-1876, joint author of "The Depths of the Ocean," eic.

84. THE GROWTH OF EUROPE. By Granvilie Cole, Professor of Geology, Royal College of Science, Ireland. A study of the geology and physical geography in connection with the political geography.

\section{AMERICAN HISTORY.}

47. THE COLONIAL PERIOD (1607-1766). By Charles McLean Ardrews, Professor of American History, Yale.

82. THE WARS BETWEEN ENGLAND AND AMERICA (1763-1815). By Theodore C. Smith, Professor of American History, Williams College. A history of the period, with especial emphasis on The Revolution and The War of 1812.

67. FROM JEFFERSON TO LINCOLN (1815-1860). By William MacDonald, Professor of History, Brown University. The author makes the history of this period circulate about constitutional ideas and slave:y sentiment.

25. THE CIVIL WAR (1854-1865.) By Frederic L. Paxson, Professor of American History, University of Wisconsin.

39. RECONSTRUCTION AND UNION (1865-1912). By Paul Leland Haworth. A History of the United States in our own times.

OTMER VOLUMES IN PREPARATION

HENRY . HOLT AND COMPANY

19 West 44th Street

New York 




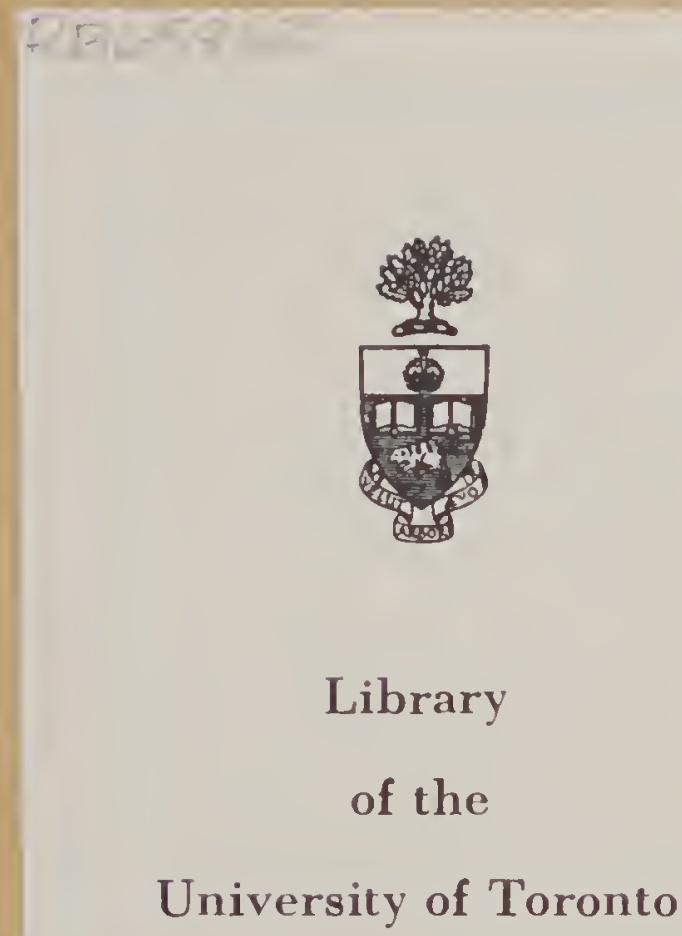



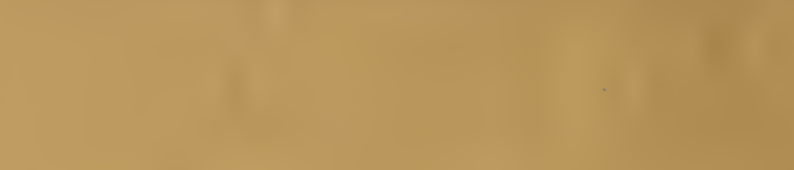

\section{s}

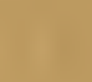

(t)

\section{$x^{2}$}
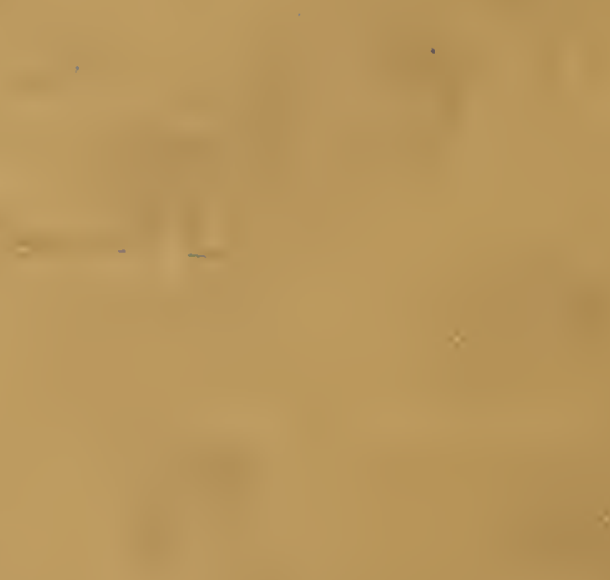

\section{7.}

\section{$x$}

... :

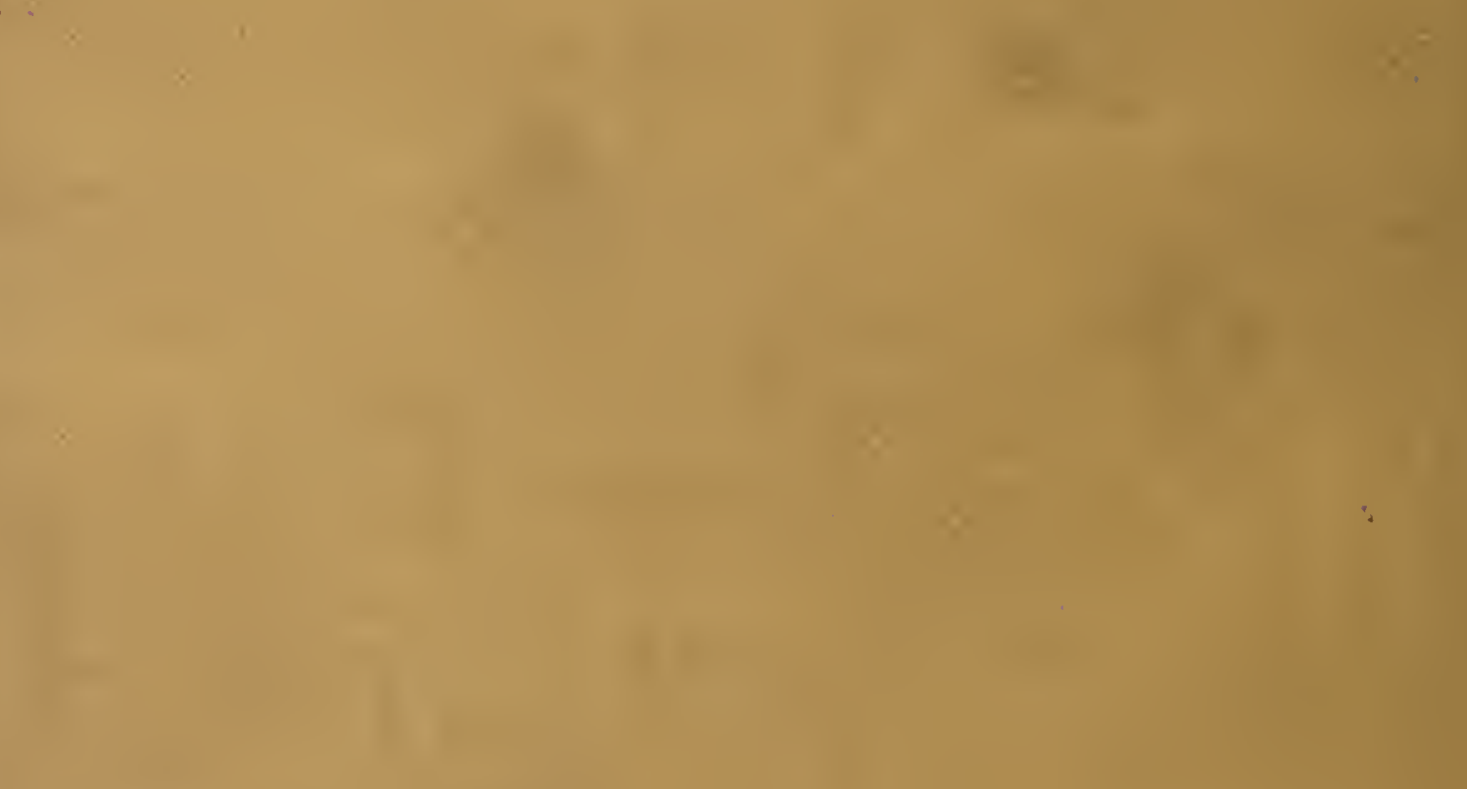

